Synt heses of bi I i n chromphor es t oward the i nvest i gat i on of st ruct ure and functi on of phyt ochr orres

\begin{tabular}{|l|l|}
\hline 著者 & I nomat a Kat suhi ko \\
\hline $\begin{array}{l}\text { j our nal or } \\
\text { publ i cat } \mathrm{i} \text { on } \mathrm{t} \text { i t l e }\end{array}$ & Het er ocycl es \\
\hline vol une & 85 \\
\hline number & 12 \\
\hline page r ange & $2879-2926$ \\
\hline year & 2012-01-01 \\
\hline URL & ht t p: //hdl . handl e. net /2297/33403 \\
\hline
\end{tabular}


HETEROCYCLES, Vol. 85, No. 12, 2012, pp. -. (C) 2012 The Japan Institute of Heterocyclic Chemistry

Received, 28th August, 2012, Accepted, 25th October, 2012, Published online,

DOI: 10.3987/REV-12-750

\title{
SYNTHESES OF BILIN CHROMOPHORES TOWARD THE \\ INVESTIGATION OF STRUCTURE AND FUNCTION OF \\ PHYTOCHROMES
}

\section{Katsuhiko Inomata*}

Division of Material Sciences, Graduate School of Natural Science and Technology, Kanazawa University, Kakuma, Kanazawa, Ishikawa 920-1192, Japan; E-mail: inomata@se.kanazawa-u.ac.jp

\begin{abstract}
We studied on the syntheses of linear tetrapyrrole (bilin) chromophores including the sterically locked derivatives toward the investigation of structure and function of phytochromes as photoreceptors. The synthesized chromophores were successfully assembled with bacterial and plant apophytochromes in vitro and/or in vivo to demonstrate that they are valuable tools for studies on phytochromes.
\end{abstract}

\section{CONTENTS}

1. Introduction

2. Development of General Synthetic Method of Bilin Chromophores

2-1. Preparation of the A- and D-Ring Components

2-2. Preparation of the B- and C-Ring Components

2-3. Preparation of Pyrromethenone Derivatives as the AB- and CD-Ring Components

2-4. Preparation of Linear Tetrapyrrole (Bilin) Chromophores

3. In Vitro and In Vivo Assembly of the Synthesized Bilin Chromophores with Apophytochromes

4. Development of General Synthetic Method of Sterically Locked Bilin Chromophores

5. In Vitro and In Vivo Assembly of the Synthesized Locked Bilin Chromophores with Apophytochromes

6. Development of General Synthetic Method of Doubly Locked Bilin Chromophores

7. Conclusion 


\section{INTRODUCTION}

Phytochromes are bilin-containing photoreceptors ${ }^{1-5}$ in plants, ${ }^{6,7}$ bacteria, ${ }^{8-10}$ and fungi, ${ }^{11}$ which regulate numerous photoresponses such as phototaxis and pigmentation in bacteria, seed germination, chloroplast development, modulation of gravitropism, inhibition of hypocotyl elongation, induction of cotyledon opening and side branches, flowering, and gene regulation in plants through the photointerconversion between a red-light-absorbing form (Pr) and a far-red-light-absorbing form (Pfr). ${ }^{1,7}$ All phytochromes have a covalently attached bilin chromophore that absorbs light in red and far-red region. ${ }^{5,12-18}$ Land plants use phytochromobilin (PФB), ${ }^{1}$ cyanobacteria use phycocyanobilin $(\mathrm{PCB}),{ }^{19,20}$ and other bacteria use biliverdin (BV) (Figure 1). ${ }^{11,21,22}$

The natural chromophores $\mathrm{P} \Phi \mathrm{B}$ and $\mathrm{PCB}$ are coupled by a thioether bond between the $\mathrm{C} 3^{1}$ position of the A-ring ethylidene side chain and a conserved cysteine residue within the GAF domain of the proteins. Many bacterial phytochromes carry BV as a natural chromophore, which is coupled at the $\mathrm{C}^{2}$ position in a different manner to the protein.

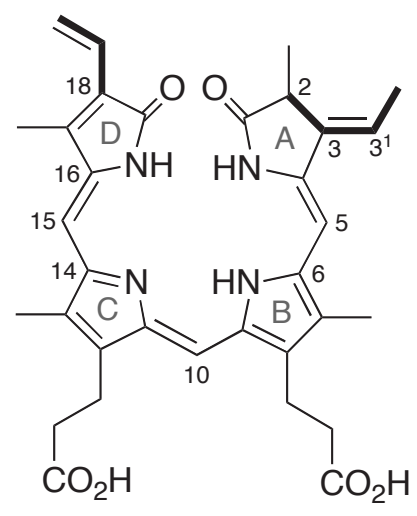

phytochromobilin

РФВ

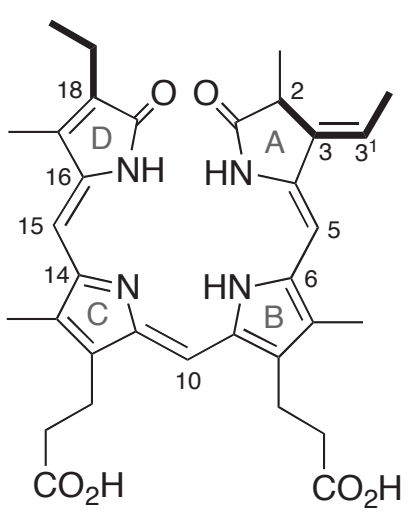

phycocyanobilin PCB

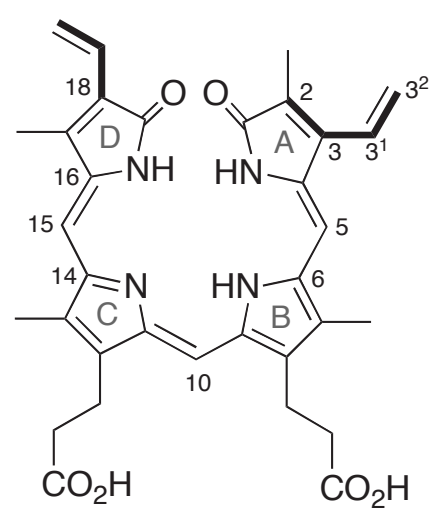

biliverdin

BV

Figure 1. Bilin chromophores used in plants (РФВ), cyanobacteria (PCB), and other bacteria (BV).

For many years, it has been assumed that the primary event of the photoconversion from $\operatorname{Pr}$ to $\operatorname{Pfr}$ is a $Z$ to $E$ isomerization of the $\mathrm{C} 15=\mathrm{C} 16$ methine bridge between the $\mathrm{C}$ - and D-rings of the bilin chromophores. ${ }^{23}$ However, this view was recently challenged by the hypothesis formulated in the context of NMR data on a phytochrome-like protein from a thermophilic cyanobacterium $S y B$-Cph1, i.e., light-induced rotation of the A-ring but not the D-ring is the primary motion of the chromophore during photoconversion. ${ }^{24}$ 
Furthermore, even in the traditional view based on the $Z$ to $E$ photoconversion around the $\mathrm{C} 15=\mathrm{C} 16$ double bond, the chromophore can also move around the exocyclic single bonds. Each single bond can adopt either a syn or anti conformation. ${ }^{12}$ Vibrational spectroscopy have provided indirect insight into the conformation of the phytochrome chromophore in the Pr, Pfr, and intermediate states, but the data have been interpreted in different ways. ${ }^{25-28}$ For example, it has been proposed that the formation of Pfr is accompanied by a syn/anti rotation around the $\mathrm{C} 14-\mathrm{C} 15$ single bond. ${ }^{27}$ More recently, interpretation of resonance Raman spectra of plant phytochromes by density functional theory (DFT) calculations indicated that the $\mathrm{C} 14-\mathrm{C} 15$ single bond is in an anti conformation throughout the entire photocycle and that the C5-C6 single bond rotates from anti to syn upon photoconversion from Pr to Pfr (Figure 2). ${ }^{28}$
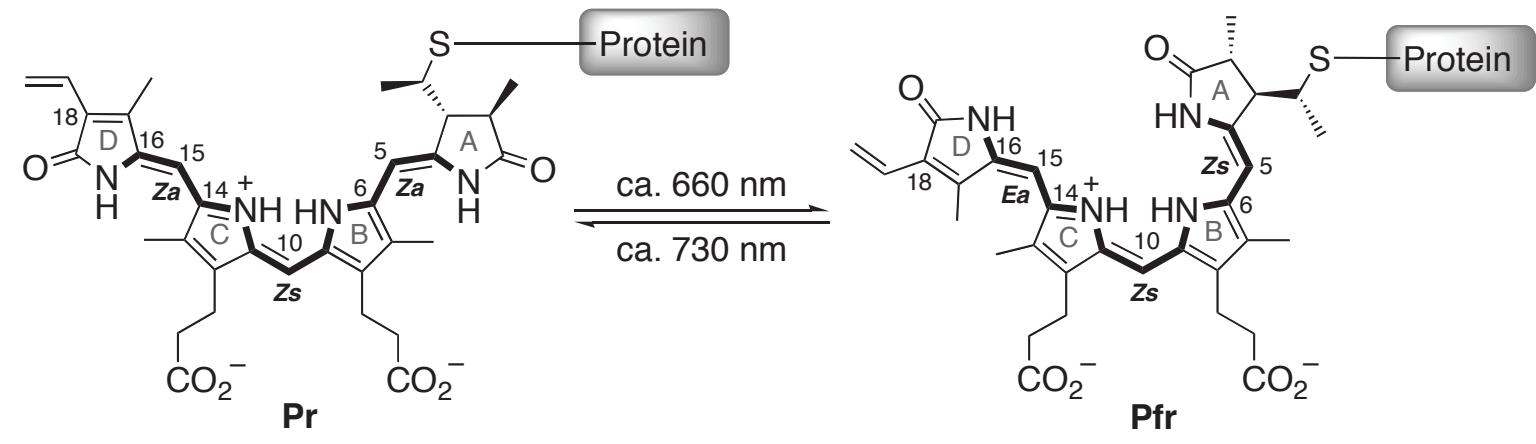

Figure 2. One of the proposed structures of chromophore in Pr and Pfr of phytochrome. ${ }^{28}$

By photoconverting between $\mathrm{Pr}$ and Pfr, phytochromes act as unique light-regulated switches in various signal transduction cascades. Despite intensive physico-chemical analysis of various phytochromes, we do not yet understand how contacts between polypeptide and the bilin enable photoconversion between $\operatorname{Pr}$ and Pfr, how this transformation reversibly alters the activity of the photoreceptor, or how the holoprotein dimerizes. $^{18,29}$

The development of yeast and bacterial system for the expression of recombinant phytochrome apoproteins has allowed investigation of the biochemical and spectroscopic properties of the reconstituted phytochromes. ${ }^{30}$ Moreover, the photophysical and photochemical properties of wild type phytochrome are quite similar to those of the reconstituted chromoproteins. ${ }^{31,32}$ Other strategies, including systematic Nand C-terminal truncations and site-directed mutagenesis of the apoprotein, have been used to study the structural requirements of the chromophore-apoprotein interaction in terms of photochromism. ${ }^{33-35}$ Even though such bilin chromophores could be isolated from natural sources, knowledge of the relationship between the structure of synthetic bilin chromophores and the biochemical properties of the 
holoproteins assembled with apophytochromes is quite interesting and important to determine the precise function of the bilin chromophores. However, little had been done to examine the relationships among chromophore structure, its assembly to apoprotein, and photochromism of the holoprotein, because of the difficulty of synthesizing the natural bilin chromophores and their structural analogs.

Although Gossauer and his co-workers reported total syntheses of dimethyl ester derivatives of PФB and

PCB around 1980, they could not assemble these analogs with phytochrome apoprotein. ${ }^{36-38}$ Since then, there was no report regarding the synthesis of the free acid form of РФВ or PCB applicable to assemble with the phytochrome apoproteins for a decade.

Therefore, we studied on the syntheses of natural and unnatural bilin chromophores, ${ }^{39-49}$ and have succeeded in synthesizing $\mathrm{P} \Phi \mathrm{B},{ }^{44} \mathrm{PCB},{ }^{42,43,48} \mathrm{BV}$ and their analogs including sterically locked derivatives $^{45,46,49}$ in free acid forms by developing efficient synthetic methods of each pyrrole ring, a new coupling reaction, and palladium-catalyzed deprotection of the allyl propanoate side chains of the B-and C-rings under mild conditions. Finally, assembly experiments of the synthesized chromophores with phytochrome apoproteins in vitro and/or in vivo have provided us new insights into the structure and function of phytochromes.

The background of our studies, including assembly experiments with apophytochromes, have been described in the previous review. ${ }^{50}$ Thus, this paper focuses on our recent studies on the syntheses of various bilin chromophores.

\section{DEVELOPMENT OF GENERAL SYNTHETIC METHOD OF BILIN CHROMOPHORES}

Toward establishment of an efficient method for the preparation of bilin chromophores of phytochromes, we initially tried to improve the method employed by Gossauer and his co-workers for the preparation of dimethyl esters of $\mathrm{P} \Phi \mathrm{B}$ and $\mathrm{PCB},{ }^{36-38}$ according to a retrosynthetic analysis shown in Figure 3 . To prepare free acid forms of bilin chromophores as final products, we replaced the methyl esters of propanoic acid side chains at the C8 and C12 positions and the benzyl ester at the C5 meso position, which were employed by Gossauer's group, to allyl esters, respectively. ${ }^{50}$ Furthermore, we developed a new coupling reaction between the C- and D-rings, instead of the classical method using a strong base, to avoid the hydrolysis of the ester groups. ${ }^{50}$ 


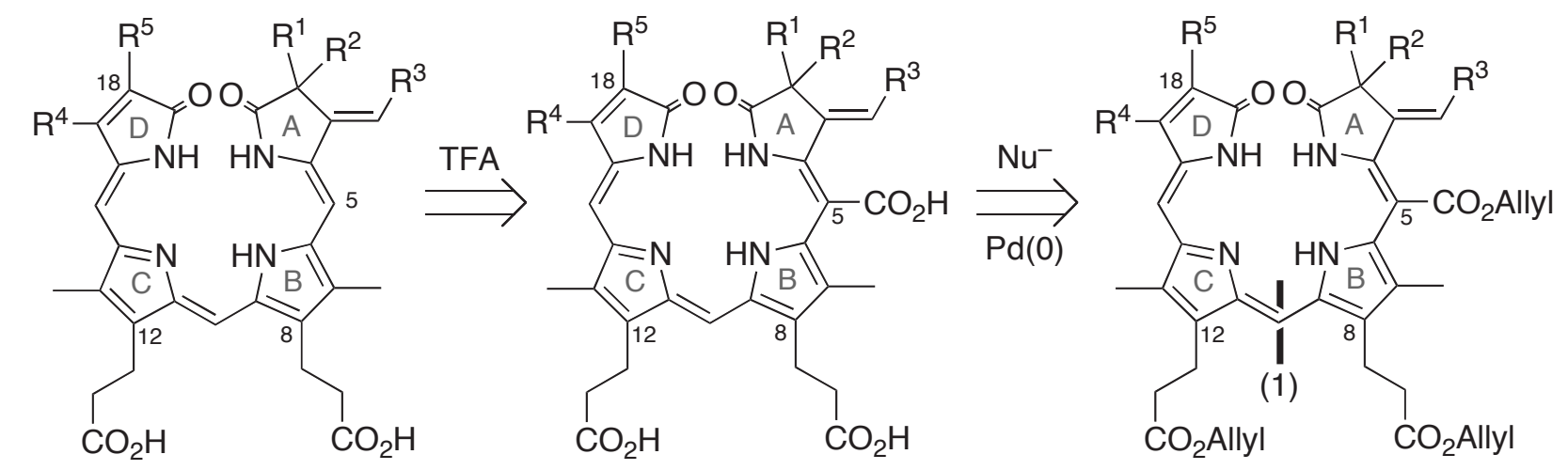

$$
\begin{aligned}
& \text { PФB }\left(R^{1}, R^{3}, R^{4}=\text { Me }, R^{2}=H, R^{5}=\text { vinyl }\right) \\
& \text { PCB }\left(R^{1}, R^{3}, R^{4}=M e, R^{2}=H, R^{5}=E t\right)
\end{aligned}
$$

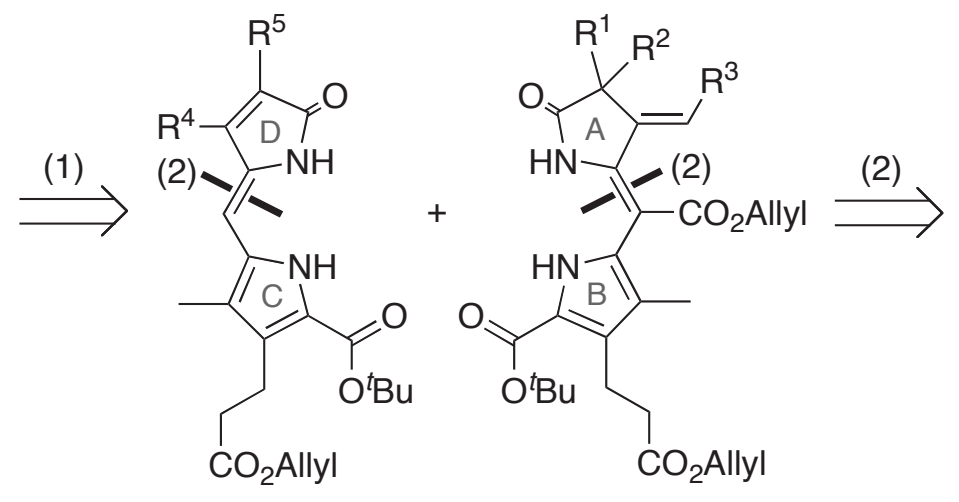<smiles>[R]C1=C([P])C([3H])NC1=O</smiles><smiles>[R]C=C1C(=S)NC(=O)C1([R])[R]</smiles><smiles>CCOC(=O)c1[nH]c(C=O)c(C)c1CCC(=O)O</smiles><smiles>CCOC(=O)CCc1c(C(=O)OCC)[nH]c(C(=P)P)c1C(=O)O</smiles>

$\mathrm{Ts}=-\mathrm{SO}_{2}-\longrightarrow \mathrm{Me}$

Figure 3. A retrosynthetic analysis of bilin chromophores.

This method was useful for the preparation of PCB and its analogs modified at the A-ring (1-4 in Figure 4), B- and/or C-ring(s) (5-12), and D-ring (13-20) as well as the PCB derivatives bearing a photoreactive 4-[3-(trifluoromethyl)diaziren-3-yl]phenyl group ${ }^{51,52}$ on the D-ring for a photoaffinity study. ${ }^{42,43,48,53}$ However, it was found to be difficult to apply this method to the synthesis of РФВ bearing an acid labile vinyl group at the $\mathrm{C} 18$ position $\left(\mathrm{R}^{5}=\right.$ vinyl), since this method required the treatment with trifluoroacetic acid (TFA) for decarboxylation at the $\mathrm{C} 5$ meso position at the final step of the synthesis. 


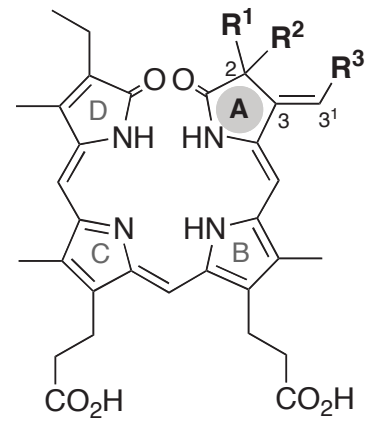

PCB $\left(R^{1}, R^{3}=M e, R^{2}=H\right)$

$1\left(R^{1}, R^{2}=H, R^{3}=M e\right)$

$2\left(R^{1}=E t, R^{2}=H, R^{3}=M e\right)$

$3\left(R^{1}, R^{2}, R^{3}=M e\right)$

$4\left(R^{1}=M e, R^{2}=H, R^{3}=E t\right)$

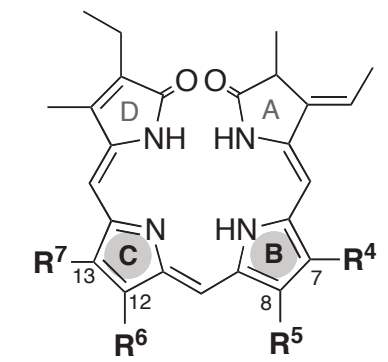

$5\left(\mathrm{R}^{4}=\mathrm{Me}, \mathrm{R}^{5}=\left(\mathrm{CH}_{2}\right)_{2} \mathrm{CO}_{2} \mathrm{Me}\right.$, $\left.\mathrm{R}^{6}=\left(\mathrm{CH}_{2}\right)_{2} \mathrm{CO}_{2} \mathrm{H}, \mathrm{R}^{7}=\mathrm{Me}\right)$

$6\left(\mathrm{R}^{4}=\mathrm{Me}, \mathrm{R}^{5}=\left(\mathrm{CH}_{2}\right)_{2} \mathrm{CO}_{2} \mathrm{H}\right.$, $\left.\mathrm{R}^{6}=\left(\mathrm{CH}_{2}\right)_{2} \mathrm{CO}_{2} \mathrm{Me}, \mathrm{R}^{7}=\mathrm{Me}\right)$

$7\left(\mathrm{R}^{4}=\left(\mathrm{CH}_{2}\right)_{2} \mathrm{CO}_{2} \mathrm{H}, \mathrm{R}^{5}=\mathrm{Me}\right.$, $\left.\mathrm{R}^{6}=\left(\mathrm{CH}_{2}\right)_{2} \mathrm{CO}_{2} \mathrm{H}, \mathrm{R}^{7}=\mathrm{Me}\right)$

$8\left(\mathrm{R}^{4}=\mathrm{Me}, \mathrm{R}^{5}=\left(\mathrm{CH}_{2}\right)_{2} \mathrm{CO}_{2} \mathrm{H}\right.$, $\left.R^{6}=\mathrm{Me}, \mathrm{R}^{7}=\left(\mathrm{CH}_{2}\right)_{2} \mathrm{CO}_{2} \mathrm{H}\right)$

$9\left(\mathrm{R}^{4}=\left(\mathrm{CH}_{2}\right)_{2} \mathrm{CO}_{2} \mathrm{H}, \mathrm{R}^{5}=\mathrm{Me}\right.$, $\left.R^{6}=\mathrm{Me}, \mathrm{R}^{7}=\left(\mathrm{CH}_{2}\right)_{2} \mathrm{CO}_{2} \mathrm{H}\right)$

$10\left(R^{4}=\mathrm{Me}, \mathrm{R}^{5}=\left(\mathrm{CH}_{2}\right)_{3} \mathrm{CO}_{2} \mathrm{H}\right.$, $\left.\mathrm{R}^{6}=\left(\mathrm{CH}_{2}\right)_{2} \mathrm{CO}_{2} \mathrm{H}, \mathrm{R}^{7}=\mathrm{Me}\right)$

$11\left(\mathrm{R}^{4}=\mathrm{Me}, \mathrm{R}^{5}=\left(\mathrm{CH}_{2}\right)_{2} \mathrm{CO}_{2} \mathrm{H}\right.$, $\left.\mathrm{R}^{6}=\left(\mathrm{CH}_{2}\right)_{3} \mathrm{CO}_{2} \mathrm{H}, \mathrm{R}^{7}=\mathrm{Me}\right)$

$12\left(\mathrm{R}^{4}=\mathrm{Me}, \mathrm{R}^{5}=\left(\mathrm{CH}_{2}\right)_{3} \mathrm{CO}_{2} \mathrm{H}\right.$, $\left.\mathrm{R}^{6}=\left(\mathrm{CH}_{2}\right)_{3} \mathrm{CO}_{2} \mathrm{H}, \mathrm{R}^{7}=\mathrm{Me}\right)$

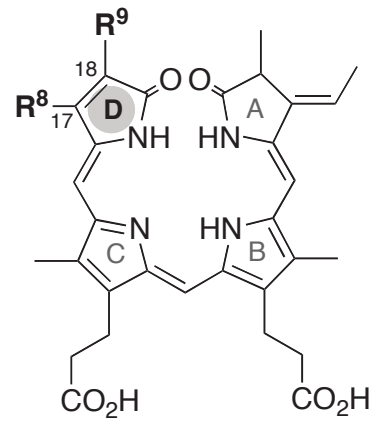

$13\left(\mathrm{R}^{8}=\left(\mathrm{CH}_{2}\right)_{2} \mathrm{Me}, \mathrm{R}^{9}=\mathrm{Me}\right)$

$14\left(\mathrm{R}^{8}=\left(\mathrm{CH}_{2}\right)_{4} \mathrm{Me}, \mathrm{R}^{9}=\mathrm{Me}\right)$

$15\left(\mathrm{R}^{8}=\left(\mathrm{CH}_{2}\right)_{7} \mathrm{Me}, \mathrm{R}^{9}=\mathrm{Me}\right)$

$16\left(\mathrm{R}^{8}=\mathrm{Me}, \mathrm{R}^{9}=\left(\mathrm{CH}_{2}\right)_{2} \mathrm{Me}\right)$

$17\left(\mathrm{R}^{8}=\mathrm{Me}, \mathrm{R}^{9}=\left(\mathrm{CH}_{2}\right)_{4} \mathrm{Me}\right)$

$18\left(\mathrm{R}^{8}=\mathrm{Me}, \mathrm{R}^{9}=\left(\mathrm{CH}_{2}\right)_{7} \mathrm{Me}\right)$

$19\left(\mathrm{R}^{8}=\mathrm{Me}, \mathrm{R}^{9}=\left(\mathrm{CH}_{2}\right)_{2} \mathrm{OAc}\right)$

$20\left(R^{8}=\mathrm{Me}, \mathrm{R}^{9}=\left(\mathrm{CH}_{2}\right)_{2} \mathrm{STol}\right)$

Figure 4. PCB and its derivatives synthesized according to the retrosynthetic analysis shown in Figure 3.

Therefore, we developed an alternative more flexible method (Scheme 1), which does not require the decarboxylation at the $\mathrm{C} 5$ position different from the above method. It was applicable not only for the preparation of $\mathrm{PCB}, \mathrm{P} \Phi \mathrm{B}$ and their derivatives, but also for the preparation of $\mathrm{BV}$ and its derivatives.<smiles>[R]C1=C([2H])C(=O)NC1[13CH]=O</smiles><smiles>[R7]C1=C([R])/C(=C/c2[nH]c([Y])c([2H])c2[R7])NC1=O</smiles>

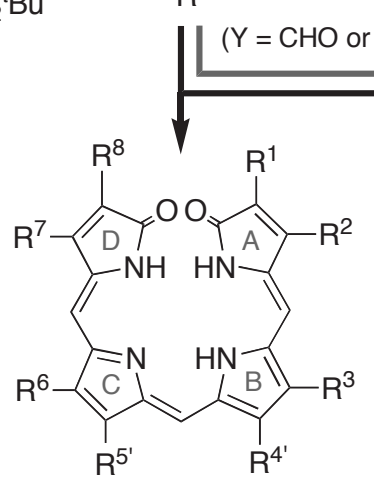

BV and its derivatives

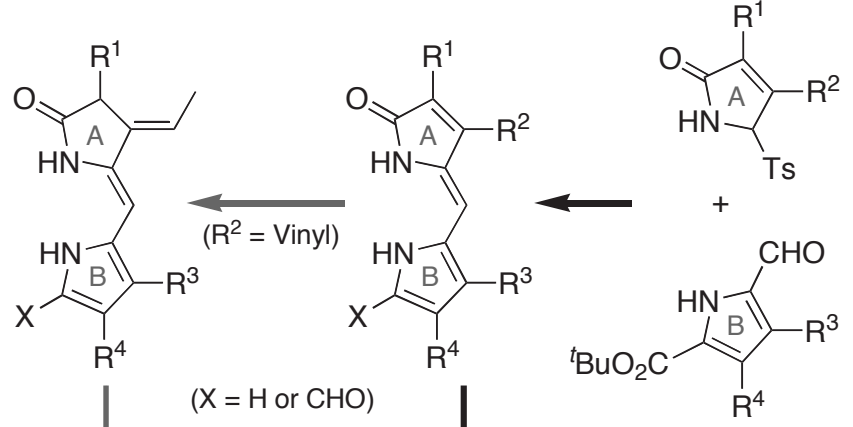

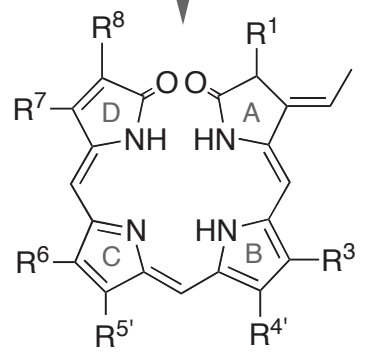

PФB, PCB, and their derivatives

Scheme 1. A general synthetic method of BV, РФB, PCB, and their derivatives. 


\section{2-1. Preparation of the A- and D-Ring Components}

3,4-Disubstituted 5-tosylpyrrolinones 22 as the A- or D-ring precursor of bilin chromophores were derived from the corresponding 2-bromo-5-tosylpyrroles 21 by the redox reaction shown in Scheme 2.
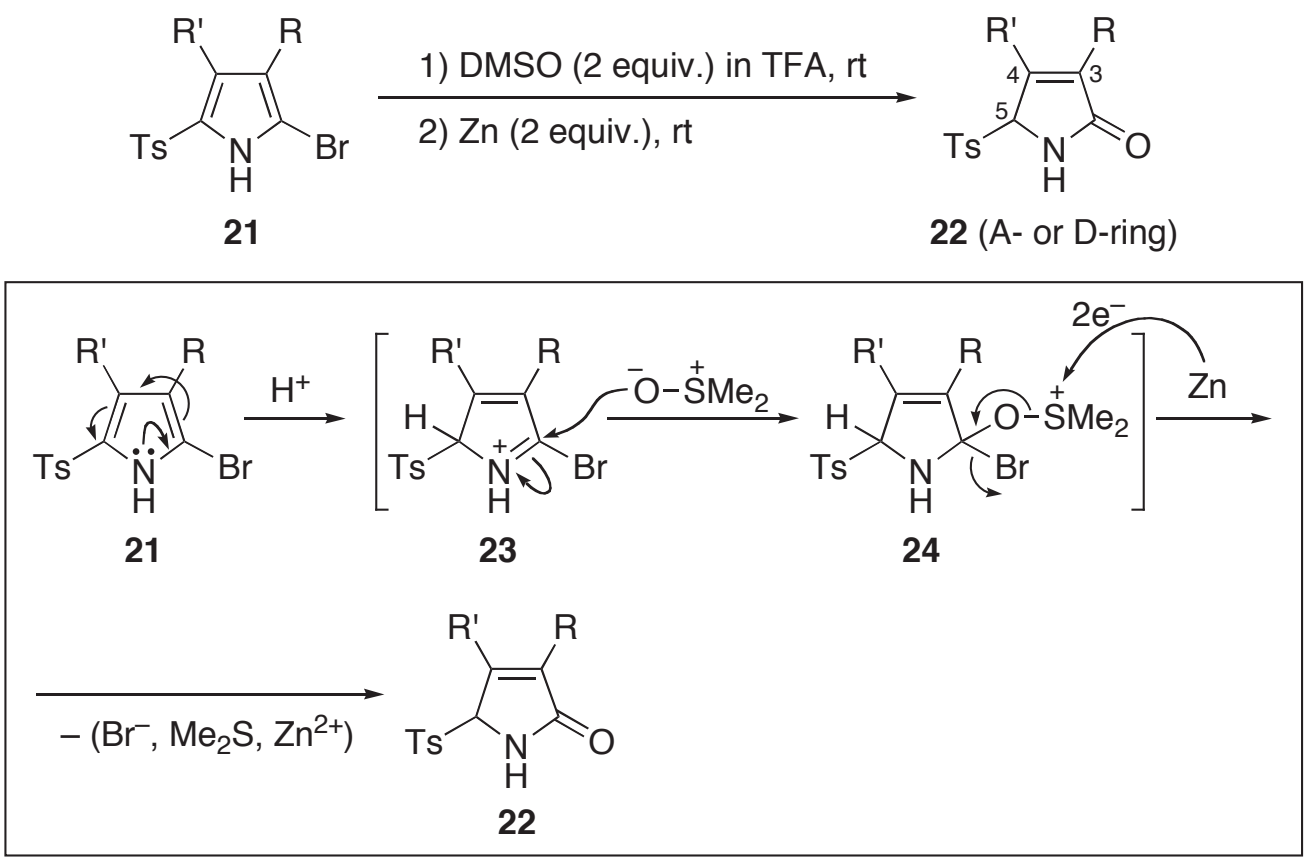

Scheme 2. Conversion of 2-bromo-5-tosylpyrroles 21 to the corresponding 5-tosylpyrrolinones 22 as the A- or D-ring precursor of bilin chromophores by a redox reaction.

The starting 3,4-disubstituted 2-bromo-5-tosylpyrroles 21 were readily available by bromination of the corresponding 2-tosypyrroles $\mathbf{2 7}$, which were prepared from nitroalkane and aldehyde via nitro-acetate $\mathbf{2 5}$ and/or nitroolefin 26, followed by the reaction with tosylmethyl isocyanide ${ }^{54}$ by applying the Barton's method $^{55}$ as shown in Scheme 3.

In the course of the investigation of the synthesis of 2-tosylpyrroles $\mathbf{2 7}$, the isolated $\mathbf{2 7}$ was found to be contaminated with its regioisomer 27' from NMR spectrum taken in $\mathrm{CDCl}_{3}$, even though it was carefully purified on TLC. Furthermore, such phenomenon was not observed when $\mathrm{CDCl}_{3}$ treated with basic alumina was used for NMR measurement. This fact strongly suggested that the tosyl group of 3,4-disubstituted 2-tosylpyrrole 27 rearranged from the $\mathrm{C} 2$ position to the $\mathrm{C} 5$ position under the mild acidic conditions. Actually, the tosyl group of 27 could be readily rearranged in $\mathrm{CDCl}_{3}$ containing trifluoroacetic acid (TFA) $\left(\mathrm{TFA} / \mathrm{CDCl}_{3}=1 / 9\right)$. The ratio of the regioisomers (27 and $\left.27^{\prime}\right)$ at equilibrium was definitely influenced by the bulkiness of the substituent R' (marked with a grey circle in Scheme 3) at the $\mathrm{C} 3$ position of the starting 4-methyl-3-substituted 2-tosylpyrroles $27(\mathrm{R}=\mathrm{Me})$. When the substituent $\mathrm{R}^{\prime}$ was $t$-butyl group, 27 was completely transformed to $27^{\prime}\left(\mathrm{R}=\mathrm{Me}, \mathrm{R}^{\prime}={ }^{t} \mathrm{Bu}\right){ }^{56}$ 


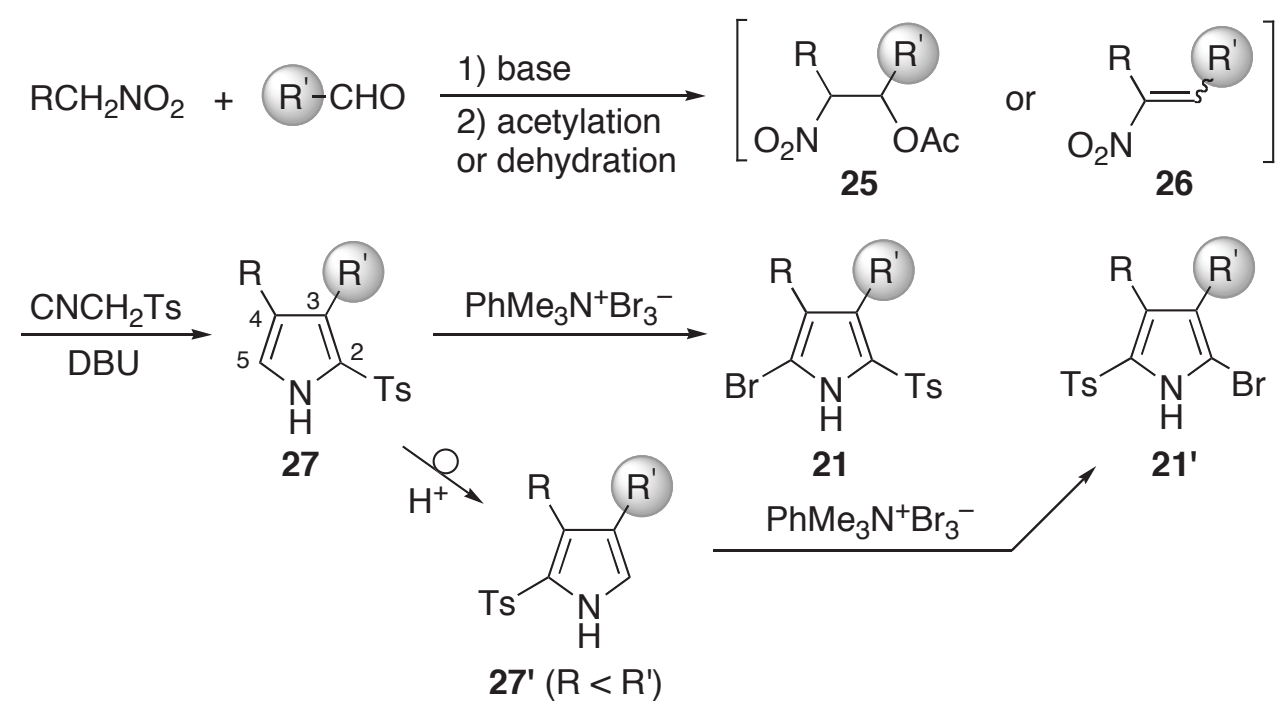

Scheme 3. Synthesis of 2-bromo-5-tosylpyrrole 21 and its regioisomer 21' through 2-tosylpyrroles 27 and $27^{\prime}$ available by rearrangement of a tosyl group.

From the fact that addition of a catalytic amount of $p$-toluenesulfinic acid $\left(p\right.$ - $\left.\mathrm{TolSO}_{2} \mathrm{H}=\mathrm{TsH}\right)$ remarkably accelerated the reaction, ${ }^{57}$ the rearrangement of a tosyl group from the $\mathrm{C} 2$ position to the $\mathrm{C} 5$ position seemed to proceed through the mechanism shown in Scheme 4. Namely, initial protonation takes place selectively at the $\mathrm{C} 2$ position bearing a tosyl group due to the strong inductive effect of the tosyl group to afford the cationic intermediate 28, just like in the case of reversible sulfonation of aromatic compounds under acidic conditions. Then addition of $p$-toluenesulfinate at the $\mathrm{C} 5$ position takes place to afford the intermediate 29, which has two tosyl groups at both $\alpha$-positions. From the intermediate 29, $p$-toluenesulfinic acid must be selectively eliminated to release the unfavorable steric repulsion between a bulkier substituent $\mathrm{R}^{\prime}$ and a tosyl group found in the starting 2-tosylpyrrole $27 \mathbf{a}(\mathrm{R}=\mathrm{Me}<\mathrm{R}$ '). The ratio of $\mathbf{2 7 / 2 7}$ ' at equilibrium was proven to be dependent only on the steric requirement between a tosyl group and the substituent ( $\mathrm{R}^{\prime}$ or $\mathrm{R}$ ) at the $\mathrm{C} 3$ or $\mathrm{C} 4$ position of 27.

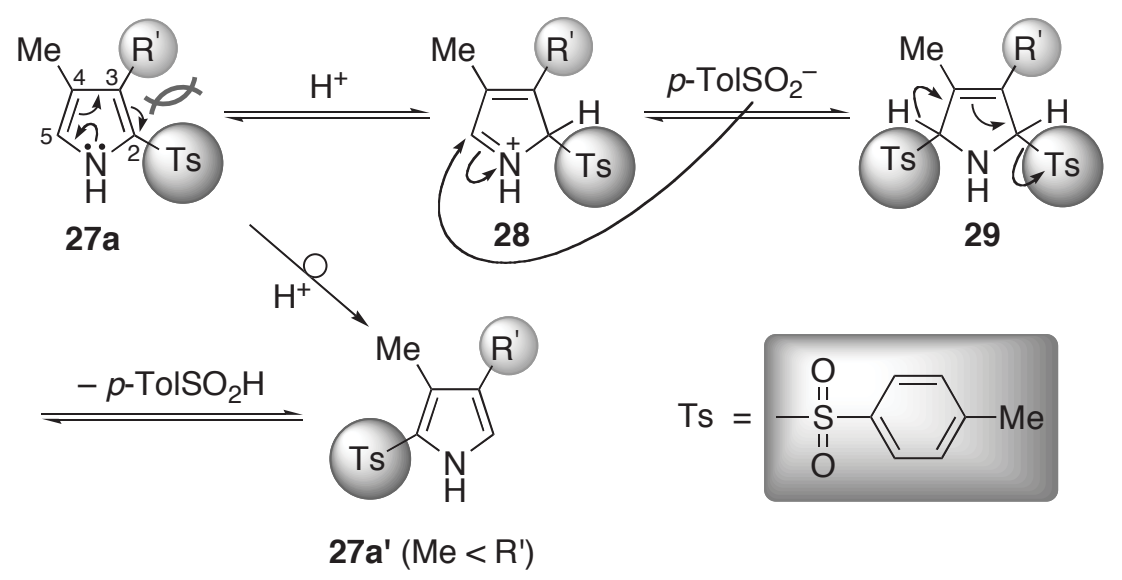

Scheme 4. A possible mechanism of the isomerization of 2-tosylpyrrole 27a to the corresponding regioisomer 27a' under acidic conditions. 
This rearrangement is synthetically very useful. Barton and his coworkers have reported a convenient method for the preparation of substituted pyrroles through the reaction of isonitrile with a nitroolefin or its equivalent available from nitroalkane and aldehyde. ${ }^{55}$ However, we were sometimes confronted with the difficulty of introducing arbitrary substituents at the $\mathrm{C} 3$ and $\mathrm{C} 4$ positions of pyrroles according to the Barton's method. The synthesis of the sterically unfavorable 4-methyl-3-substituted 2-tosylpyrrole 27a (R $=\mathrm{Me}<\mathrm{R}$ ', Eq. 1 in Scheme 5) is much easier than that of its regioisomer, 3-methyl-4-substituted 2-tosylpyrrole 27a' $\left(\mathrm{R}=\mathrm{Me}<\mathrm{R}\right.$ ', Eq. 2 in Scheme 5), because substituent $\mathrm{R}^{\prime}$ at the C3 position of pyrrole $\mathbf{2 7}$ a is originated from commercially available aldehydes $\mathbf{3 0}$ in Eq. 1, whereas the substituent R' at the $\mathrm{C} 4$ position of the pyrrole $\mathbf{2 7} \mathbf{a}^{\prime}$ in Eq. 2 is originated from nitroalkanes 31, which are not commercially available except simple ones.

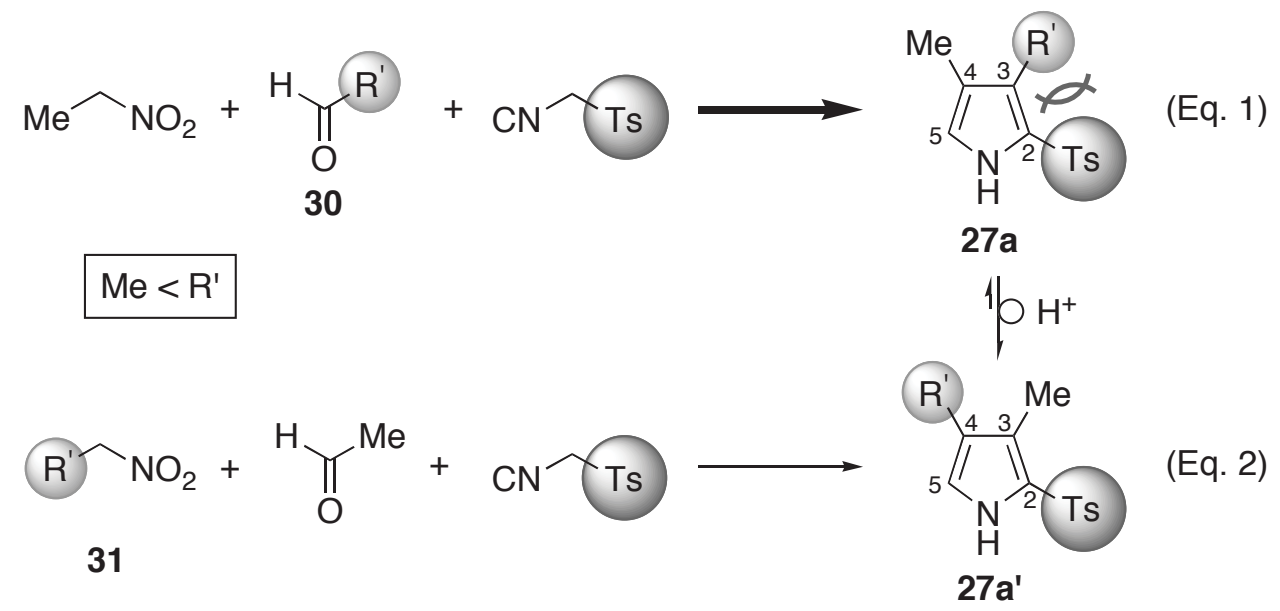

Scheme 5. Sterically unfavorable pyrrole $\mathbf{2 7 a}$ is easier to prepare compared with the regioisomer $\mathbf{2 7} \mathbf{a}$, which is available by acidic isomerization of $\mathbf{2 7} \mathbf{a}$.

Consequently, this rearrangement allowed us to exchange the substituents (R and R') at the C3 and C4 positions of 5-tosylpyrrolinones 22 as precursors of the A- or D-ring of bilin chromophores through the intermediary pyrroles 27 and 27 '.

\section{2-2. Preparation of the B- and C-Ring Components}

The formylpyrrole $33\left(\mathrm{R}^{\prime}=\mathrm{CH}_{2} \mathrm{CH}_{2} \mathrm{CO}_{2} \mathrm{Allyl}\right)$ as the $\mathrm{B}$ - or C-ring precursor of bilin chromophores was readily available by applying the Barton's method, ${ }^{55}$ followed by the Vilsmeier-Haack reaction, as shown in Scheme 6. 


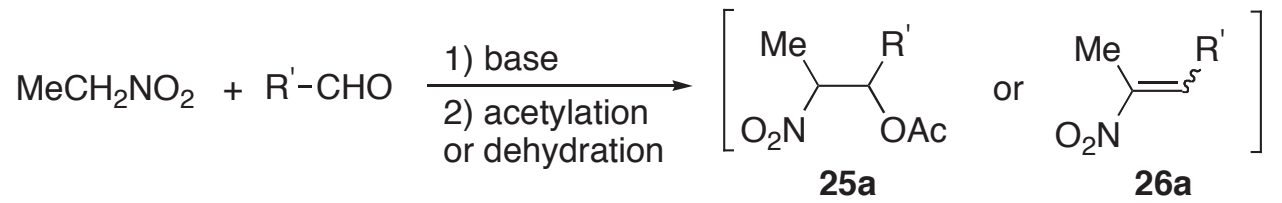

$$
\begin{aligned}
& \underset{\mathrm{DBU}}{\mathrm{CNCH}_{2} \mathrm{CO}_{2}{ }^{\mathrm{t}} \mathrm{Bu}}
\end{aligned}
$$

Scheme 6. Preparation of formylpyrrole $\mathbf{3 3}$ as the B- or C-ring precursor of bilin chromophores.

\section{2-3. Preparation of Pyrromethenone Derivatives as the AB- and CD-Ring Components}

Now, various kinds of the A-, B-, C-, and D-rings as the starting compounds shown in Scheme 1 have become available.

On the other hand, 5-tosylpyrrolinone 22 was found to undergo the Wittig-type coupling reaction with aldehydes ( $\mathrm{R}$ "CHO) in the presence of $\mathrm{DBU}$ and tributylphosphine to give the corresponding 5-exomethylene derivatives $\mathbf{3 4}$, including a pyrromethenone derivative $(\mathrm{R} "=2$-pyrrolyl). This reaction seems to proceed through the mechanism shown in Scheme $7 .^{39-41}$
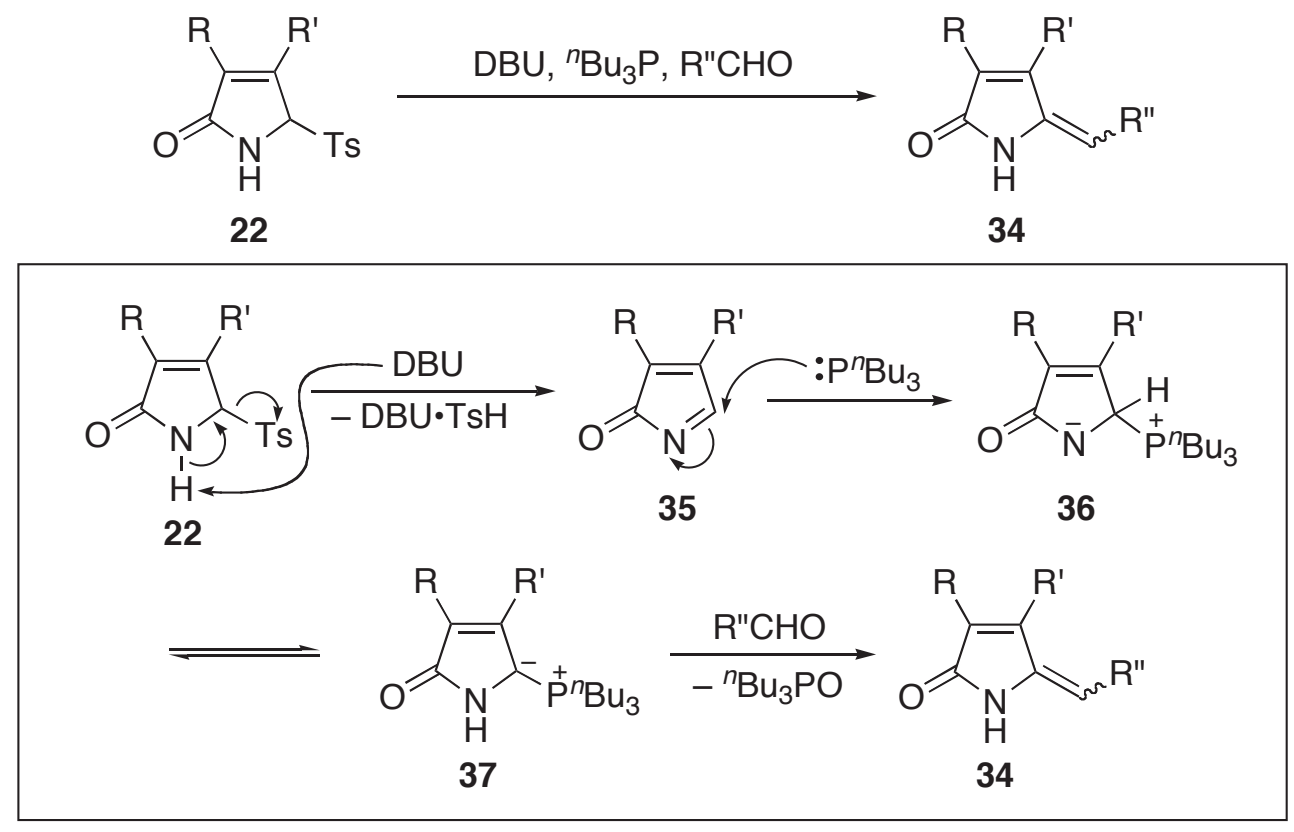

Scheme 7. A plausible mechanism of the Wittig-type coupling reaction of 5-tosylpyrrolinone 22 with an aldehyde.

Applying this Wittig-type coupling reaction, we could develop an alternative method for the synthesis of the AB-ring components, 41 of $\mathrm{BV}$ and $\mathbf{4 3}$ of $\mathrm{P} \Phi \mathrm{B} / \mathrm{PCB}$, without an ester group at the $\mathrm{C} 5$ meso-position. 
When 5-tosylpyrrolinone $\mathbf{3 8}$ as an A-ring precursor was coupled with formylpyrrole $\mathbf{3 3}$ in the presence of tributylphosphine and DBU in THF at room temperature, a mixture of $(E)$ - and $(Z)$-pyrromethenone intermediate 39 was obtained in $80 \%$ yield. The $E$-isomer of 39 was readily converted to the thermodynamically more stable $Z$-isomer by treating with a catalytic amount of iodine in $\mathrm{CH}_{2} \mathrm{Cl}_{2}$ at room temperature in quantitative yield. A 2-(tolylthio)ethyl group of the coupling product $\mathbf{3 9}$ was oxidized to the corresponding sulfoxide 40 with $m \mathrm{CPBA}$ in $\mathrm{CH}_{2} \mathrm{Cl}_{2}$ and converted to a vinyl group by heating in xylene to afford 41, which can be regarded as the AB-ring component of BV. The pyrromethenone derivative $\mathbf{4 1}$ having a vinyl group on the A-ring could be further converted to the AB-ring component $\mathbf{4 3}$ of $\mathrm{P} \Phi \mathrm{B}$ and $\mathrm{PCB}$, i.e., compound $\mathbf{4 1}$ was treated with $\mathrm{Al}(\mathrm{Hg})$ to the reduced intermediate $\mathbf{4 2},{ }^{58}$ followed by acid treatment without purification to obtain $\mathbf{4 3}$ via rearrangement of a proton at the C5 meso-position as a single $Z$-isomer (confirmed by NOE measurement) in good yield as shown in Scheme $8{ }^{43,44,59}$

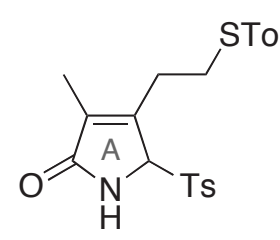

38 (= 22; $\left.\mathrm{R}=\mathrm{Me}, \mathrm{R}^{\prime}=\mathrm{CH}_{2} \mathrm{CH}_{2} \mathrm{STOl}\right)$<smiles>CCCCOC(=O)c1[nH]c(C=C2NC(=O)C(C)=C2CC[Se-]([O-])[O-])c(C)c1CCCOC(C)=O</smiles>

40
1) $33,{ }^{n} \mathrm{Bu}_{3} \mathrm{P} / \mathrm{DBU}$ in THF

2) cat. $\mathrm{I}_{2}$ in $\mathrm{CH}_{2} \mathrm{Cl}_{2}$

TolS

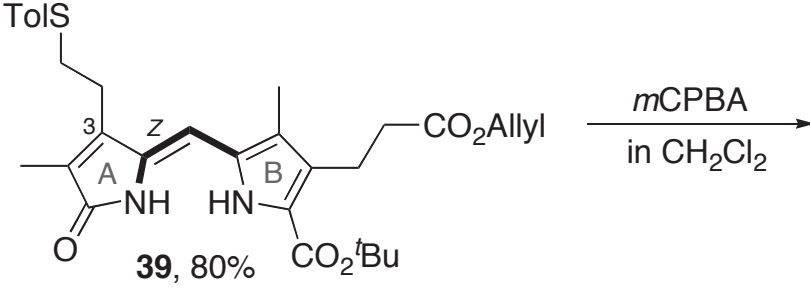<smiles>[Mg][Mg][Mg]</smiles><smiles>C=CC1=C(C)C(=O)N/C1=C\c1[nH]c(C(=O)OC(C)(C)C)c(CCC(=O)OCc2ccccc2)c1C</smiles>

41, 95\% (from 39) (AB-ring of BV)<smiles>C=CC1=C(C(C)C)NC(=O)C1C</smiles>

42
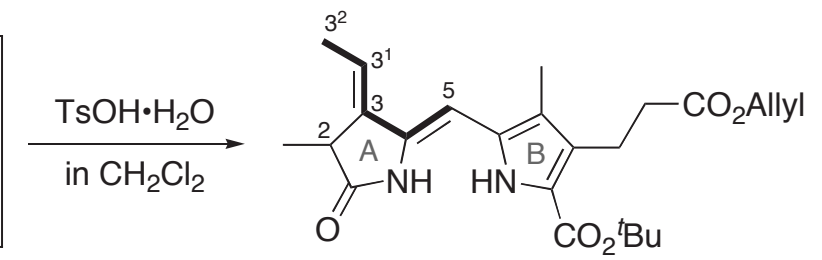

43, $70 \%$

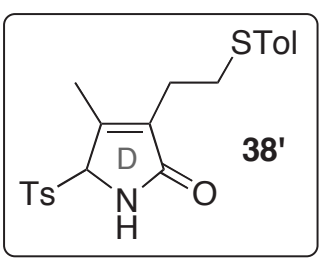

(AB-ring of $\mathrm{P} \Phi \mathrm{B}$ and $\mathrm{PCB}$ )

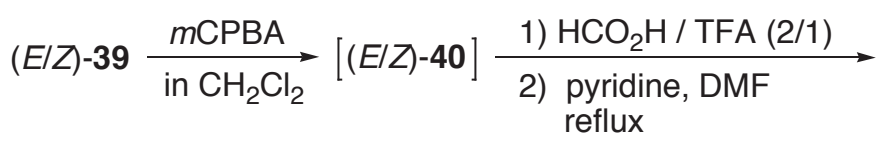<smiles></smiles>

$44,57 \%$ (from 39)

(AB-ring used for the locked BV)

Scheme 8. A flexible method for the preparation of the AB-ring components of BV, РФB and PCB starting from 5-tosylpyrrolinone $\mathbf{3 8}$ and formylpyrrole $\mathbf{3 3}$. 
Decarboxylated AB-ring component 44, which has an acid labile vinyl group, was prepared from (E/Z)-39 via oxidation to the sulfoxide $(E / Z)-40$ and subsequent treatment with a mixture of formic acid and TFA for decarboxylation, followed by refluxing in DMF containing pyridine to introduce a vinyl group under basic conditions resulting in the formation of $\mathbf{4 4}$ as only $Z$-isomer in $57 \%$ yield in three steps from 39 (Scheme 8). ${ }^{60}$ Compound 44 was used for the synthesis of the locked BV derivatives as will be described later.

In a similar manner, the CD-ring components of $\mathrm{P} \Phi B / \mathrm{BV}(\mathbf{5 1})$ and $\mathrm{PCB}(\mathbf{5 0})$ were prepared from 5-tosylpyrrolinones 38', which is a regioisomer of the A-ring precursor 38, and $\mathbf{4 5}$ as the D-ring precursor of PCB, by coupling with formylpyrrole $\mathbf{3 3}$ through our original Wittig-type reaction. The resulting E/Z-mixtures of $\mathbf{4 6}$ and $\mathbf{4 8}$ were treated with a catalytic amount of iodine to give only Z-isomers in good yields, respectively. A thioether bond of the coupling product $\mathbf{4 6}$ was oxidized with $m$ CPBA to afford sulfoxide 47. Pyrromethenone derivatives $\mathbf{4 7}$ and $\mathbf{4 8}$ were treated with TFA for decarboxylation, followed by formylation with methyl orthoformate to afford the corresponding formylated products 49 and $\mathbf{5 0}$, the latter of which is the CD-ring component of PCB. The CD-ring component $\mathbf{5 1}$ of PФB and BV was obtained by heating 49 in xylene in the presence of pyridine to introduce a vinyl group on the D-ring as shown in Scheme 9. ${ }^{44}$
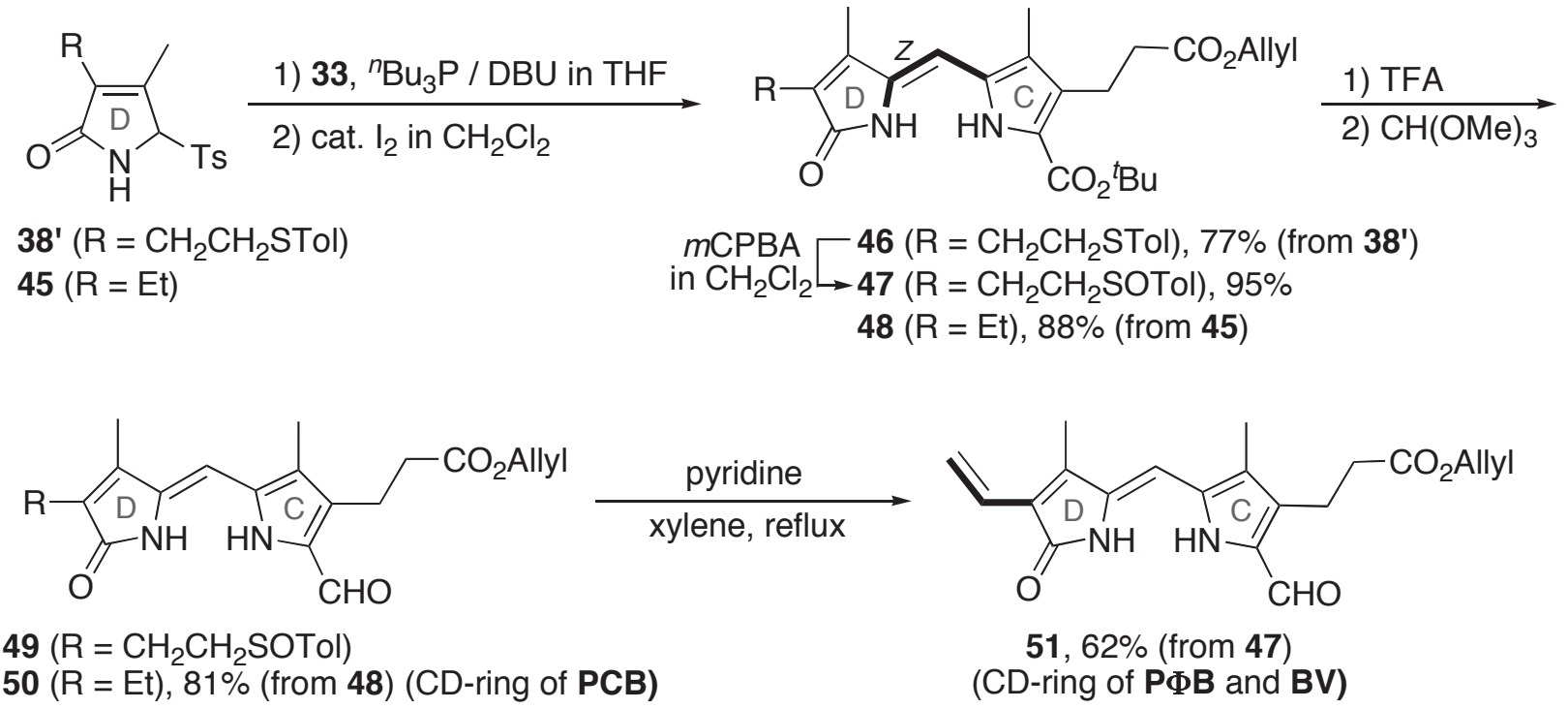

Scheme 9. An efficient method for the preparation of the CD-ring component of PCB (50) and $\mathrm{P} \Phi \mathrm{B} / \mathrm{BV}(\mathbf{5 1})$. 


\section{2-4. Preparation of Linear Tetrapyrrole (Bilin) Chromophores}

As described above, the AB- and CD-ring components were in hand. They were next coupled in alcohol in the presence of an acid catalyst to construct the corresponding linear tetrapyrrole (bilin) derivatives. Scheme 10 shows the coupling in the case of PФB between the CD-ring component $\mathbf{5 1}$ and the AB-ring component 52, which was obtained from $\mathbf{4 3}$ by decarboxylation in TFA. The two allyl ester groups of the coupling product $\mathbf{5 3}$ were deprotected all at once by treating with excess amounts of morpholine in the presence of Pd-catalyst, ${ }^{61}$ avoiding migration of the exocyclic olefin of the A-ring to the endocyclic position, to afford РФB in free acid form. ${ }^{44}$

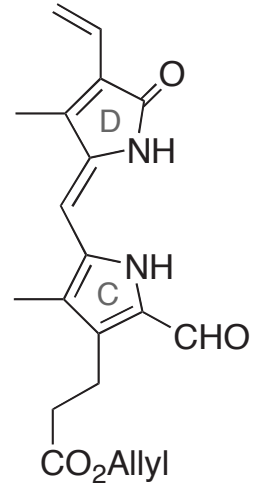

51

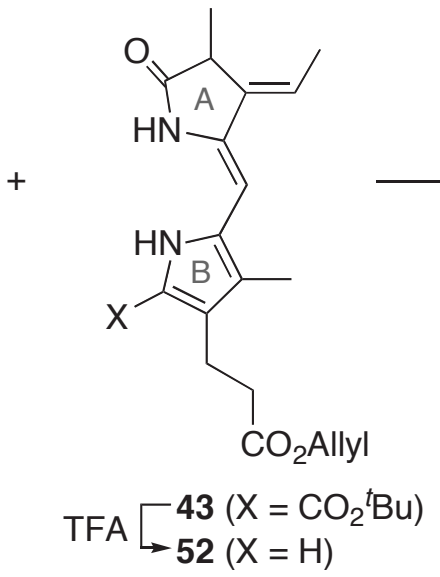

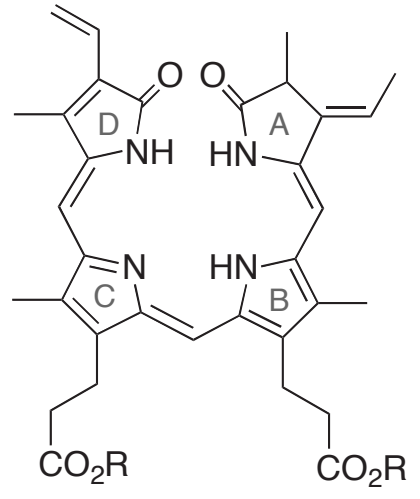

cat. $\left[\mathrm{Pd}\left(\mathrm{PPh}_{3}\right)_{4}\right][53(\mathrm{R}=\mathrm{Allyl}), \mathbf{8 0 \%}$ morpholine in THF $\rightarrow$ P $\Phi B(R=H), 7 \%$ (not yet optimized)

Scheme 10. Coupling of the AB- and the CD-ring components leading to PФB.

Finally, PФB was successfully prepared starting from only two pyrrole derivatives $27 \mathbf{b}\left(\mathrm{R}=\mathrm{Me}, \mathrm{R}^{\prime}=\right.$ $\mathrm{CH}_{2} \mathrm{CH}_{2} \mathrm{STol}$ ) and 33 as depicted in Scheme 11, by developing novel synthetic reactions described above: (1) rearrangement of the tosyl group of 2-tosylpyrroles to the 5-position under mild acidic conditions (Schemes 3 and 4), (2) efficient transformation of 2-bromo-5-tosylpyrroles to the corresponding 5-tosylpyrrolinones by a redox reaction (Scheme 2; NaI was initially used instead of $\mathrm{Zn}$ as a reducing agent $^{47}$ ), (3) the Wittig-type coupling reaction between 5-tosylpyrrolinone and 2-formylpyrrole for the preparation of the $\mathrm{AB}$ - and $\mathrm{CD}$-ring components (Schemes 7-9), (4) reductive transformation of the AB-ring component of BV to the AB-ring component of $\mathrm{P} \Phi \mathrm{B}$ and $\mathrm{BV}$ (Scheme 8), and (5) protection and palladium-catalyzed deprotection of propanoic acid side chains at the C8 and C12 positions via allyl esters (Scheme 10). 


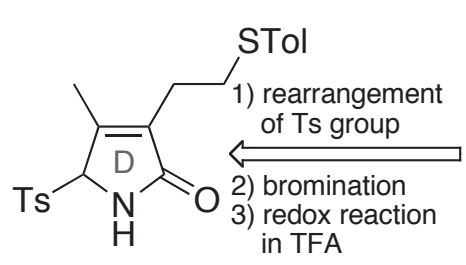

$38^{\prime}$

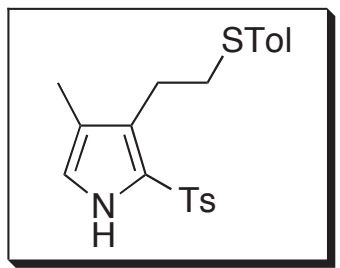

27b

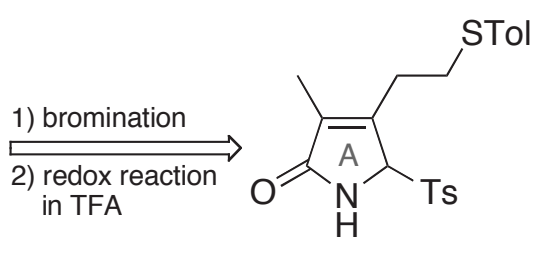

38

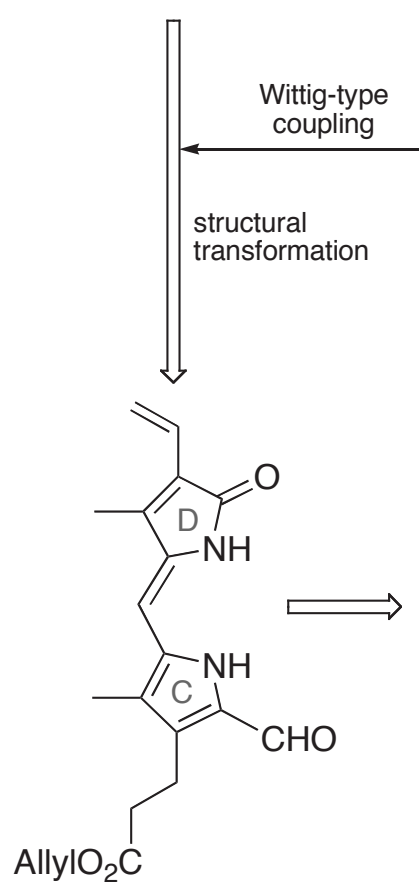

51

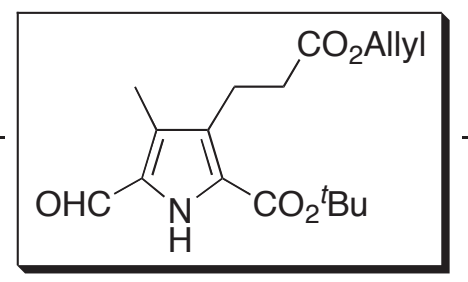

33 (B- or C-ring)

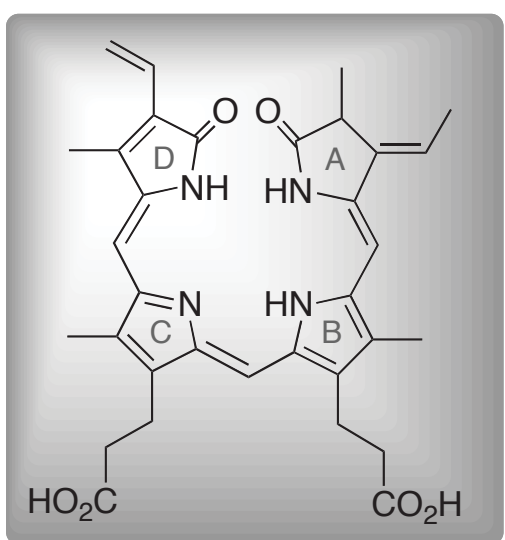

РФв
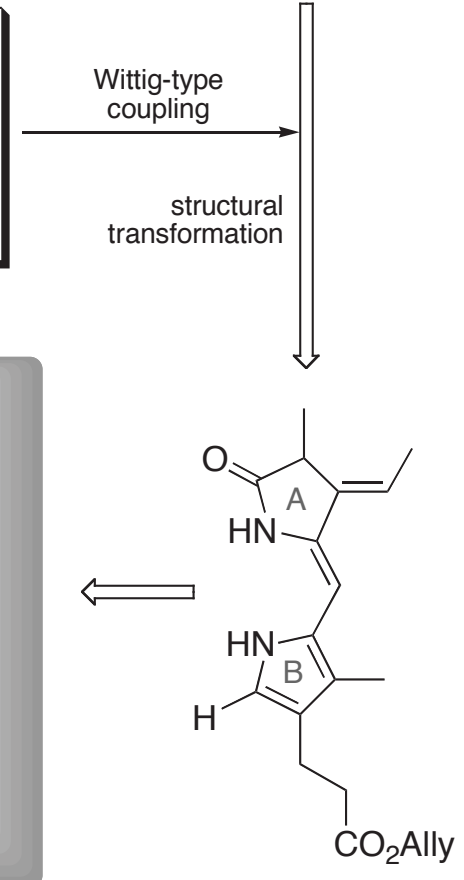

52

Scheme 11. An efficient total synthesis of РФB starting from only two pyrroles, 27b as a precursor of the A- and D-rings and $\mathbf{3 3}$ as a common precursor of the B- and C-rings, respectively.

Though it is possible to introduce a formyl group to the AB-ring component instead of the CD-ring, it looked better to introduce the electron withdrawing formyl group to the CD-ring component to stabilize an acid labile vinyl group at the D-ring. Furthermore, it was found that РФВ is extremely unstable in free acid form compared with PCB, especially without solidifying after purification.

In a similar manner, we could prepare $\mathrm{PCB}$ and various kinds of its derivatives. $3,3^{1}$-Dihydrogenated PCB derivatives were also synthesized to investigate their non-covalent interaction with apophytochromes toward the development of affinity chromatography to purify the apoproteins. ${ }^{42,46}$ It was confirmed by NOESY that all of the synthesized bilin chromophores have an all-Z configuration and an all-syn conformation, respectively.

The above synthetic method is applicable not only for the preparation of $\mathrm{PCB}, \mathrm{P} \Phi \mathrm{B}$, and their derivatives, but also for the preparation of BV and its derivatives (see Scheme 1). Actually we could prepare BV and 
its derivatives, 3EtBV, 18EtBV, 3,18EtBV, and BV-4 shown in Figure 5, for assembly experiment with Agrobacterium phytochrome Agp1 as will be described later.

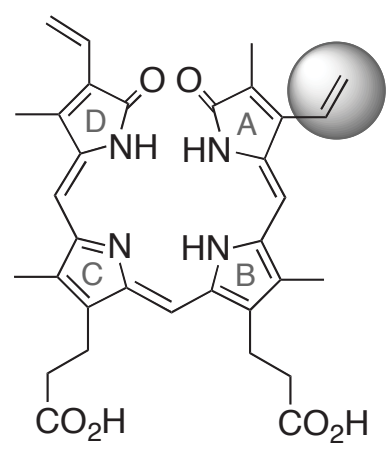

BV

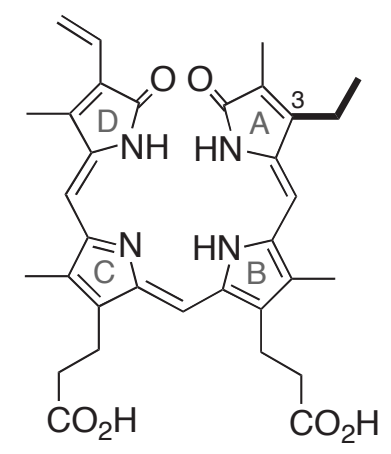

3EtBV

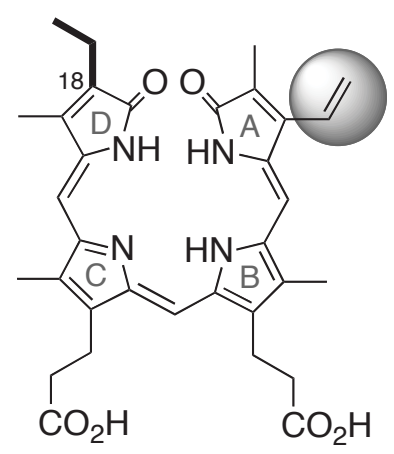

18EtBV

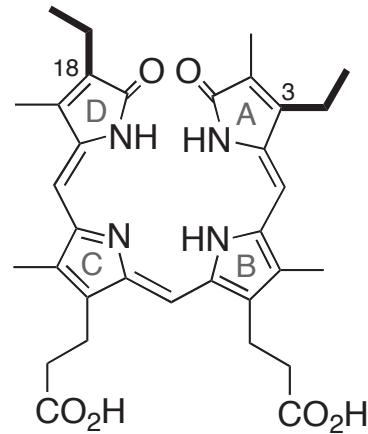

3,18EtBV

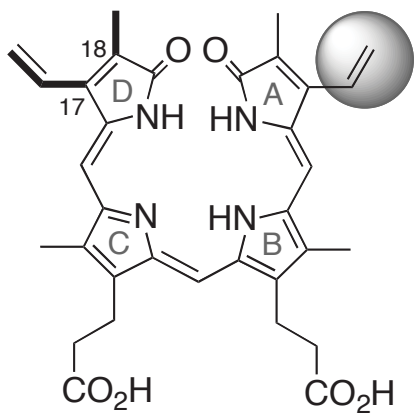

BV-4

Figure 5. BV and its derivatives synthesized according to our general synthetic method of bilin chromophores shown in Scheme 1.

\section{IN VITRO AND IN VIVO ASSEMBLY OF THE SYNTHESIZED BILIN CHROMOPHORES WITH APOPHYTOCHROMES}

Now PCВ, РФВ, BV, and various kinds of their derivatives have become available in free acid forms to study on the reconstituted phytochromes. By photointerconversion between Pr and Pfr, phytochromes act as light-regulated switches for measuring the fluence, direction, duration and color of the ambient light environment. ${ }^{62}$

Phytochromes A and B (PhyA and PhyB) in the model plant species Arabidopsis thaliana recognize light in essentially different manners. ${ }^{63}$ PhyB photoreversibly switches responses on or off upon irradiation with red/far-red light, whereas PhyA triggers very low-fluence or high-irradiance responses. ${ }^{64}$

To analyze the structural requirements of the chromophore for the spectral properties of PhyB, we designed and chemically synthesized more than 20 bilin chromophore derivatives (1-20 in Figure 4) including natural PФB (Scheme 11) and PCB. These chromophores were assembled with recombinant Arabidopsis PhyB apoprotein (PHYB) through collaborative study with biologists. ${ }^{65}$ 
The difference absorption spectra of the in vitro-assembled adducts of the synthetic bilin chromophores (РФВ, PCB, and 1-20) with PHYB were measured on far-red and red light irradiations. The adduct with PCB showed a similar difference spectrum to that of the РФВ adduct, although its peaks were slightly blue shifted due to the difference of the length of $\pi$-conjugation system when compared with the PФB adduct corresponding to the natural phytochrome, ${ }^{66-68}$ as shown in Figure $6 .{ }^{65}$

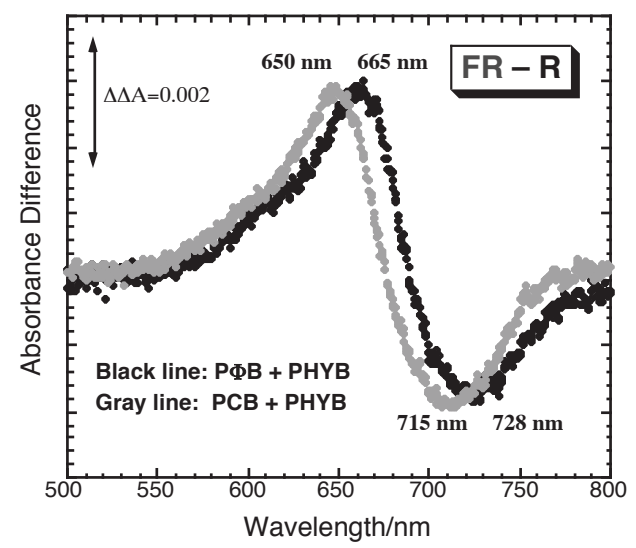

Figure 6. Difference absorption spectra of the PHYB adducts with the chemically synthesized PФB and PCB. ${ }^{65}$ The difference spectra were obtained by subtracting the absorption spectrum recorded after red light irradiation from that recorded after far-red light irradiation.

From the results of the difference absorption spectra of PHYB adducts and the biding efficiency (by zinc blot analysis) of the synthesized PCB analogs (1-20) modified at the A-, B-, C-, and D-rings, respectively, we could find valuable insights into phytochromes. ${ }^{65}$ Namely, (1) the A-ring acts mainly as the anchor for ligation to PHYB, because the modification of the side chains at the C2 and C3 positions (analogs 1-4) did not significantly influence the biding efficiency and/or difference spectra of adducts. These results indicated that a hydrophobic environment and open space accommodate the A-ring of the bilin chromophore at the binding site of PHYB, and also that stereochemistry at the $\mathrm{C} 2$ position was not crucial, since the analog 3 , dimethylated at the $\mathrm{C} 2$ position, showed similar difference spectra.

In contrast, (2) the side chains of the B- and C-rings were found to be crucial to position the chromophore properly in the chromophore pocket of PHYB and for photoreversible spectral changes by using analogs 5-12. Exchanging the methyl groups and the propanoic acid side chains of the B-and C-rings decreased the binding efficiency remarkably, ${ }^{65}$ suggesting that free-acid elements are required for chromophore binding, probably dictated by the electrostatic interaction between propanoic acid side chains and basic amino acid residues of the phytochrome apoprotein. When PHYB adducts retained a propanoic acid side chain at the $\mathrm{C} 8$ position of the B-ring, they displayed photochromism. Thus, propanoic acid side chain at the $\mathrm{C} 8$ position was found to be more crucial for photoreversible conversion of phytochrome than that at the $\mathrm{C} 12$ position. 
(3) The side-chain structure of the D-ring was required for the photoreversible spectral change of the adducts. ${ }^{65}$ When methyl and ethyl groups at the $\mathrm{C} 17$ and $\mathrm{C} 18$ positions of PCB were replaced with a propyl or octyl group (analogs 13-18), respectively, the photoreversible spectral change of the adducts depended on the length of the side chains. Comparison of the difference absorption spectra of the adducts replaced with an octyl group (analogs $\mathbf{1 5}$ and 18) suggested that the environment around the C18 position of the chromophore within the chromophore-biding pocket of PHYB is hydrophobic and more flexible than that of the $\mathrm{C} 17$ position. This suggestion was supported by the results from other two analogs $\mathbf{1 9}$ and 20, which have the 2-(acetoxy)ethyl or 2-(tolylthio)ethyl groups at the $\mathrm{C} 18$ position. ${ }^{65}$

From these studies, we proposed that each pyrrole ring of the linear tetrapyrrole (bilin) chromophore plays a different role in chromophores assembly and the photochromic properties of PhyB.

Furthermore, these results allowed us to outline the order of events during in vitro assembly of PHYB with its chromophore as shown in Figure 7.
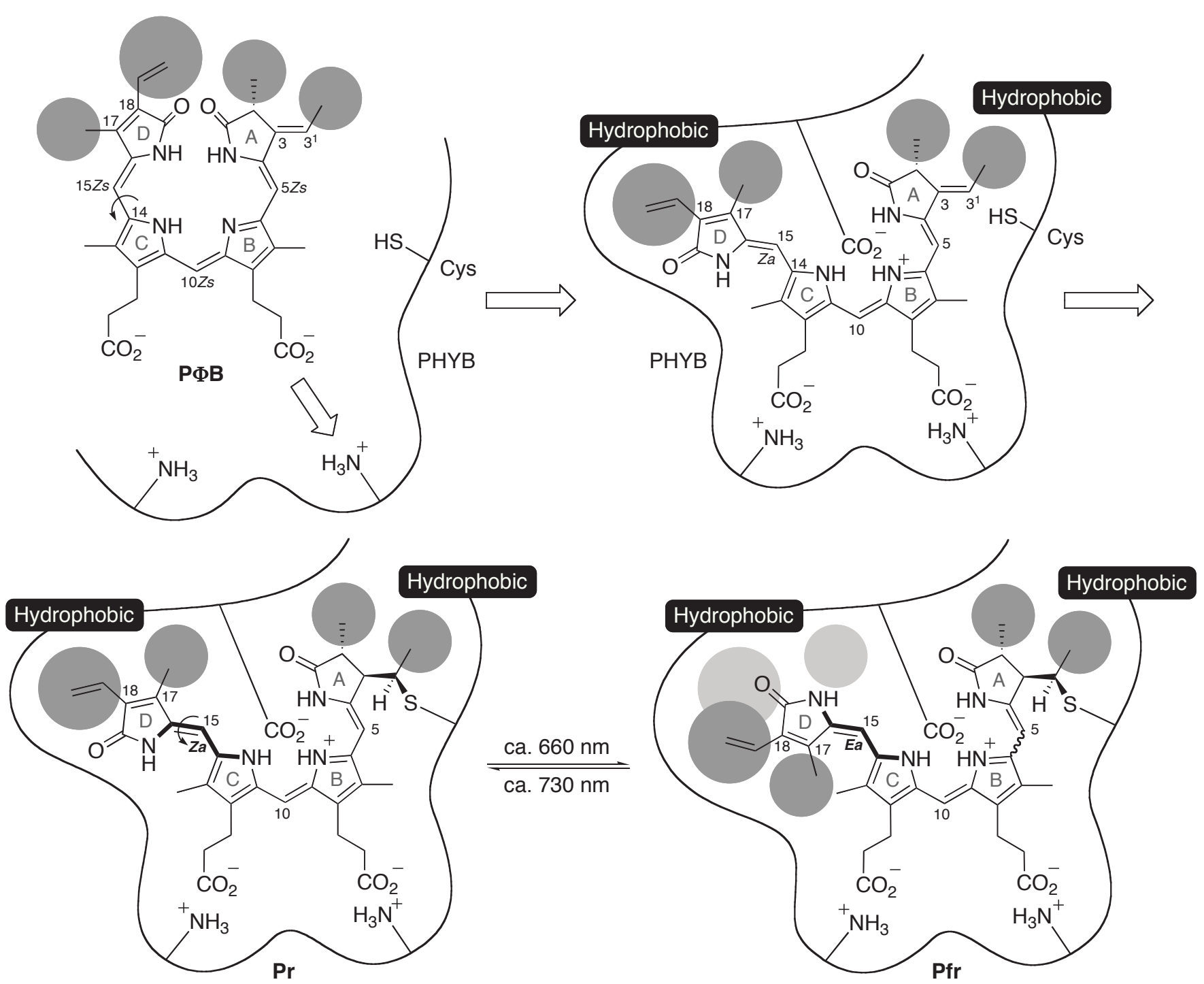

Figure 7. An outline of events during in vitro assembly of PHYB with РФВ. 
The ligation of chromophore to PHYB is initiated by an electrostatic interaction between the propanoic acid side chains of the B- and C-rings and basic amino acid residues such as Arg or Lys, probably accompanied by an additional interaction between an acidic amino acid residue and the basic nitrogen of the pyrrole (the ring-B in Figure 7). Rotation around the $\mathrm{C} 14-\mathrm{C} 15$ single bond of the original all- $Z$ and all-syn bilin chromophore would occur at this initial stage to form an extended anti conformation of the chromophore in PHYB, as will be discussed later. The A-ring falls into the hydrophobic site close to the Cys within the GAF domain of PHYB, followed by nucleophilic attack of a thiol group of the Cys onto the $\mathrm{C} 3^{1}$ position of the ethylidene substituent of the A-ring to form a thioether bond through a sort of the Michael-type addition reaction. The D-ring also falls into a hydrophobic pocket where open space exists particularly around the $\mathrm{C} 18$ position of the chromophore to afford $\mathrm{Pr}$ form, which acts as the photoreceptor for red/far-red reversible reaction (Figure 7).

It was possible to replace a side chain at the $\mathrm{C} 17$ or $\mathrm{C} 18$ position of the D-ring with a bulky substituent without loss of photoconversion. Thus, these positions were labeled with a photoreactive group for photoaffinity studies. PCB analogs carrying a photoreactive 4-[3-(trifluoromethyl)diaziren-3-yl]phenyl group at the $\mathrm{C} 17$ or $\mathrm{C} 18$ position of the D-ring, however, were not incorporated into PHYB, probably due to the bulkiness and the lack of flexibility of the employed photoreactive group.

Phytochromes are encoded by a small gene family, and five distinct phytochromes (A to E) have been identified in the model plant species Arabidopsis thaliana, ${ }^{69,70}$ in which phytochromes A (PhyA) and B (PhyB) are most abundant, principally working throughout the life cycle. Photobiological analyses have established that, under continuous irradiation, PhyA is primarily responsible for plant's sensitivity to far-red light, whereas the other phytochromes respond mainly to red light, using various phytochrome-deficient mutants. ${ }^{4}$ To elucidate a question whether different bilin structures affect the photobiological activities of phytochromes in vivo, we have collaborated with biologists to incorporate synthetic bilin chromophores into apopytochromes A (PHYA) and B (PHYB) in Arabidopsis hyl and hy2 mutants, which are deficient in PФB biosynthesis. ${ }^{71-73}$ Parks and Quail have restored photomorphogenesis in these mutants with exogenously supplied biliverdin IX $\alpha$ (BV), a direct precursor of $\mathrm{P} \Phi \mathrm{B} .^{74}$ By using an analogous approach, synthetic bilins were fed exogenously to hyl and hy2 seedlings to test whether they restore the photobiological functions of PhyA and PhyB in vivo. ${ }^{75}$

The far-red light sensitivity of PhyA was found to depend on the structure of the bilin chromophore, i.e., a double bond on the D-ring of РФB was required for restoring PhyA function, whereas PhyB function was restored with both $\mathrm{P} \Phi \mathrm{B}$ and $\mathrm{PCB}$ with a saturated D-ring substituent. ${ }^{75}$

This collaborative work with biologists demonstrated a quite suggestive discovery that a double bond in the vinyl side chain at the $\mathrm{C} 18$ position of D-ring of РФВ is crucial for the photosensory function of PhyA, and has opened an avenue of research toward understanding the nature of holophytochrome assembly and 
the chromophore pocket in vitro and in vivo.

Different from plant phytochromes, many bacterial phytochromes carry biliverdin (BV) as a natural chromophore, which is coupled in a different manner to the protein, because BV has a vinyl side chain on the A-ring instead of an ethylidene side chain of Р $\Phi \mathrm{B}$ and PCB. In phytochrome Agp1 of Agrobacterium tumefaciens, BV is covalently attached to a cysteine residue close to the $\mathrm{N}$-terminus (position 20). It had been proposed that BV binds via its D-ring to the protein, ${ }^{76}$ but the assumption had not been confirmed by chemical studies.

Therefore, we used different natural and synthetic BV analogs prepared above (Figure 5), three BV-derivatives with a reduced A-ring and/or D-ring side chains, namely 3EtBV, 18EtBV, 3,18EtBV, and $\mathrm{BV}-4$, in which the D-ring vinyl group of the C18 position was exchanged with the methyl group of the C17 position, to test whether the A-ring or D-ring vinyl side chain is used for covalent BV attachment in Agp $1{ }^{77}$ Chromophore assembly was carried out by German biologists as our collaborative work, and it was found that all tested chromophores formed adducts with the Agp1 apoprotein. In addition, all adducts showed typical photoconversion into Pfr form upon irradiation with red light. ${ }^{77}$

Covalent attachment of the chromophores was further tested by SDS-denaturation/dissociation followed by separation of protein and the free bilin on desalting columns. If the chromophore is covalently bound, it elutes together with the protein from the desalting column, whereas noncovalently bound chromophore is separated from the protein by treating with SDS and remains almost entirely inside the column. The assay showed that BV, 18EtBV and BV-4 adducts were covalently attached. All three covalently bound chromophores have an A-ring vinyl side chain (marked with a grey circle in Figure 5) but differ by their D-ring side chains. Those chromophores that contain an A-ring ethyl or ethylidene side chain, namely 3EtBV, 3,18EtBV, РФB, PCB, were noncovalently bound to the protein.

From these results, we could conclude that a vinyl group of the A-ring of BV chromophore forms a thioether bond with the cysteine 20 residue of Agp $1 .^{77}$ This result was then confirmed by X-ray crystallography of a truncated phytochrome from Deinococcus radiodurans consisting of the N-terminal 321 amino acids. $^{78}$

\section{DEVELOPMENT OF GENERAL SYNTHETIC METHOD OF STERICALLY LOCKED BILIN CHROMOPHORES}

As mentioned above, we could establish an efficient and flexible synthetic method of various kinds of bilin chromophores, ${ }^{41-46}$ including $\mathrm{P} \Phi \mathrm{B},{ }^{44} \mathrm{PCB},{ }^{42,43}$ and various kinds of PCB derivatives, ${ }^{45,46}$ in free acid forms, which made it possible to assemble them with the apoproteins not only in vitro to analyze the spectral properties of the resulting holoproteins, ${ }^{65}$ but also in vivo to observe their physiological functions. $^{75}$ 
On the other hand, it has been shown for plant phytochrome that the first step of the Pr to Pfr photoconversion is a $Z$ to $E$ isomerization of the chromophore around the $\mathrm{C} 15=\mathrm{C} 16$ double bond, ${ }^{23}$ which occurs on the picosecond time scale. ${ }^{79-81}$ Isomerization is followed by spectral changes in the microsecond and millisecond time scale. ${ }^{82-84}$ During photoconversion, the chromophore also undergoes movement around the exocyclic single bonds. In principle, each exocyclic single bond can adopt either a syn or anti conformation during photoconversion. ${ }^{12}$ Vibrational spectroscopy gained indirect insight into the conformation of the phytochrome chromophore in the Pr, Pfr, and intermediate states, but the data were ambiguous and have been interpreted in different ways. ${ }^{25-28}$ For example, it has been proposed that the formation of Pfr is accompanied by a syn/anti rotation around the C14-C15 single bond. ${ }^{27}$ More recently, interpretation of resonance Raman spectra by using density functional theory (DFT) calculations indicated that the C14-C15 single bond is in an anti conformation throughout the entire photocycle and that the C5-C6 single bond rotates from anti to syn upon conversion from Pr to Pfr as shown in Figure $2 .^{28}$ Therefore, to directly confirm the stereochemistry of the chromophore in phytochrome around the C15 position for both Pr- and Pfr-forms, we first prepared four different types of BV derivatives (62-65), in which the C- and D-rings are sterically locked by cyclizing with an additional carbon chain, by applying the above general synthetic method of bilin chromophores.

The AB-ring component 44 common to all of the locked BV derivatives (62-65) were prepared as shown in Scheme 8 from $(E / Z)-39 .^{60}$ Thus, total syntheses of the four different types of BV derivatives (62-65), in which the stereochemistry between the C-and D-rings are locked in Z-syn, Z-anti, E-syn, and E-anti configuration and conformation, respectively, were accomplished via establishment of new and efficient methods for the construction of the sterically locked CD-ring components (58-61) based on the retrosynthetic analyses depicted in Figure 8.

The Z-syn CD-ring precursor 66 was prepared by treating $(Z)-48$, which is available by the Wittig-type coupling of 45 and 33 (Scheme 9), with 1,2-dibromoethane in the presence of $\mathrm{NaH}$ in $84 \%$ yield. The $t$-butoxycarbonyl group of $\mathbf{6 6}$ was converted to a formyl group by treating with TFA, followed by addition of methyl orthoformate at room temperature to give the formylated CD-ring component $\mathbf{5 8}$ in quantitative yield (Scheme 12). Coupling reaction between the CD-ring component 58 and the AB-ring component 44 was carried out in methanol under acidic conditions to afford 15Zs-18Et-BV diallyl ester 67 in $69 \%$ yield. The two allyl ester groups were deprotected by a $\mathrm{Pd}(0)$-catalyzed reaction using sodium $p$-toluenesulfinate (NaTs) as a nucleophile in $\mathrm{THF} / \mathrm{MeOH}$ to give locked chromophore 62 $(15 Z s-18 E t-B V)$ in free acid form in $80 \%$ yield. $^{49}$ 

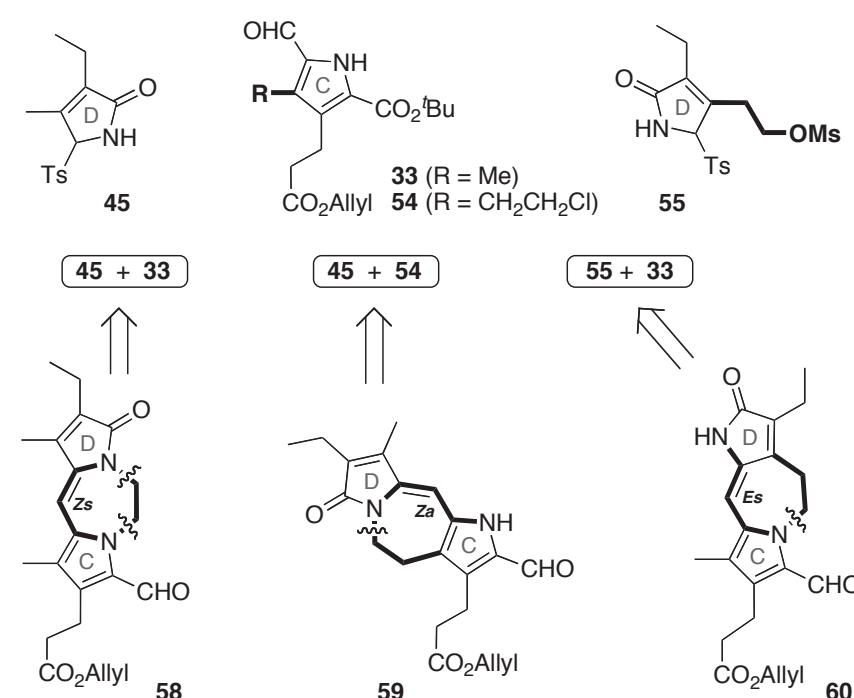

$55+33$

58

$\uparrow$ AB-ring 44

59
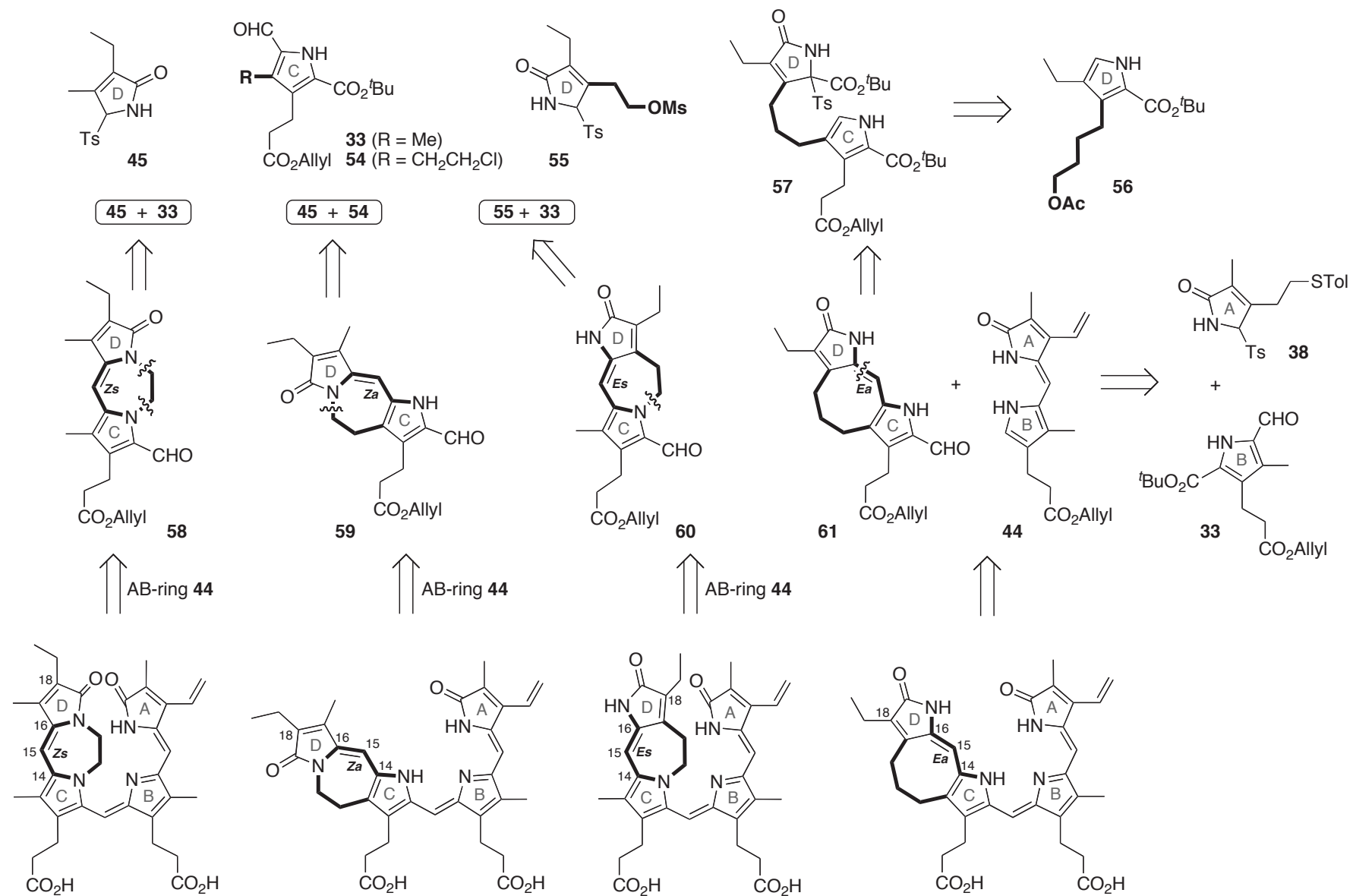

$62(15 Z s-18 E t-B V)$
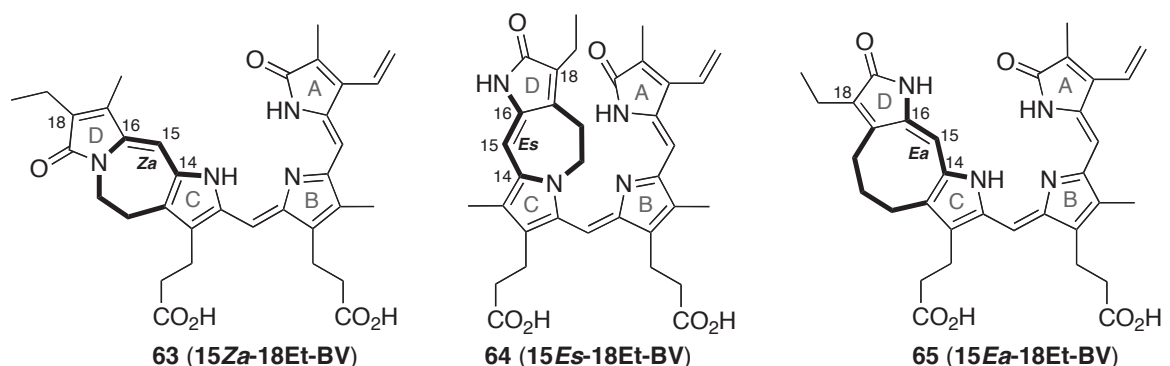

65 (15Ea-18Et-BV)

Figure 8. Retrosynthetic analyses of the sterically locked BV derivatives (62-65).
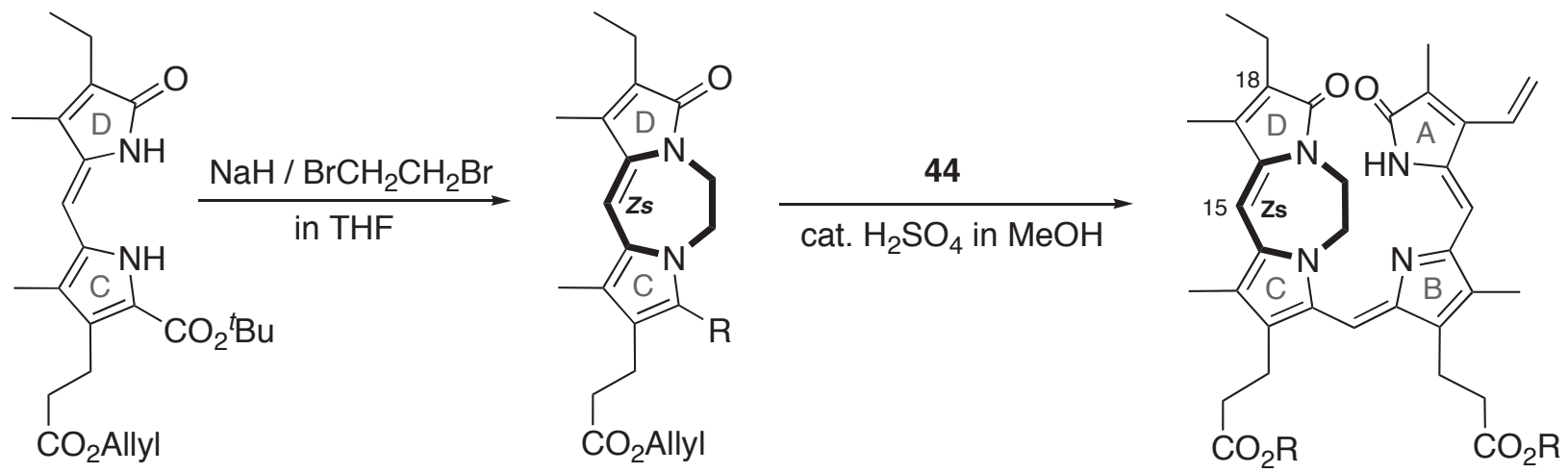

48

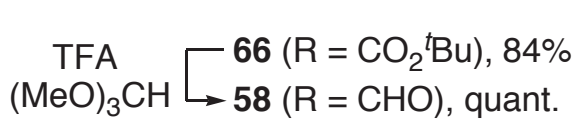

TFA
$(\mathrm{MeO})_{3} \mathrm{CH} \longrightarrow 58(\mathrm{R}=\mathrm{CHO})$, quant.

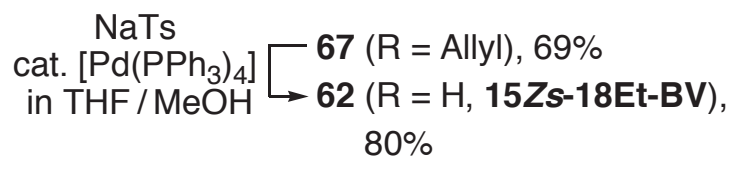

Scheme 12. Synthesis of $15 Z s-18$ Et-BV (62).

The Z-anti CD-ring component 59 was prepared from the D-ring $\mathbf{4 5}$ and the C-ring $\mathbf{5 4}$ bearing a leaving group for cyclization. ${ }^{60}$ As shown in Scheme 13, commercially available 3-bromo-1-propanol (68) was 
acetylated, followed by nitration using sodium nitrite in the presence of phloroglucinol in DMF to give 3-nitropropyl acetate (69) in 60\% yield. Compound 69 was coupled with oxoester 70 in a similar manner for the preparation of the B- and C-rings of bilin chromophore. ${ }^{41,45}$ Subsequent acetylation of the resulting alcohol gave nitro-acetate 71 in 66\% yield, along with a small amount of nitroolefin. When compound 71 was treated with $t$-butyl isocyanoacetate and DBU in acetonitrile according to the Barton's method, ${ }^{55}$ pyrrole derivative 72 was obtained in 55\% yield. Hydrolysis of 72 with $\mathrm{KOH}$ in $\mathrm{MeOH}$, followed by allylation with allyl bromide in the presence of DBU in THF/DMF, gave pyrrole 73 in $60 \%$ yield. When compound $\mathbf{7 3}$ was formylated by the Vilsmeier reaction to give the formylated product, chlorination of the hydroxy group proceeded simultaneously to afford formylpyrrole 54 in $94 \%$ yield.

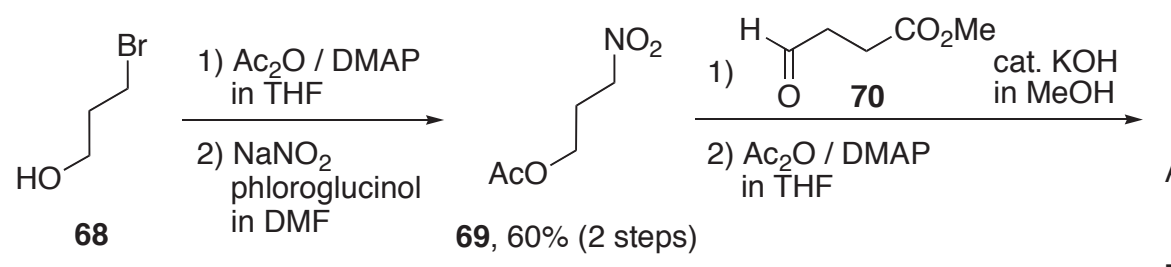

$69,60 \%$ (2 steps)

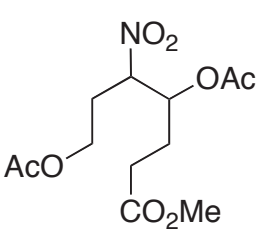

$\mathbf{7 1}, 66 \%$ (2 steps)
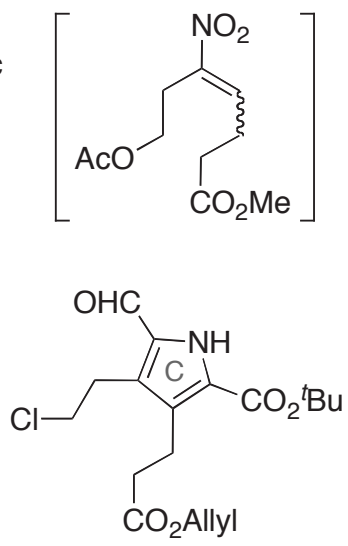

$54,94 \%$

Scheme 13. Synthesis of the C-ring 54 bearing a 2-chloroethyl group for cyclization.

The Wittig-type coupling reaction between 5-tosylpyrrolinone 45 and formylpyrrole 54 proceeded satisfactorily in the presence of tributylphosphine and DBU in THF at $0{ }^{\circ} \mathrm{C}$ to room temperature to afford the CD-ring components 74 as a mixture of $E$ - and $Z$-isomers in 98\% yield (Scheme 14). It turned out that compound $(E)-74$ had to be converted to the $Z$-isomer by treating with a catalytic amount of iodine in $\mathrm{CH}_{2} \mathrm{Cl}_{2}$ prior to the cyclization. Compound (Z)-74 was then cyclized at $50{ }^{\circ} \mathrm{C}$ in the presence of DBU in THF affording the desired cyclized product 75 in $76 \%$ yield. Subsequent formylation was accomplished by treating with methyl orthoformate in TFA to give the formylated CD-ring component $\mathbf{5 9}$ in quantitative yield. ${ }^{49,60}$

Coupling reaction between the CD-ring 59 and the AB-ring 44 was carried out under acidic conditions to afford the sterically locked $15 Z a-18 \mathrm{Et}-\mathrm{BV}$ diallyl ester derivative $\mathbf{7 6}$ in $87 \%$ yield. Finally, the deprotection of the allyl ester moiety of $\mathbf{7 6}$ was achieved by a $\mathrm{Pd}(0)$-catalyzed reaction ${ }^{42,44}$ using sodium $p$-toluenesulfinate as a nucleophile in $\mathrm{THF} / \mathrm{MeOH}$ to give the desired locked chromophore 63 (15Za-18Et-BV) in $90 \%$ yield. $^{49,60}$ 


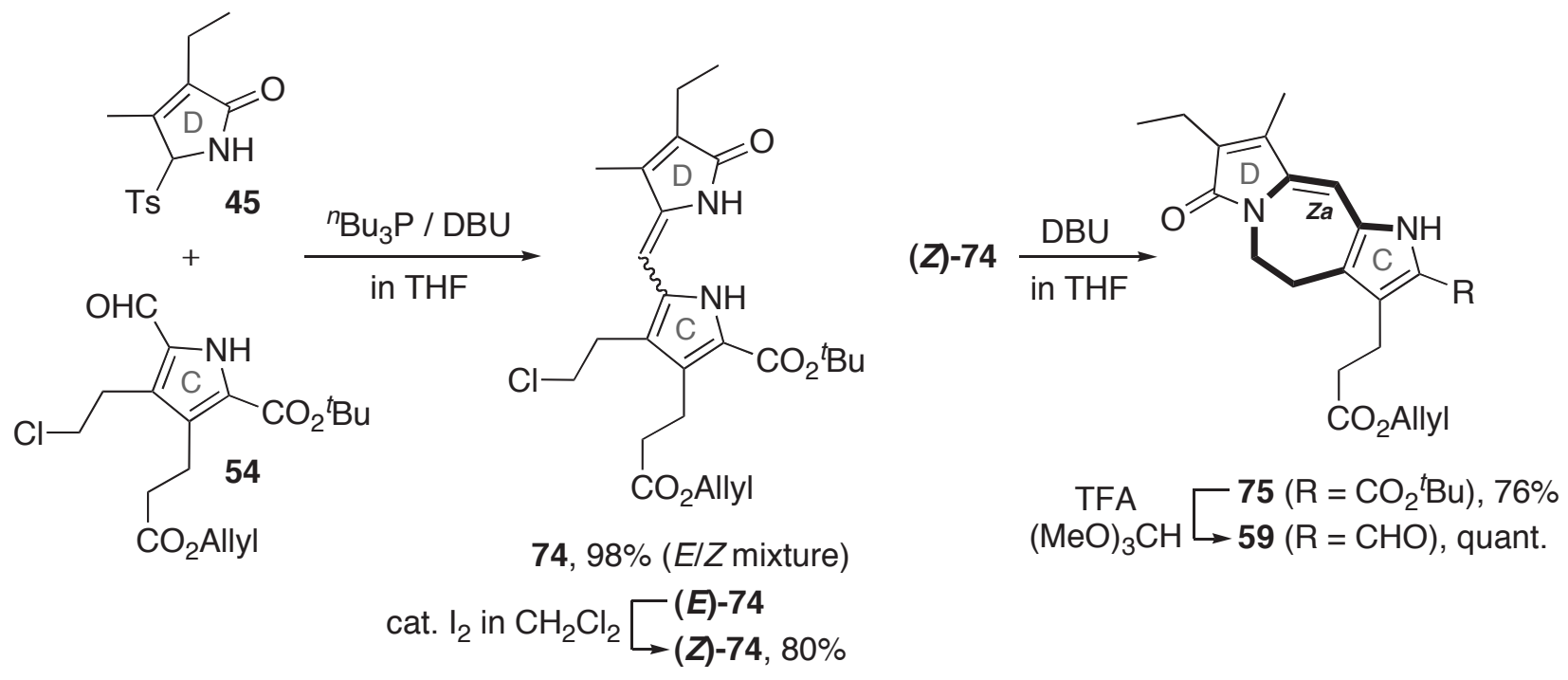

59
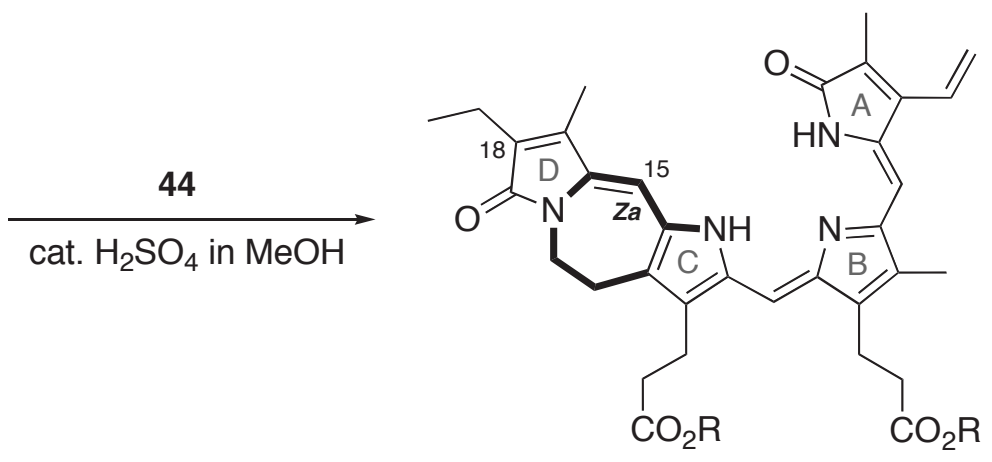

$\begin{gathered}\text { TsNa / cat. }\left[\mathrm{Pd}\left(\mathrm{PPh}_{3}\right)_{4}\right] \\ \text { in } \mathrm{THF} / \mathrm{MeOH}\end{gathered} \longrightarrow 63(\mathrm{R}=\mathrm{H}=\mathrm{H}, 15 \mathrm{Za}-18 \mathrm{Et}-\mathrm{BV}), 90 \%$

Scheme 14. Synthesis of 15Za-18Et-BV (63).

Toward the construction of 15Es-18Et-BV (64), 5-tosylpyrrolinone derivative 55 was prepared starting from propenal (77) as shown in Scheme 15. Treatment of 77 with acetic acid in the presence of a catalytic amount of zinc acetate afforded 3-acetoxypropanal (78) in 40\% yield. ${ }^{85,86}$ Compound 78 was then coupled with 1-nitropropane according to the Henry reaction in the presence of a catalytic amount of $\mathrm{KOH}$ in $\mathrm{MeOH}$. The resulting nitro-alcohol was then acetylated using acetic anhydride in the presence of a catalytic amount of 4-(dimethylamino)pyridine (DMAP) in THF to give the nitro-diacetate 79 in $85 \%$ yield in two steps. Compound $\mathbf{7 9}$ was reacted with tosylmethyl isocyanide in the presence of DBU to afford 2-tosylpyrrole derivative $\mathbf{8 0}$ in 59\% yield. Compound $\mathbf{8 0}$ was then brominated with trimethylphenylammonium tribromide in $\mathrm{CH}_{2} \mathrm{Cl}_{2}$, followed by hydrolysis of the acetoxy group with aqueous $\mathrm{NaOH}$ in $\mathrm{MeOH}$ to give compound 81 in $72 \%$ yield in two steps. Mesylation and subsequent redox-type reaction ${ }^{39,47}$ using DMSO and zinc in TFA afforded the 5-tosylpyrrolinone derivative $\mathbf{5 5}$ in $55 \%$ yield in two steps. ${ }^{49}$ 


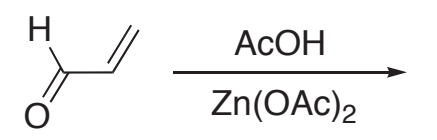

77

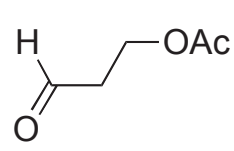

$78,40 \%$

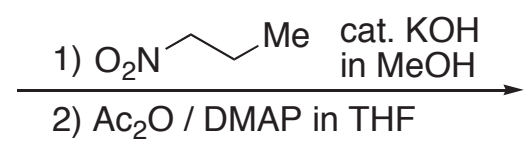

2) $\mathrm{Ac}_{2} \mathrm{O} / \mathrm{DMAP}$ in THF

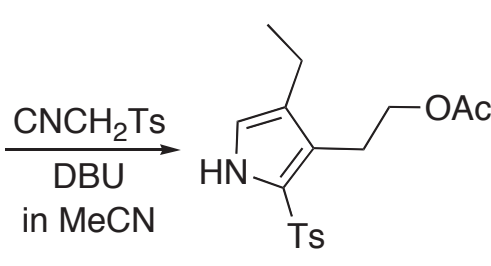

$80,59 \%$

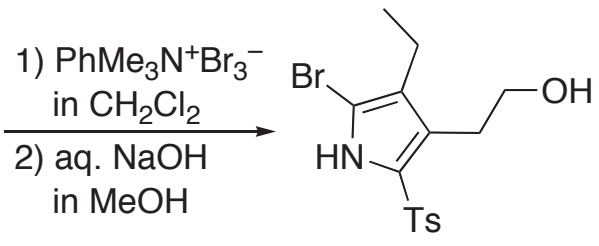

81, $72 \%$ (2 steps)

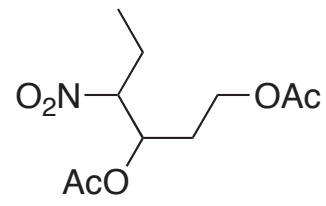

$79,85 \%$ (2 steps)

Scheme 15. Synthesis of the D-ring $\mathbf{5 5}$ carrying a leaving group for cyclization.

Compounds 55 and 33 were coupled by the Wittig-type reaction using tributylphosphine and DBU in THF to afford the cyclized E-syn CD-ring component 82 in $65 \%$ yield. Formylation of 82 with TFA and methyl orthoformate accompanied by decarboxylation gave the CD-ring component 60 in $85 \%$ yield.

Coupling reaction between the CD-ring 60 and the AB-ring 44 was carried out under acidic conditions in a similar manner as in the case of other locked chromophores described above to afford the sterically locked 15Es-18Et-BV diallyl ester derivative 83 in $45 \%$ yield. The deprotection of the allyl ester moiety of 83 by a $\mathrm{Pd}(0)$-catalyzed reaction ${ }^{42,44}$ with sodium $p$-toluenesulfinate as a nucleophile in THF/MeOH gave locked chromophore 64 (15Es-18Et-BV) in $42 \%$ yield (Scheme 16). ${ }^{49,60}$<smiles>[3H]C1NC(=O)C(CC)=C1CCOC</smiles>

$\mathrm{OHC}$<smiles>Cc1[nH]c(C(=O)OC(C)(C)C)c(CCC(=O)O)c1C</smiles>

33

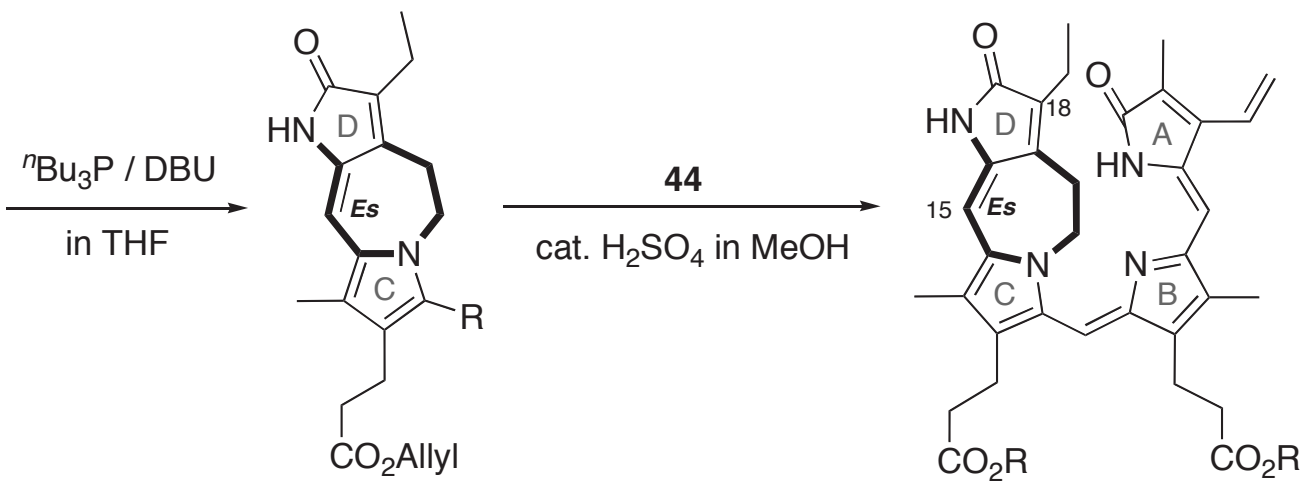

TFA
$(\mathrm{MeO})_{3} \mathrm{CH} \longrightarrow 62\left(\mathrm{R}=\mathrm{CO}_{2}{ }^{\mathrm{t}} \mathrm{Bu}\right), 65 \%$
$\mathbf{6 0}(\mathrm{R}=\mathrm{CHO}), 85 \%$

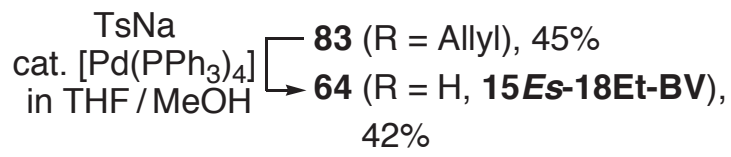


Locked BV derivative 65 (15Ea-18Et-BV) bearing an E-anti CD-ring component was synthesized through cyclization with an 8-membered ring as shown in Scheme $17 .{ }^{87}$

The CD-ring component $\mathbf{6 1}$ was prepared starting from commercially available 3,4-dihydro- $2 H$-pyran (84). 5-Hydroxypentanal (86) obtained by acid hydrolysis of 84 was reacted with 1-nitropropane in the presence of a base according to the Henry reaction to afford nitro-alcohol $\mathbf{8 7}$, followed by acetylation in the presence of DMAP to give nitro-diacetate $\mathbf{8 8}$ along with nitro-olefin $\mathbf{8 9}$ in three steps. A mixture of compounds $\mathbf{8 8}$ and $\mathbf{8 9}$ was reacted with $t$-butyl isocyanoacetate in the presence of DBU in THF applying the Barton's method ${ }^{55}$ to give pyrrole derivative 56 in 26\% yield from 84 in four steps.

Iodination of $\alpha$-position of pyrrole 56 with $N$-iodosuccinimide (NIS) to 90 (99\% yield) and subsequent oxidation utilizing $\mathrm{Pb}(\mathrm{OAc})_{4}$ in toluene gave pyrrolinone derivative 91 in $91 \%$ yield. The $\alpha$-acetoxy group of the pyrrolinone derivative 91 was replaced by a Ts group to afford 92 in $94 \%$ yield using anhydrous sodium $p$-toluenesulfinate $(\mathrm{TsNa})$ in refluxing $\mathrm{THF}$, followed by protection of the pyrrolinone-NH group using di-t-butyl dicarbonate $\left(\mathrm{Boc}_{2} \mathrm{O}\right)$ in $\mathrm{MeCN}$ to give compound 93 in $86 \%$ yield. Then, hydrolysis of the acetate group of 93 in $0.5 \mathrm{M}$ methanolic $\mathrm{HCl}$ afforded $N$-protected tosylpyrrolinone derivative 94a and its regioisomer 94b, which was formed by allylic rearrangement of a tosyl group, in $97 \%$ total yield $(\mathbf{9 4 a} / \mathbf{9 4 b}=$ ca. $1 / 2)$. Iodination of the resulting alcohol using iodine and triphenylphosphine in the presence of imidazole in MeCN afforded 95 in 89\% total yield. The product 95 was converted to a mixture of tosylpyrrolinone derivatives 96a and $96 \mathbf{b}$ bearing a nitro group in its side chain in $60 \%$ yield by treating with sodium nitrite in the presence of phloroglucinol in DMF. The resulting nitro compound 96 was reacted with allyl 4-oxobutanoate (97) that was readily available from $\gamma$-butyrolactone (101) (Scheme 18), ${ }^{45,88}$ followed by acetylation and reaction with $t$-butyl isocyanoacetate to give a mixture of dipyrrole derivatives, 57a and its regioisomer $\mathbf{5 7 b}$, in 28\% total yield from 96. Compound $\mathbf{5 7}$ was subjected to the Vilsmeier reaction to afford a mixture of formylated dipyrrole derivatives $\mathbf{9 8 a}$ and $\mathbf{9 8 b}$ in $67 \%$ yield. Compound 98 was then treated with $99 \%$ formic acid to cleave the Boc and $t$-butyl esters giving dicarboxylic acid derivative, which was further subjected to the Wittig-type intramolecular coupling using tributylphosphine in the presence of DBU in THF/DMF to give the pyrromethenone derivative 99 in $49 \%$ yield. It was confirmed that isolated both isomers $\mathbf{9 8 a}$ and $\mathbf{9 8 b}$ could be converted to the same product 99, respectively, under the same reaction conditions. Compound 99 was formylated by treating with methyl orthoformate in TFA to give the desired formylated E-anti CD-ring component $\mathbf{6 1}$ in $63 \%$ yield.

Coupling reaction between the CD-ring 61 and the AB-ring 44 was carried out under acidic conditions to afford $15 \mathrm{Ea}-18 \mathrm{Et}-\mathrm{BV}$ diallyl ester derivative $\mathbf{1 0 0}$ in $71 \%$ yield. Finally, deprotection of the allyl esters was achieved by a $\mathrm{Pd}(0)$-catalyzed reaction in the presence of sodium $p$-toluenesulfinate $(\mathrm{TsNa})$ as a

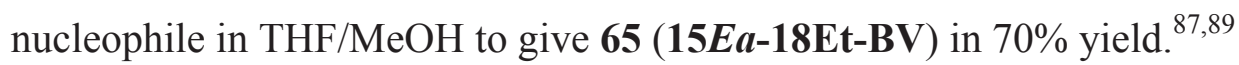



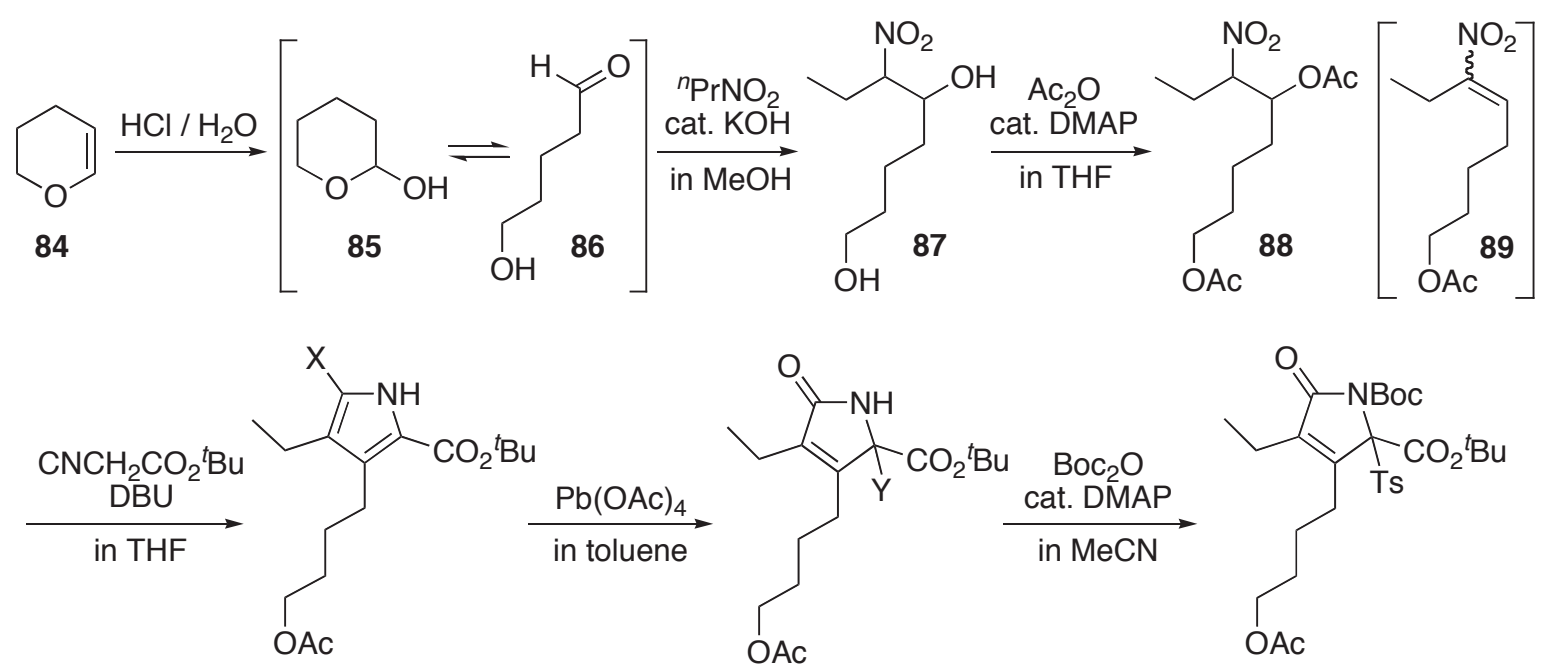

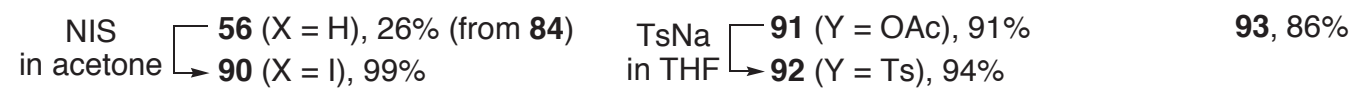

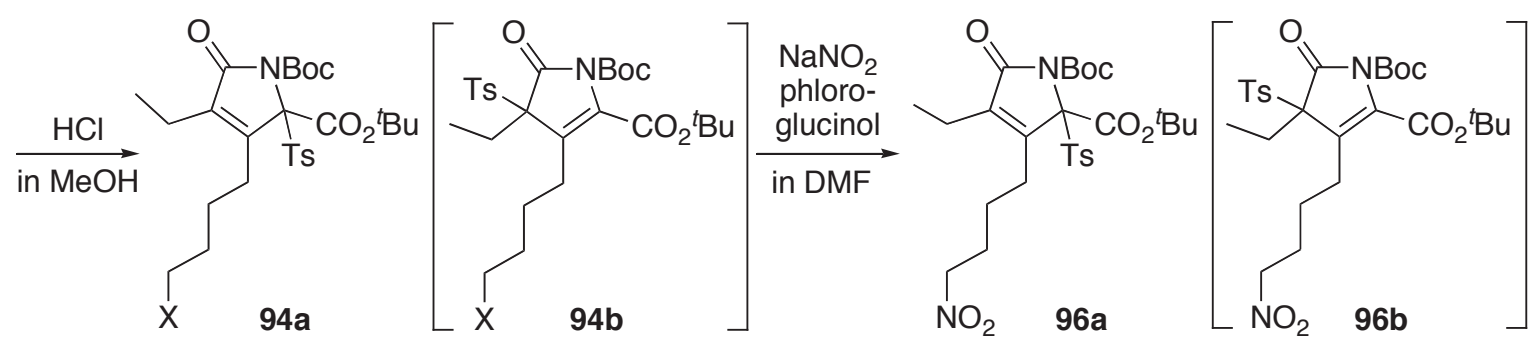

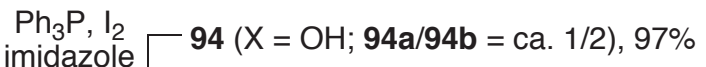

in $\mathrm{CH}_{3} \mathrm{CN} \longrightarrow 95(\mathrm{X}=\mathrm{I})$, totally $89 \%$

96a/96b (ca. 1/2), 60\%
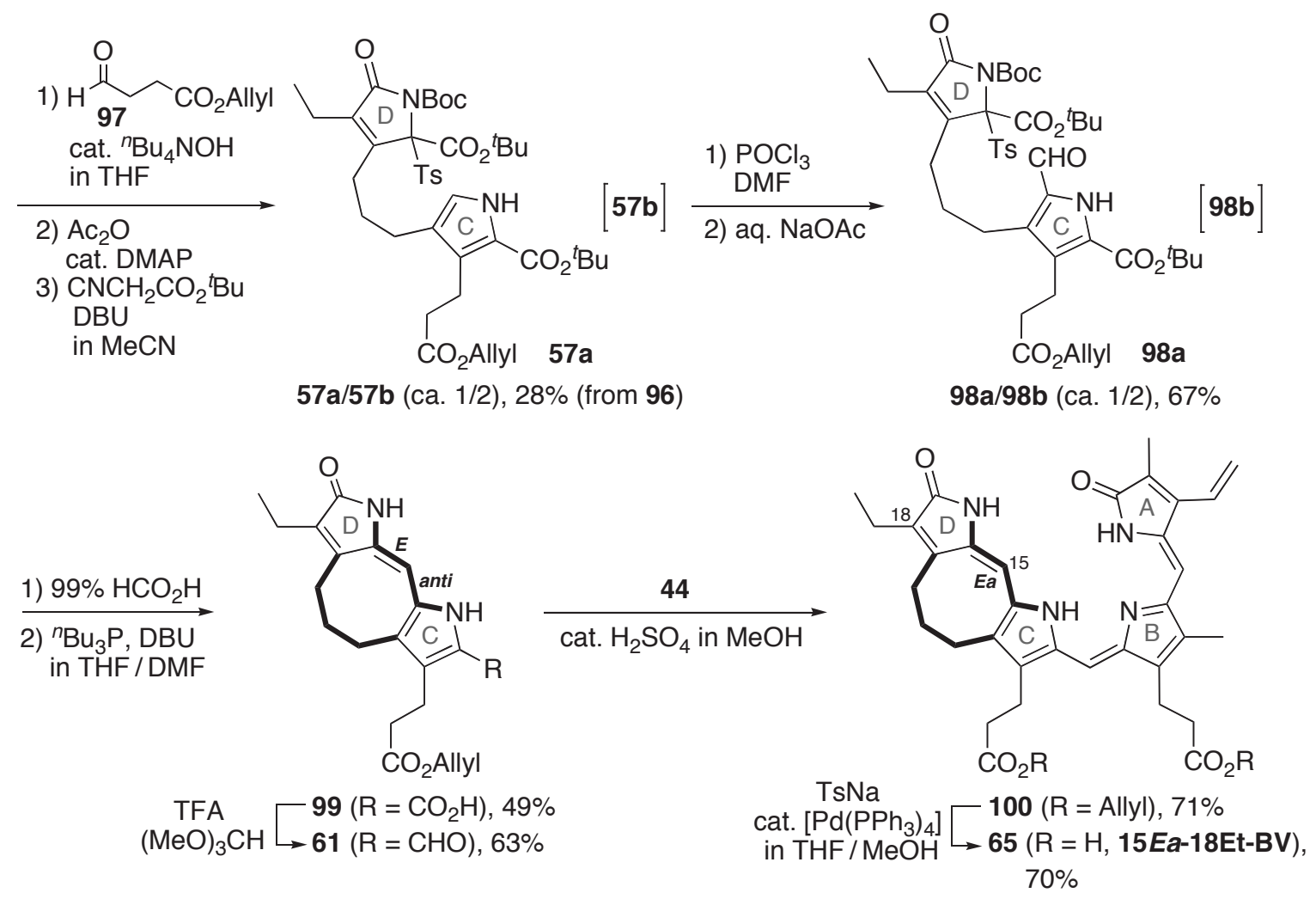

Scheme 17. Synthesis of 15Ea-18Et-BV (65). 


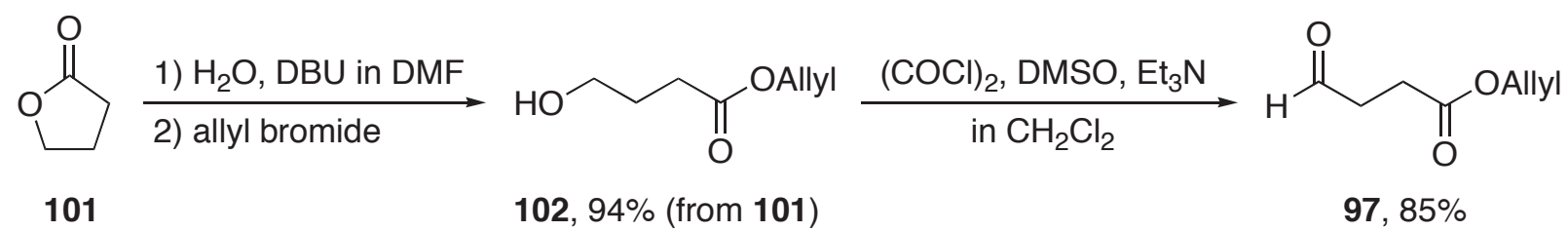

Scheme 18. A convenient method for the preparation of allyl 4-oxobutanoate (97).

Now, we could synthesize four different types of locked BV derivatives, simply termed 15Zs (62), 15Za (63), 15Es (64), and $15 E a(65)$ hereafter, in which the $\mathrm{C} 15=\mathrm{C} 16$ double bond is locked in either the $Z$ or $E$ configuration and the $\mathrm{C} 14-\mathrm{C} 15$ single bond in either the syn or anti conformation by cyclizing with an additional carbon chain as described above.

\section{IN VITRO AND IN VIVO ASSEMBLY OF THE SYNTHESIZED LOCKED BILIN CHROMOPHORES WITH APOPHYTOCHROMES}

To understand how the structure of chromophore is linked with the conformation of the protein, the synthesized locked BV derivatives 62-65 were assembled in vitro with Agrobacterium phytochrome
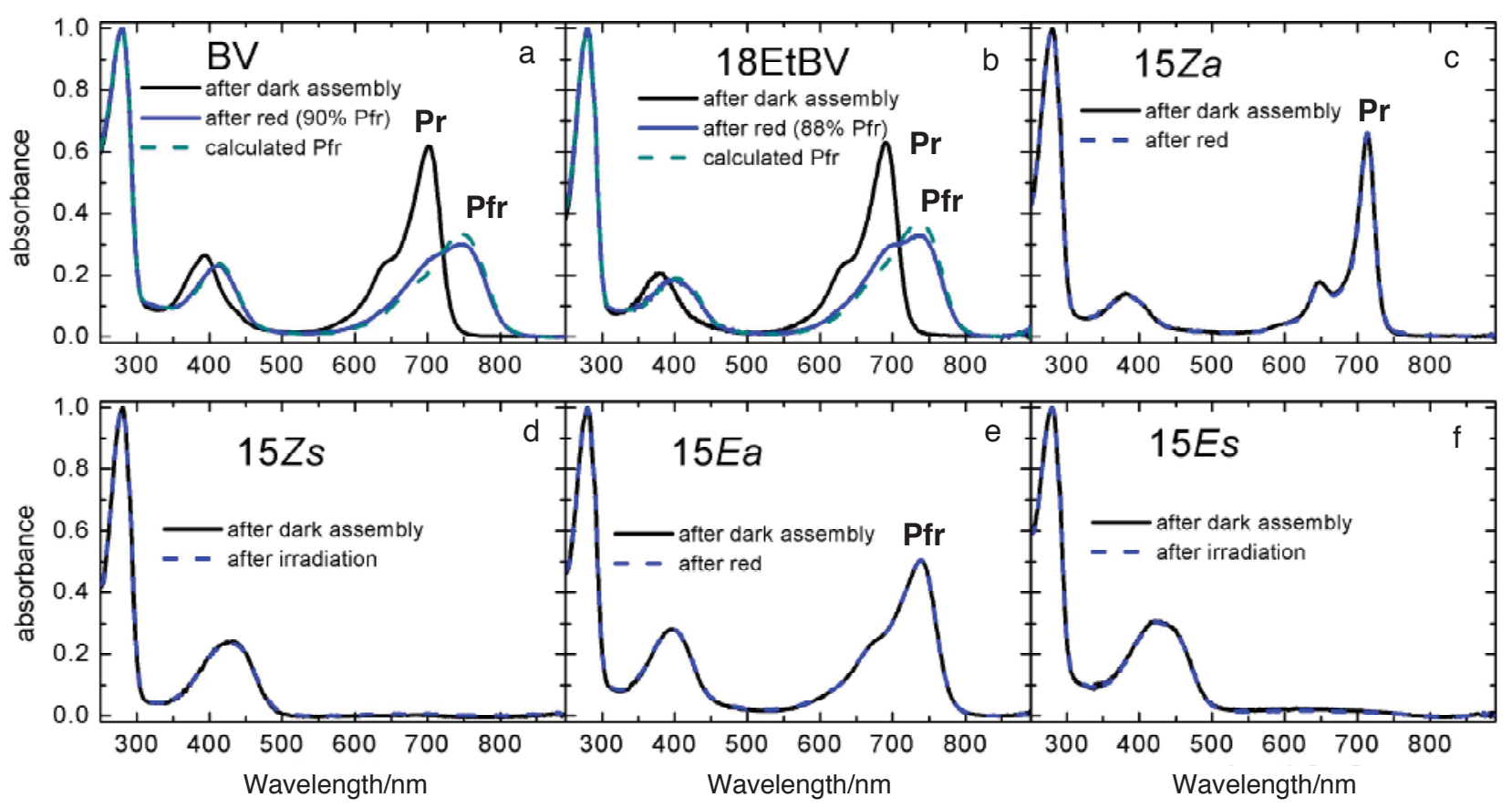

Figure 9. Effect of irradiation on Agp1 adducts (a-f). ${ }^{90}$ The BV, 18EtBV, 15Za, 15Ea adducts were irradiated with red light and the $15 Z s$ and $15 E s$ adducts with white light. The spectrum before and after irradiation is given in each panel. Only the BV and $18 \mathrm{EtBV}$ adducts underwent photoconversion $(\mathrm{a}, \mathrm{b})$; adducts with locked chromophores were stable in the light $(\mathrm{c}-\mathrm{f})$. In the case of the BV and 18EtBV adducts, the Pfr levels after saturating red irradiation were estimated to be 90 and $88 \%$, respectively, and their spectra of pure Pfr were calculated and presented in the panels $(a, b)$. 
Agp1 by German biologists as collaborative work. Biliverdin (BV), the natural chromophore of Agp1, and 18EtBV (Figure 5) were used as controls. Both BV and 18EtBV chromophores completely formed a covalent bond between 1 and $5 \mathrm{~min}$ and produced adducts that show typical red/far-red reversible photoconversion (Figure 9a, b). ${ }^{90}$

All locked BV derivatives also bound covalently to the protein, which was confirmed by using SDS-denaturation/dissociation, followed by separation of protein and the free bilin on desalting columns, and the binding was completed between 1 and 5 min except $15 E a$ that required about 140 min, producing adducts with characteristic spectral properties. The $15 \mathrm{Za}$ adduct is spectrally similar to the Pr form (Figure 9c), and the 15Ea adduct is similar to the Pfr form (Figure 9e) of the BV adduct. Thus, the chromophore of Agp1 adopts a $\mathrm{C} 15=\mathrm{C} 16 \mathrm{Z}$ configuration and a $\mathrm{C} 14-\mathrm{C} 15$ anti conformation in the $\operatorname{Pr}$ form and a $\mathrm{C} 15=\mathrm{C} 16 \mathrm{E}$ configuration and a $\mathrm{C} 14-\mathrm{C} 15$ anti conformation in the Pfr form. Both the $15 \mathrm{Zs}$ and the $15 E s$ adducts absorbed only in the blue region of the visible spectra (Figure 9d, f). ${ }^{90}$

The results with the 15Zs and 15Es chromophores show that the Agp1 protein is rather tolerant for bilins that have the "wrong" conformation. Both locked syn bilins might adopt a helical conformation within the Agp1 chromophores pocket as compared with the stretched conformation of other bilins. Another possibility could be that the conjugation system of tetrapyrrole chromophore is broken by a nucleophilic attack of an amino acid side chain to the $\mathrm{C} 10$ position. However, the addition reaction must be reversible, because the red absorption band appeared again upon SDS treatment of the holoprotein, as found during our tests for covalent binding. We observed a related phenomenon using doubly locked BV derivatives. ${ }^{88}$ The covalent bond with $15 \mathrm{Ea}$ formed rather slowly as compared with the other chromophores. It could be that after the rapid incorporation of $15 \mathrm{Ea}$ into the Agp1 chromophore pocket, the distance between the Cys-20 thiol group and the A-ring vinyl side chain of $15 E a$ is rather large and that the likelihood for covalent bond formation is thereby decreased. In this model, thermal conformational motions of the protein and/or the chromophore would be required for covalent bond formation. For the chromophore, a syn/anti rotation around the C5-C6 single bond is the most likely option. Once the E-isomer is present, the protein adopts its conformation in a proper manner.

It has been shown that the first step in the Pr to Pfr photoconversion of plant phytochromes is a $Z$ to $E$ isomerization around the $\mathrm{C} 15=\mathrm{C} 16$ double bond. ${ }^{23}$ Because of the spectral similarities, this mechanism was most likely universal for all phytochromes, although direct experimental evidence was lacking. If Agp1 follows the same mechanism, all adducts with locked chromophores should remain stable in the light. Indeed, we did not observe any spectral changes upon irradiation with either red or white light (Figure 9c-f) under conditions that induced saturating conversions of the BV and 18EtBV adducts.

The Pr/Pfr photocycle is associated with conformational change of the protein that have been measured by using size exclusion chromatography (SEC), CD spectroscopy, or limited proteolysis. ${ }^{91-93}$ Most 
bacterial phytochromes are histidine kinases, in which kinase activity is modulated by light-induced conformational changes of the protein. Kinase activity is generally stronger in the Pr and weaker in the Pfr form, although other phosphorylation patterns have also been found. ${ }^{8,11,76,94}$

Mobility of proteins subjected to SEC was dependent on the shape and quaternary structure of the molecules. All chromophore adducts with Agp1-M15 (the N-terminal 504 amino acids of Agp1) apoprotein were analyzed by using SEC, and also histidine kinase activity to probe for protein conformation. ${ }^{90}$ In either case, the $15 \mathrm{Za}$ adduct behaved like the Pr, and the $15 \mathrm{Ea}$ adduct behaved like the Pfr form of Agp1. Replacing the natural chromophore with a locked $15 E a$ derivative can thus bring phytochrome holoprotein in the Pfr form in the dark. In this way, physiological action of Pfr could be studied in vivo and separated from Pr/Pfr cycling and other light effects by using locked PCB derivatives as will be described later.

Agp1 and Agp2 have antagonistic properties: in the dark, Agp1 converts slowly from Pfr to Pr, whereas Agp2 converts slowly from Pr to Pfr. To see whether and how locked chromophores are incorporated into Agp2, the set of the above mentioned chromophores was also tested with purified recombinant Agp2. ${ }^{95}$ Interesting differences between Agp1 and Agp2 and between different chromophores were found for the assembly rates. The slowest assembly with Agp1 was found for the $15 E a$ chromophore. In the case of Agp2, the $15 E a$ assembly rate is faster than that of $15 \mathrm{Za}$. The assembly rates for $15 E a / 15 Z a$ for both phytochromes are in line with the finding that Agp1 adopts a Pr form and Agp2 adopts a Pfr form in the dark. $^{95}$

For analysis of stereochemistry of the C5-C6 single bond, new locked chromophores $5 Z s$ and $5 Z a$, in which $\mathrm{C} 4=\mathrm{C} 5$ double bond was fixed in a $Z$ configuration and the $\mathrm{C} 5-\mathrm{C} 6$ single bond was fixed in either a syn or anti conformation (Figure 10), were synthesized in a similar manner described above for the chromophores locked at the C15 position. They were also used for assembly experiments with Agp1 and Agp2 and provided deeper insight into the similarities and differences between Agp1 and Agp2, giving further clues for the understanding of chromophore stereochemistry in the ground state and during photoconversion. ${ }^{95}$ 


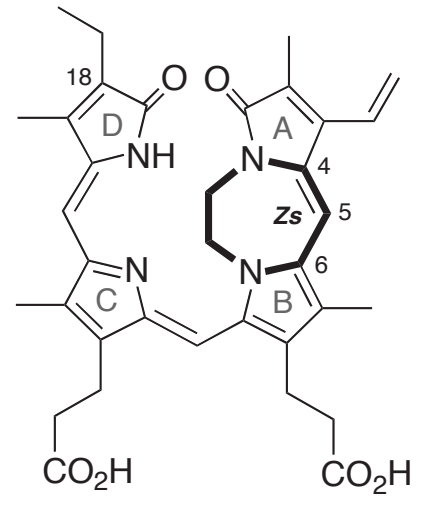

$5 Z s(=5 Z s-18 \mathrm{Et}-\mathrm{BV})$

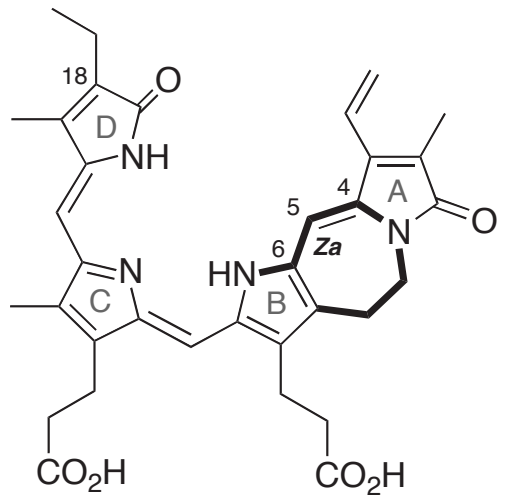

$5 Z a(=5 Z a-18 E t-B V)$

Figure 10. BV derivatives locked at the $\mathrm{C} 5$ position.

Results of the assembly experiments with the $5 Z s$ and $5 Z a$ chromophores are summarized as follows: ${ }^{95}$ (1) Both chromophores form covalent bonds with either Agp1 or Agp2. (2) The spectra and the absorption maxima of the $5 Z s$ adducts are similar to those of the Pr form of the 18EtBV control. (3) The absorption spectra of the $5 Z a$ adducts are also similar to Pr, but their maxima are shifted to shorter wavelengths. (4) Photoconversion shifted the absorption maxima of the 5Zs adducts to shorter wavelengths, whereas the $5 \mathrm{Za}$ adducts were shifted to longer wavelengths. Thus, the $\mathrm{C} 5-\mathrm{C} 6$ single bond of the Pfr chromophore is in an anti conformation, supporting the previous suggestion that during photoconversion of phytochromes, a rotation around the C5-C6 single bond connecting the A- and B-rings occurs, ${ }^{28}$ though direction of the rotation was opposite, and the $5 Z a$ photoproducts are spectrally not exactly identical with Pfr. All of the data that were obtained with these chromophores lead to the conclusion that a flexibility around the A- and B-rings connecting methine bridge is essential for proper photoconversion from Pr to Pfr and for Pr to Pfr dark conversion of Agp2, although the role of C15=C16 $Z$ to $E$ isomerization as the initial step is beyond doubt from our results.

The spectral analogy between Pr and the 5Zs adducts was in line with the data from the crystal structure of phytochrome reported. ${ }^{78,96}$ In their structures, the configuration and conformation of the chromophores were found to be $5 Z s / 10 Z s / 15 Z a$, i.e., the single bond between the A- and B-rings, is in the syn conformation.

Furthermore, in 5Zs-Agp1 adduct the photoconversion proceeded via the Lumi-R intermediate to Meta- $\mathrm{R}_{\mathrm{A}}$, but the following millisecond-transition to Meta- $\mathrm{R}_{\mathrm{C}}$ was blocked. Consistently, no transient proton release was detected. The photoconversion of 5Zs-Agp1 is apparently arrested in a Meta- $\mathrm{R}_{\mathrm{A}}$-like intermediate, since the subsequent syn to anti rotation around the C5-C6 single bond is prevented by the 
lock. The Meta- $\mathrm{R}_{\mathrm{A}}$-like photoproduct was characterized by its distinctive $\mathrm{CD}$ spectrum suggesting a reorientation of the ring $\mathrm{D} .{ }^{97}$

Based on the above results, we proposed that the stereochemistry of the Agp1 and Agp2 chromophores is $5 Z s / 10 Z s / 15 Z a$ in the $\operatorname{Pr}$ and $5 Z a / 10 Z s / 15 E a$ or $5 E a / 10 Z s / 15 E a$ in the Pfr form. ${ }^{95}$ A schematic presentation of the proposed stereochemistry of Pr and Pfr is given in Figure 11, ${ }^{95}$ taking into account the data from the crystal structure of the chromophore-binding domain of the bacteriophytochromes. ${ }^{78,96,98}$

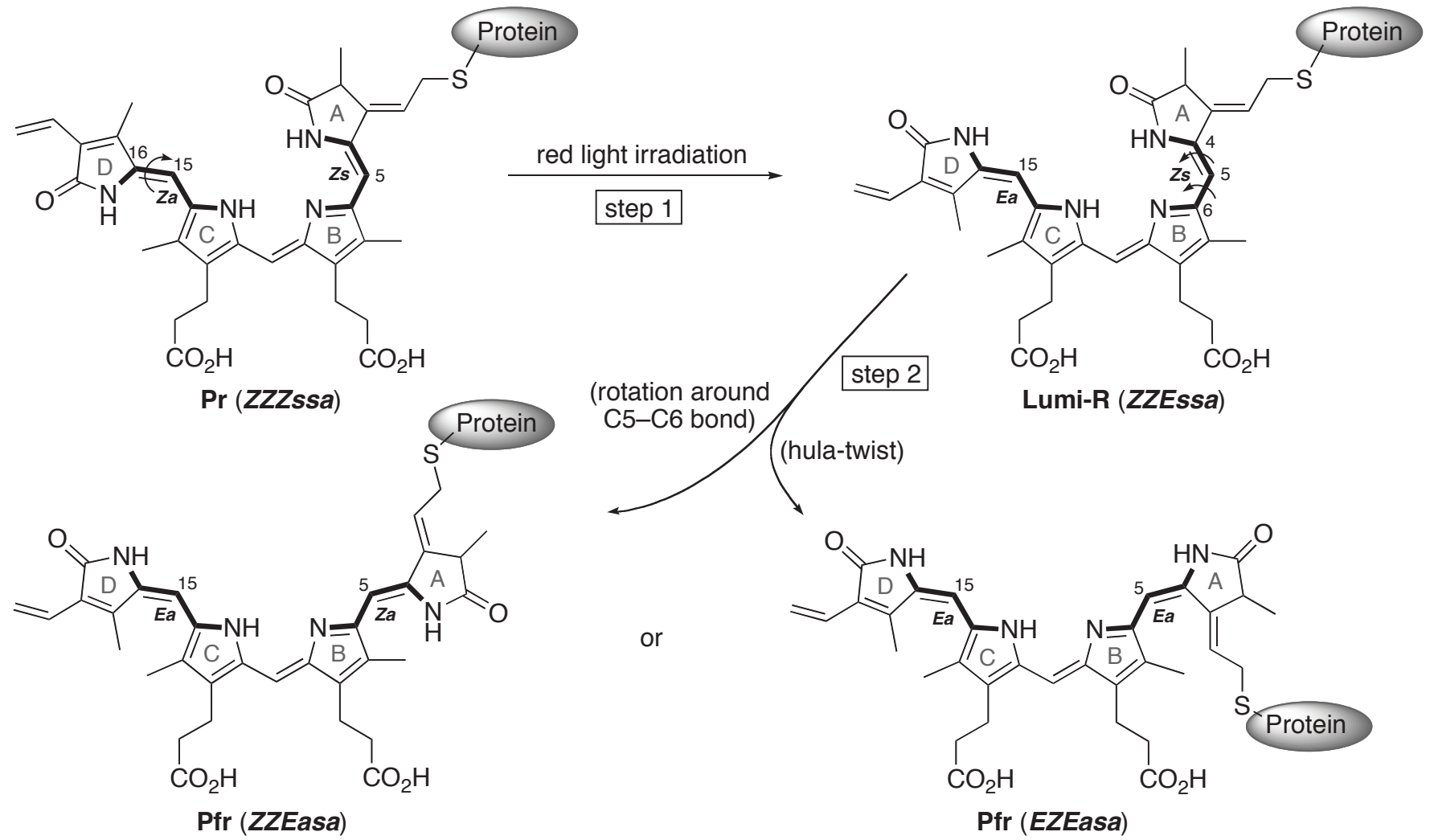

Figure 11. Proposed stereochemistry of the Agp1 and Agp2 chromophores during conversion of $\operatorname{Pr}$ to $\mathrm{Pfr} .^{95}$ Step 1 is the rapid $\mathrm{C} 15=\mathrm{C} 16 Z$ to $E$ isomerization, leading to the intermediary lumi-R photoproducts. During the conversion from lumi-R to Pfr (step 2), the stereochemistry of the C5 methine bridge is changed. This can involve either a rotation around the C5-C6 single bond (from syn to anti) and/or a $Z$ to $E$ isomerization of the $\mathrm{C} 4=\mathrm{C} 5$ double bond (a hula-twist mechanism). ${ }^{99}$ Two different possibilities are drawn here.

As mentioned above, assembly of the sterically locked chromophores with apophytochrome could afford photostable Pr- and Pfr-like adducts. This fact prompted us to use the adducts of the locked chromophores with Agp1 for crystallization analysis carried out with German collaborators. ${ }^{100}$

Because of the difficulty to grow X-ray suitable crystals of full-length Agp1, our studies were focused on the truncated N-terminal photosensory chromophore module of Agp1, termed Agp1-M15 for the first 
crystallization experiments and preliminary X-ray analysis. ${ }^{100}$ This $54 \mathrm{kDa}$-fragment consists of the N-terminal 504 amino acids of Agp1 and contains the PAS-like domain (PLD), GAF domain and PHY domain but lacks the C-terminal histidine-kinase module.

The protein Agp1-M15 was either assembled with the natural chromophore biliverdin (BV) or a sterically locked synthetic BV derivative $15 Z a$. Both adducts could be crystallized, but the resolution was largely improved by the use of $15 Z a$.

In general, for crystal inspection under the microscope, light was passed through an interference filter with a maximum transmission at $520 \mathrm{~nm}$. To obtain information about the color of the crystals and to test for stability against light, some crystals were inspected under white light. The crystals of BV-Agp1-M15, which were obtained by assembling natural BV chromophore with Agp1-M15, cracked during irradiation with white light at $293 \mathrm{~K}$, and the green color gradually disappeared over time, showing that the holoprotein inside the crystal still undergoes light-induced conformational changes.

On the other hand, a locked chromophore 15Za adduct of Agp1-M15 did not undergo light-induced conformational changes, because the first step of the photocycle, the $Z / E$ isomerization around the $\mathrm{C} 15=\mathrm{C} 16$ double bond, is not possible. The sharper bands of the Vis spectrum of 15Za-Agp1-M15 than that of BV-Agp1-M15 suggested that $15 Z a$ is less flexible within the chromophore pocket as compared with BV. Thus, by using 15Za-Agp1-M15 for crystallization, we could both improve the quality of the crystals and allow for continuous work under laboratory light. The rigidity of the chromophore pocket might be one reason for the improved resolution that was obtained for these crystals. Interestingly, crystals of both the BV adduct and the $15 \mathrm{Za}$ adduct were obtained under similar conditions, belong to the same space group, and have similar unit cell parameters, indicating similar crystal packing and comparable overall conformations of the different adducts. However, we cannot yet determine the detailed structure of the chromophore in the holophytochrome. ${ }^{101}$

Most information on the configuration and conformation of the chromophore is now available for the $\operatorname{Pr}$ and Pfr forms from the crystal structures of other phytochromes, ${ }^{78,96,98,102-105}$ however, detailed knowledge of configurational and conformational changes of the chromophore that are reflected by spectral changes is still lacking.

For studies with plant phytochromes, the BV-based chromophores are inappropriate. Therefore, we recently established the syntheses of locked phycocyanobilin (PCB) derivatives, termed 15Z-anti PCB (15Za-PCB) and 15E-anti PCB (15Ea-PCB) according to a retrosynthetic analysis shown in Figure 12, which is similar to the method described for locked BV derivatives. ${ }^{89}$ Such chromophores might be covalently integrated into the chromophore pocket of plant phytochromes, because of their ethylidene side chain, and thus fulfill the required properties. 


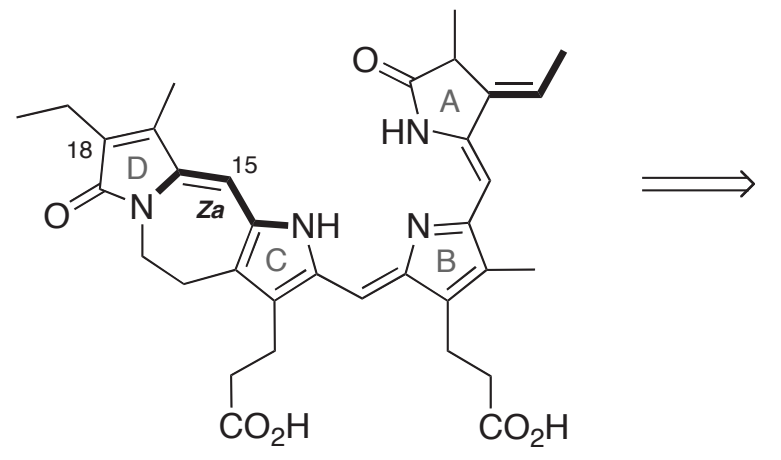

$103(15 Z a-P C B)$

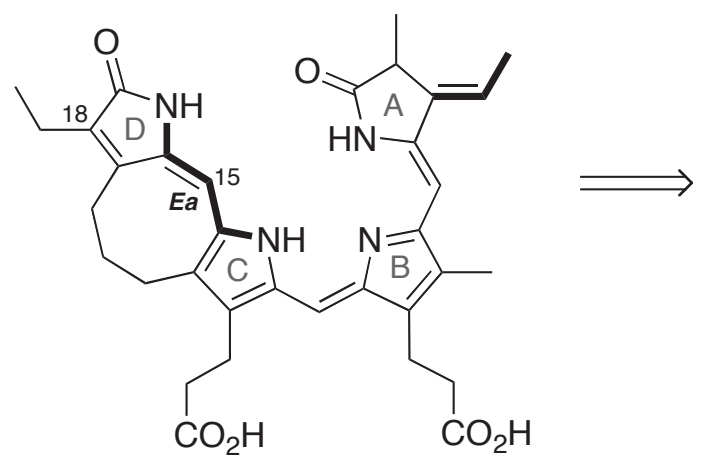

104 (15Ea-PCB)

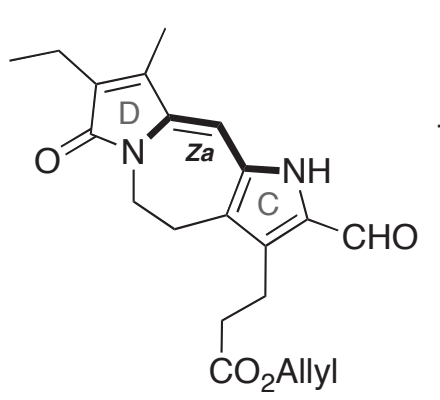

59

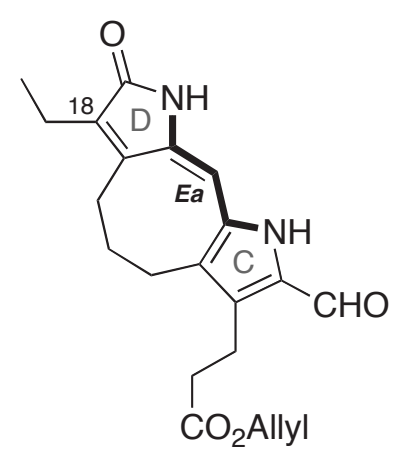

61

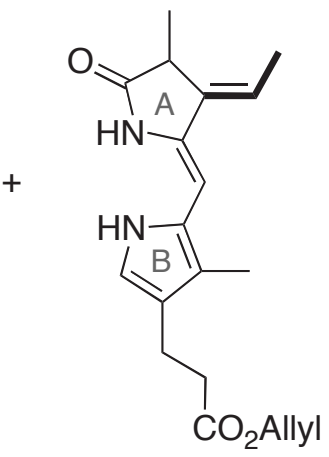

52

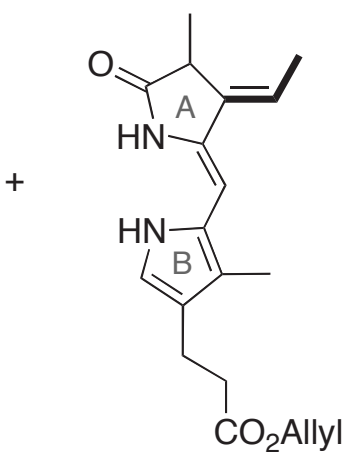

52

Figure 12. Synthesis of the sterically locked PCB derivatives, 15Za-PCB (103) and 15Ea-PCB (104).

We assembled the locked 15Za-PCB (103) and 15Ea-PCB (104) in vitro and in vivo with phytochrome in Ceratodon purpureus and Arabidopsis thaliana. ${ }^{106}$

Recombinant bacterial and plant phytochromes incorporated either chromophore in a noncovalent or covalent manner. All adducts were photoinactive as in the case of $15 \mathrm{Za}-18 \mathrm{Et}-\mathrm{BV}$ and $15 \mathrm{Ea}-18 \mathrm{Et}-\mathrm{BV}$. The absorption spectra of the $15 Z a-\mathrm{PCB}$ and $15 E a-\mathrm{PCB}$ adducts were comparable with those of the $\mathrm{Pr}$ and Pfr form, respectively. Feeding of $15 \mathrm{Ea}-\mathrm{PCB}$, but not $15 \mathrm{Za}-\mathrm{PCB}$, to protonemal filaments of the moss Ceratodon purpureus resulted in increased chlorophyll accumulation, modulation of gravitropism, and induction of side branches in darkness. The effect of locked chromophores on phytochrome responses, such as induction of seed germination, inhibition of hypocotyl elongation, induction of cotyledon opening, randomization of gravitropism, and gene regulation, were investigated in wild-type Arabidopsis thaliana and the phytochrome-chromophore-deficient long hypocotyl mutant hyl. All phytochrome responses were induced in darkness by $15 E a-P C B$, not only in the mutant but also in the wild type. These studies show that the $15 E a$ stereochemistry of the chromophore results in the formation of active Pfr-like phytochrome in the cell. ${ }^{106}$

Based on these results, the locked PCB chromophores might be used to investigate phytochrome 
responses in many other organisms without the need to isolate mutants. A further goal could be to use the locked PCB chromophores in agriculture and horticulture to induce phytochrome responses in crop plants.

\section{DEVELOPMENT OF GENERAL SYNTHETIC METHOD OF DOUBLY LOCKED BILIN CHROMOPHORES}

To confirm the structure of a chromophore in Pr form of bacteriophytochromes, we synthesized a doubly locked $5 Z s 15 Z a-B V(\mathbf{1 0 5})$ according to the retrosynthetic analysis shown in Figure $13 .{ }^{88}$

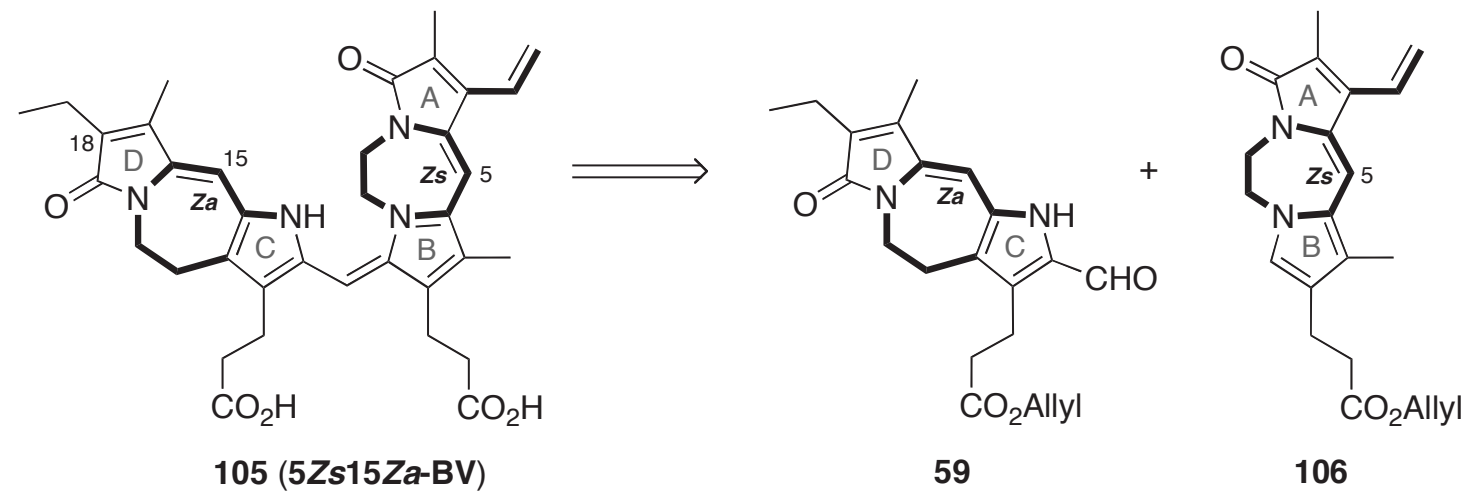

Figure 13. A retrosynthetic analysis of $5 Z s 15 Z a-B V(\mathbf{1 0 5})$.

The Z-anti AB-ring component 106 was obtained from 39 by cyclizing with $\mathrm{BrCH}_{2} \mathrm{CH}_{2} \mathrm{Br}$ in the presence of ${ }^{n} \mathrm{Bu}_{4} \mathrm{NBr}$, followed by introducing a vinyl group via oxidation and elimination of the tolylthio group in $\mathbf{1 0 7}$, and subsequent decarboxylation of the resulting compound 108 with TFA (Scheme 19). ${ }^{88}$

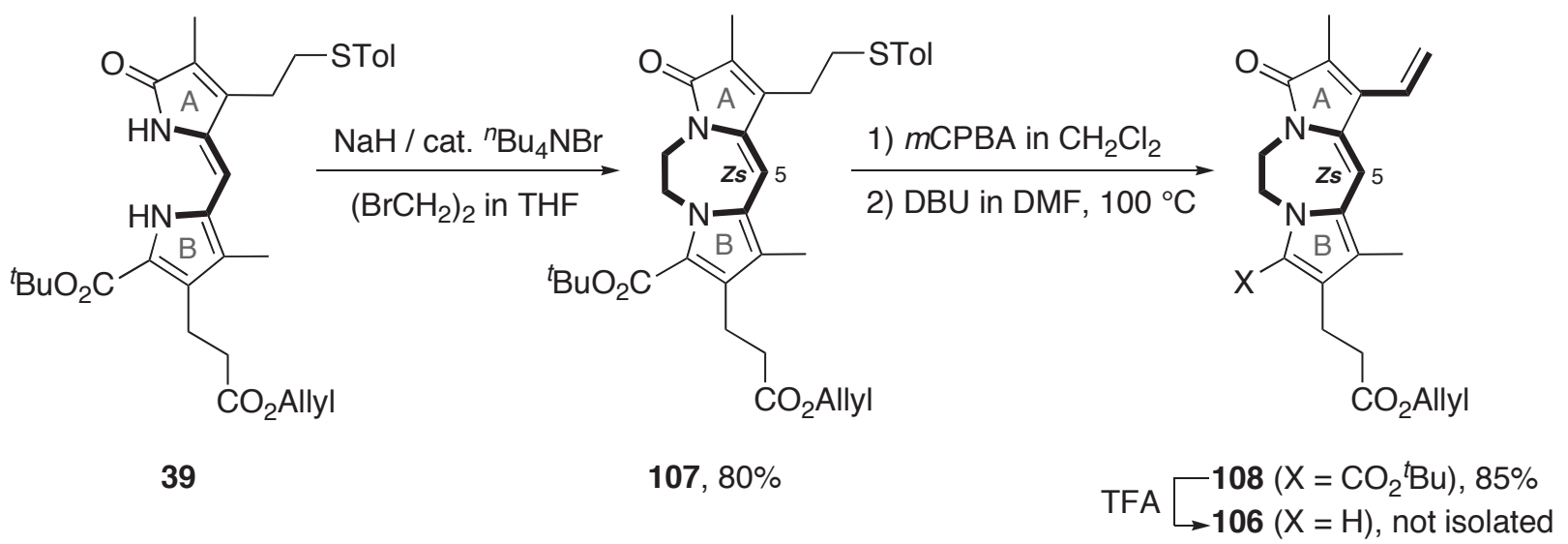

Scheme 19. Synthesis of a Z-syn AB-ring component 106. 
Coupling between the CD-ring component 59 and the AB-ring component 106 was accomplished under acidic conditions to afford $5 Z s 15 Z a$-BV diallyl ester derivative 109 in $90 \%$ yield. Final deprotection of the allyl esters was achieved by a $\operatorname{Pd}(0)$-catalyzed reaction in the presence of sodium $p$-toluenesulfinate

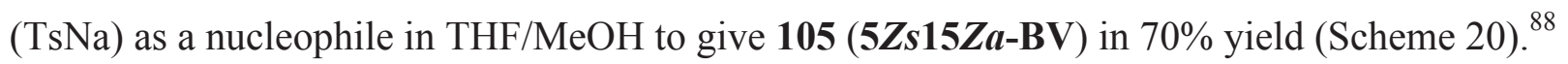

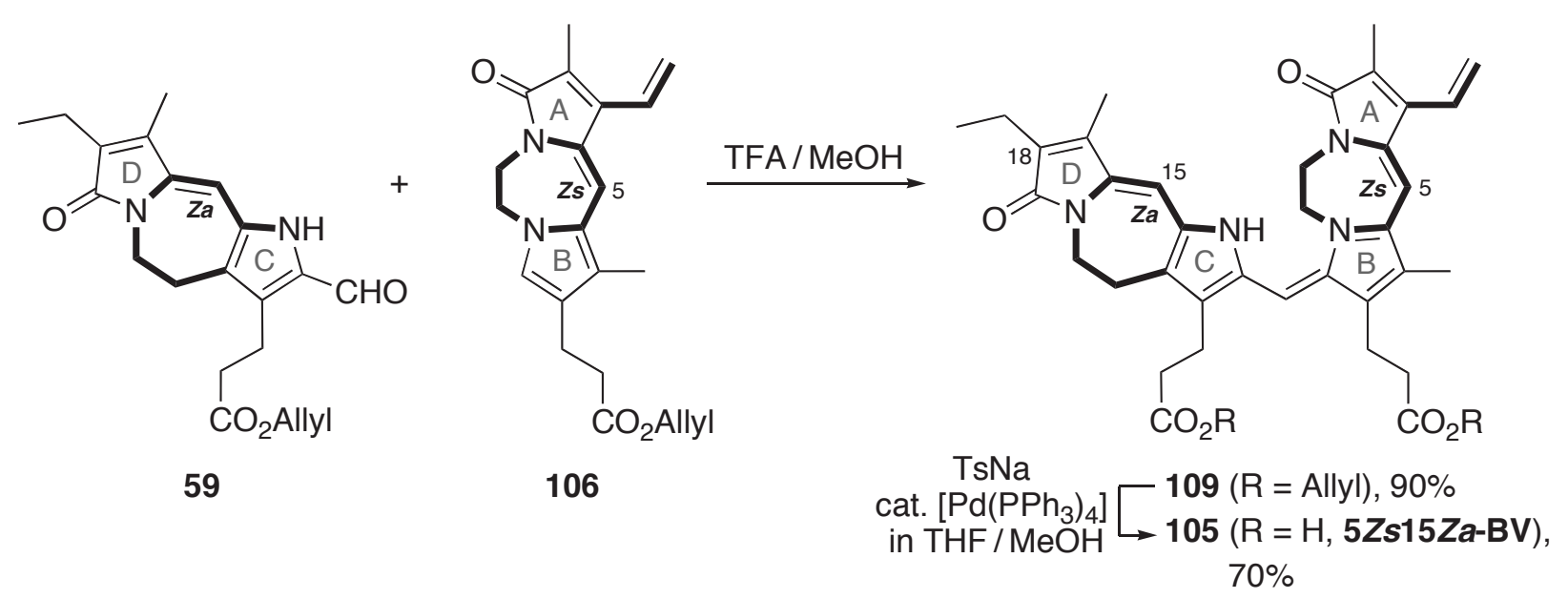

Scheme 20. Synthesis of a doubly locked 5Zs15Za-BV (105)

To our knowledge, there is as yet no evidence of a $\mathrm{C} 4=\mathrm{C} 5 E$ configuration of the Pfr chromophore. However, such configuration might have been overlooked for chemical or technical reasons. Therefore, four different types of doubly locked biliverdin (BV) derivatives, 5Zs15Ea-BV (110), 5Za15Ea-BV (111), $5 E s 15 E a-B V(112)$, and $5 E a 15 E a-B V(113)$, were synthesized for the first time in free acid forms to elucidate the stereochemistry of phytochrome chromophore in Pfr form according to the retrosynthetic analyses shown in Figure 14. ${ }^{107}$ The CD-ring component 114 was readily available by decarboxylation of an E-anti CD-ring component 99 with TFA (Scheme 21).

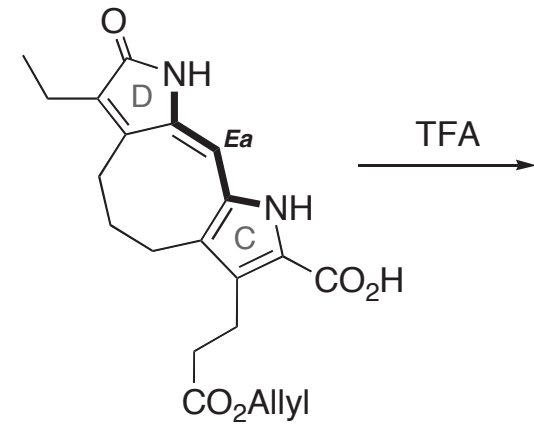

99

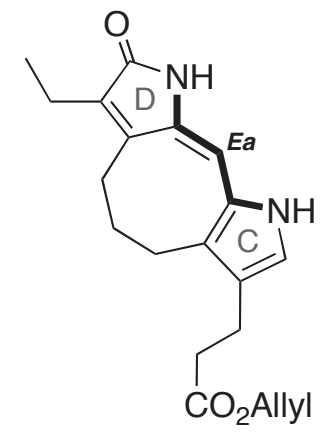

$114,70 \%$

Scheme 21. Preparation of an E-anti CD-ring component 114. 


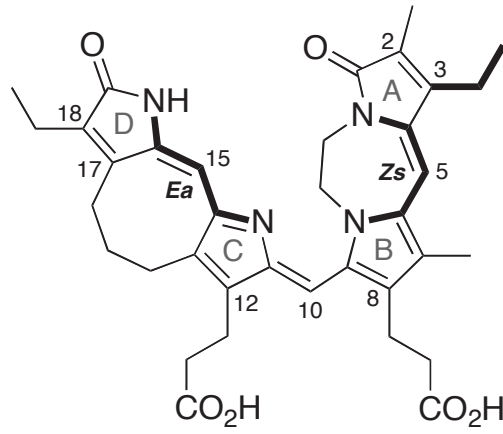

110 (5Zs15Ea-BV)

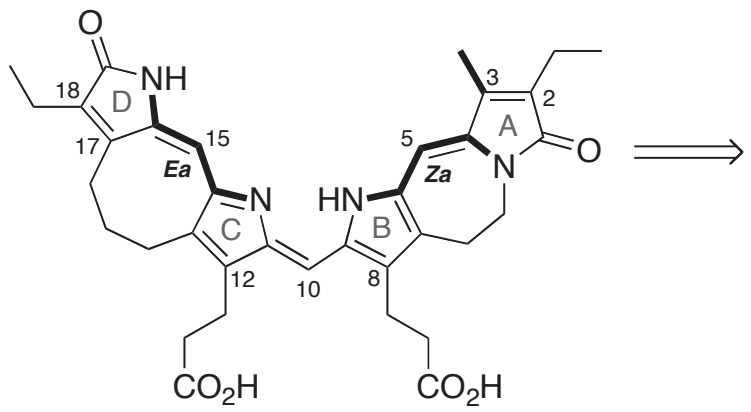

111 (5Za15Ea-BV)

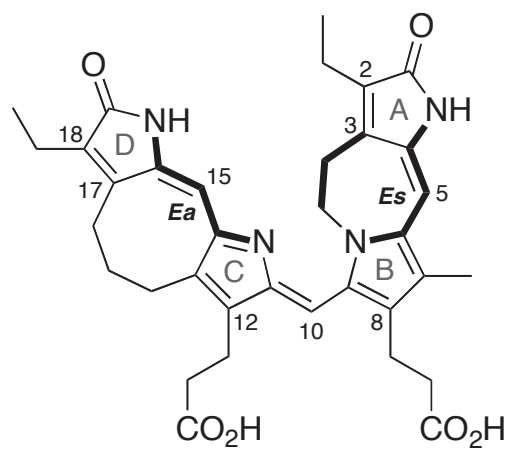

112 (5Es15Ea-BV)

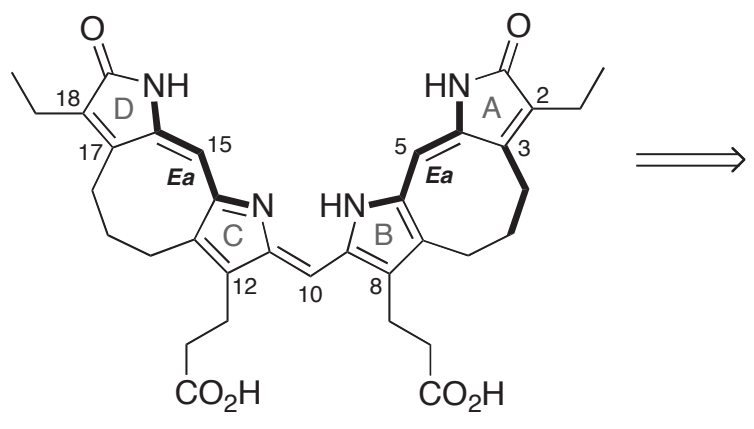

113 (5Ea15Ea-BV)

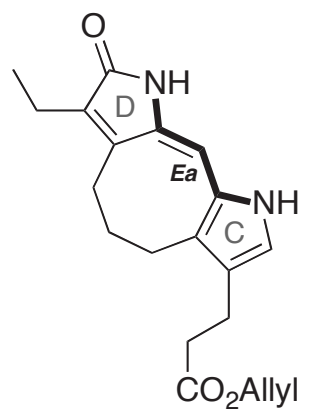

114

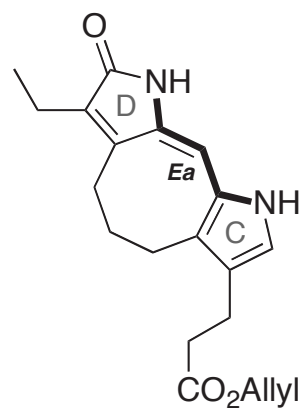

114

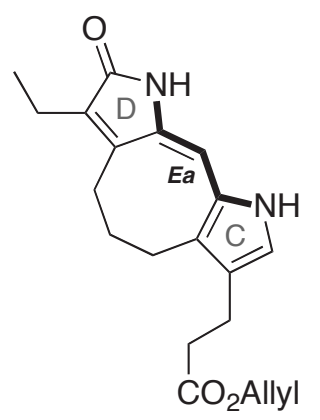

114

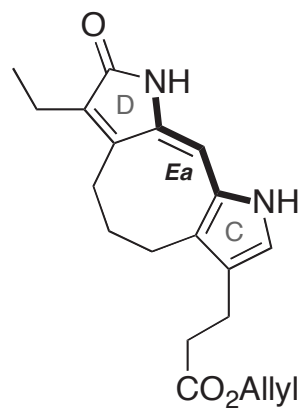

114

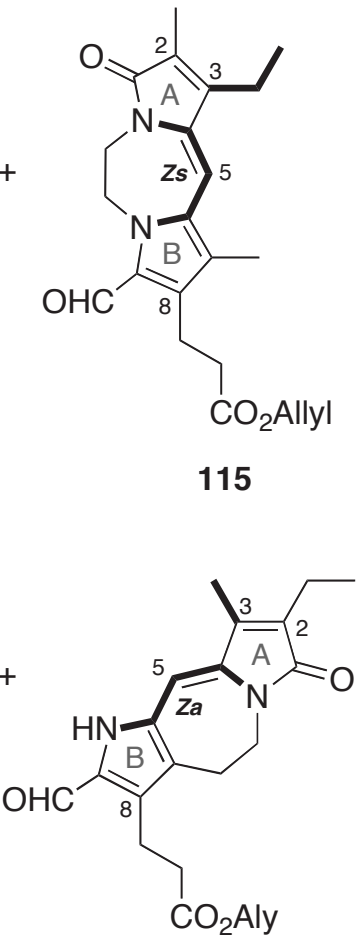

59

(CD-ring in Figure 8)

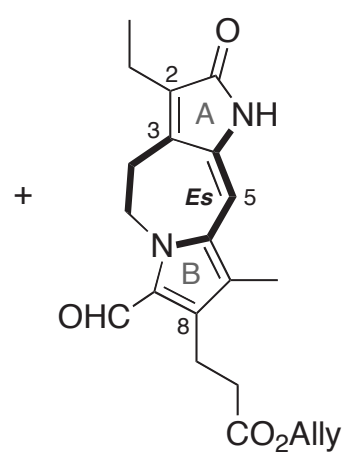

60

(CD-ring in Figure 8)

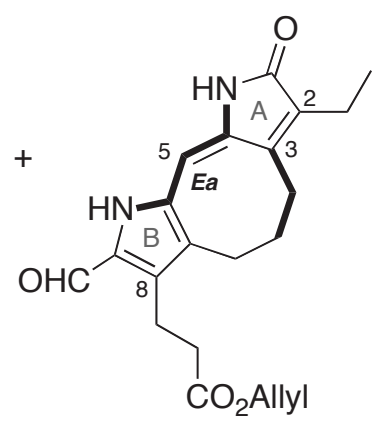

61

(CD-ring in Figure 8)

Figure 14. Retrosynthetic analyses of the doubly locked BV derivatives (110-113) as candidates for the chromophore corresponding to Pfr form, without a vinyl group at the $\mathrm{C} 3$ position on the A-ring. 
The synthesized doubly locked bilin chromophores, 105 corresponding to $\operatorname{Pr}$ form and 110-113 as candidates for the chromophore corresponding to Pfr form, were assembled with Agp1 and Agp2 apophytochromes. The absorption spectra of doubly locked $5 Z s 15 Z a$-BV (105) adducts resembled the spectrum of natural BV-binding phytochrome in Pr form as expected. ${ }^{88,95,108}$

Furthermore, we found that the absorption spectra of $5 Z a 15 E a-\mathrm{BV}$ (111) or 5Ea15Ea-BV (113) adducts resembled the spectrum of Pfr form of natural Agp1 and Agp2, though the synthesized doubly locked chromophores 111 and $\mathbf{1 1 3}$ have no vinyl group on the A-ring necessary to form a covalent bond with the apoproteins. $^{95,109}$

To investigate the structure and function of the BV chromophores in Pfr form, we further synthesized a new doubly locked BV derivative, $5 Z a 15 E a(7)-B V(116)$, which carries a vinyl group at the A-ring necessary to form a covalent bond with a Cys residue of apophytochrome. The CD-ring component was locked in E-anti stereochemistry by a 7-membered ring, different from the previous one locked by an 8 -membered ring, according to the retrosynthetic analysis shown in Figure $15 .^{110}$

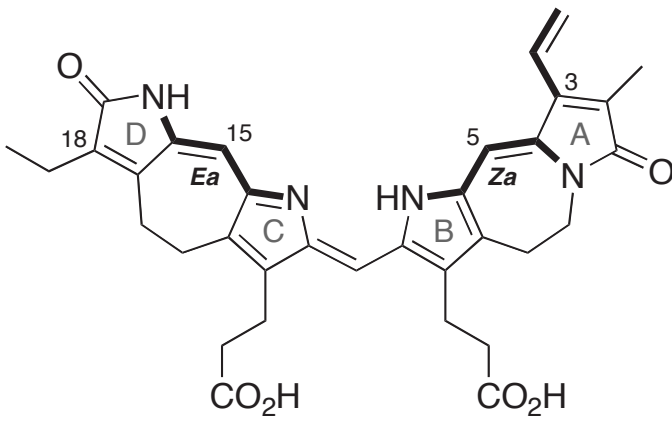

$116[5 \mathrm{Za} 15 \mathrm{Ea}(7)-\mathrm{BV}]$

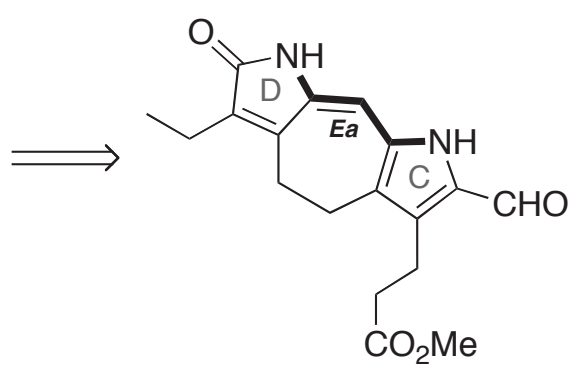

117

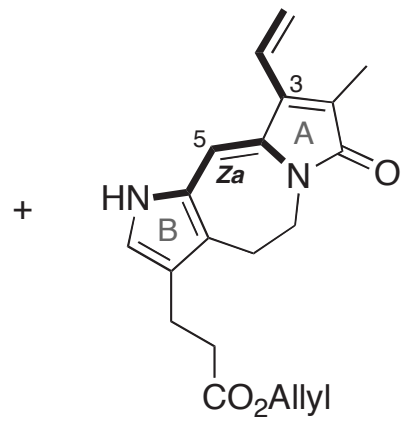

118

Figure 15. A retrosynthetic analysis of the doubly locked $5 Z a 15 E a(7)-B V(116)$ with an E-anti CD-ring component locked by a 7-membered ring and with a vinyl group at the $\mathrm{C} 3$ position on the A-ring.

The locked Z-anti AB-ring component 118 was synthesized in a similar manner described above for the locked Z-anti CD-ring component 59 according to Scheme $22 .{ }^{49,60}$ Tosylpyrrolinone 38 as the A-ring precursor and formylpyrrole $\mathbf{5 4}$ as the B-ring precursor here were coupled by our original Wittig-type reaction to give dipyrrole $\mathbf{1 1 9}$ as a mixture of $E$ - and $Z$-isomers. The $E$-isomer was converted to the $Z$-isomer by treating with a catalytic amount of iodine in $\mathrm{CH}_{2} \mathrm{Cl}_{2} \cdot(Z)-\mathbf{1 1 9}$ thus obtained was treated with DBU in THF at $50{ }^{\circ} \mathrm{C}$ to afford the desired cyclized product 120 in $80 \%$ yield. After oxidation of the tolythio group on the A-ring, a vinyl group was introduced by refluxing the resulting sulfoxide in DMF under basic conditions to afford the locked Z-anti AB-ring component 121. By treating with TFA, the decarboxylated AB-ring component 118 was obtained in situ (Scheme 22). ${ }^{110}$ 

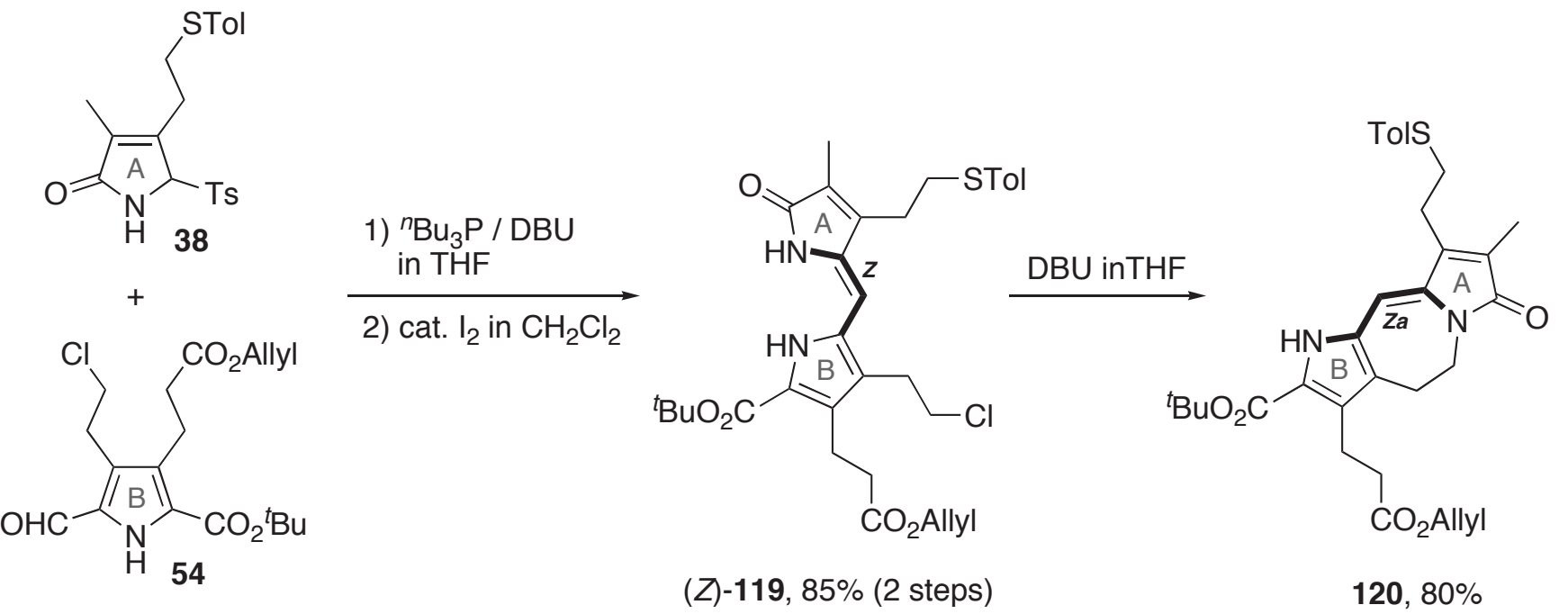

$\underset{\text { 1) } m \mathrm{CPBA} \text { in } \mathrm{CH}_{2} \mathrm{Cl}_{2}}{\stackrel{\text { pyridine in } \mathrm{DMF}}{\longrightarrow}}$

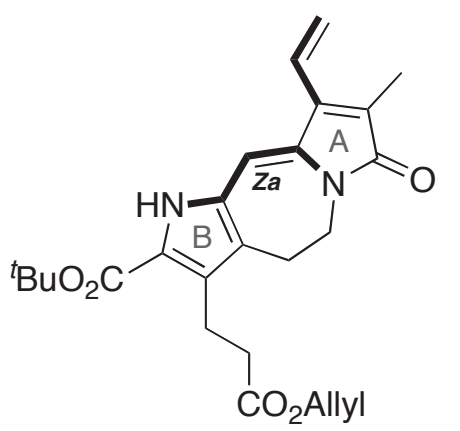

121, $80 \%$ (2 steps)

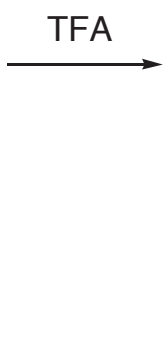

118, not isolated

Scheme 22. Synthesis of a Z-anti AB-ring component 118.

On the other hand, though we have synthesized an E-anti CD-ring component locked with an 8 -membered ring, ${ }^{87,89}$ this method still remained some unsatisfactory points due to the linear synthetic manner. Therefore, a new convergent method was established for the synthesis of the E-anti CD-ring component 117 locked with a 7-membered ring. ${ }^{110}$

We recently developed the synthesis of 4-formylpyrrole $\mathbf{1 2 2}$ as the C-ring precursor via selective oxidation of pyrrole 32a $\left(\mathrm{R}^{\prime}=\mathrm{CH}_{2} \mathrm{CH}_{2} \mathrm{CO}_{2} \mathrm{Allyl}\right)$ with DDQ in the presence of $\mathrm{MeOH}$ (Scheme 23). ${ }^{11}$

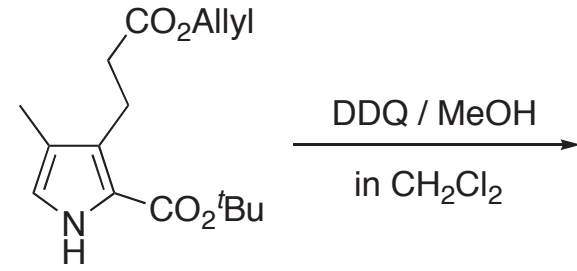

$32 a$<smiles>CCCOC(=O)c1[nH]cc(C=O)c1CCC(=O)OCC</smiles>

$122,70 \%$

Scheme 23. Regioselective oxidation of a methyl group in pyrrole 32a. 
4-(Acetoxymethyl)pyrrolinone $\mathbf{1 2 7}$ as the D-ring precursor was prepared starting from ethyl glyoxalate (123), which was coupled with 1-nitropropane via the Henry reaction. After acetylation of the resulting nitro-alcohol, the obtained mixture of nitro-acetate and nitro-olefin was converted to the corresponding pyrrole-3-carboxylate 124 by applying the Barton's method ${ }^{55}$ with tosylmethyl isocyanide. ${ }^{54}$ Pyrrole-3carboxylate 124 was then reduced to the corresponding alcohol with lithium aluminum hydride (LAH), followed by acetylation with acetic anhydride in the presence of a catalytic amount of DMAP to afford 125. After $\alpha$-bromination of $\mathbf{1 2 5}$, it was tried to convert to the corresponding tosylpyrrolinone by our previous redox reaction using TFA, DMSO and Zn metal. However, it was failed. Therefore, we directly oxidized 125 with $m$ CPBA to 5-tosylpyrrolinone 126 in 70\% yield, followed by reductive elimination of the tosyl group with $\mathrm{NaBH}_{4}$ to afford the 5-unsubstituted pyrrolinone $\mathbf{1 2 7}$ as the D-ring precursor (Scheme 24). ${ }^{110}$

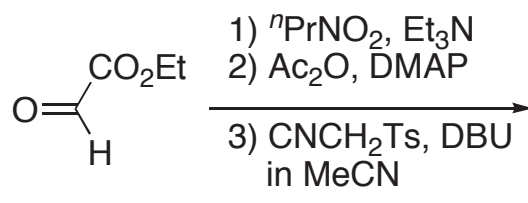

123

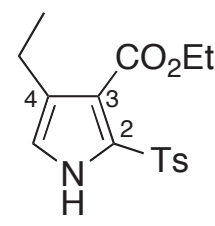

$124,50 \%$ (3 steps)

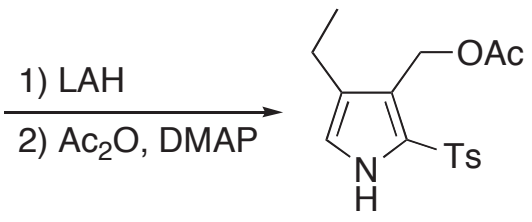

$125,76 \%$ (2 steps)

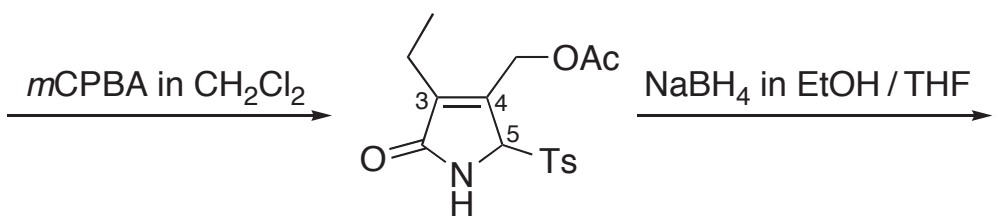

126, $70 \%$

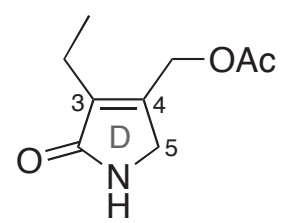

$127,70 \%$

Scheme 24. Synthesis of 5-unsubstituted pyrrolinone 127.

The D-ring precursor 127 bearing an acetoxyl group at the allylic position was activated by a catalytic amount of $\operatorname{Pd}(0)^{112}$ to react with tributylphosphine generating the phosphonium intermediate, which was further converted to the corresponding ylide by treatment with butyl lithium at low temperature to couple with 4-formylpyrrole 122 via the Wittig olefination reaction to afford the product $\mathbf{1 2 8}$ as a mixture of $E$ and $Z$-isomers. At this stage, an allyl ester group in the C-ring precursor 122 was changed to a methyl ester group under basic conditions in $\mathrm{MeOH}$. The $E / Z$ mixture of olefin 128 was reduced by hydrogenation to afford $\mathbf{1 2 9}$ in $90 \%$ yield. After treating with TFA and methyl orthoformate, the resulting $\alpha, \alpha^{\prime}$-diformylated product 131 was cyclized with DBU to afford an E-anti CD-ring component 117 locked with a 7 -membered ring in 50\% yield (Scheme 25). 


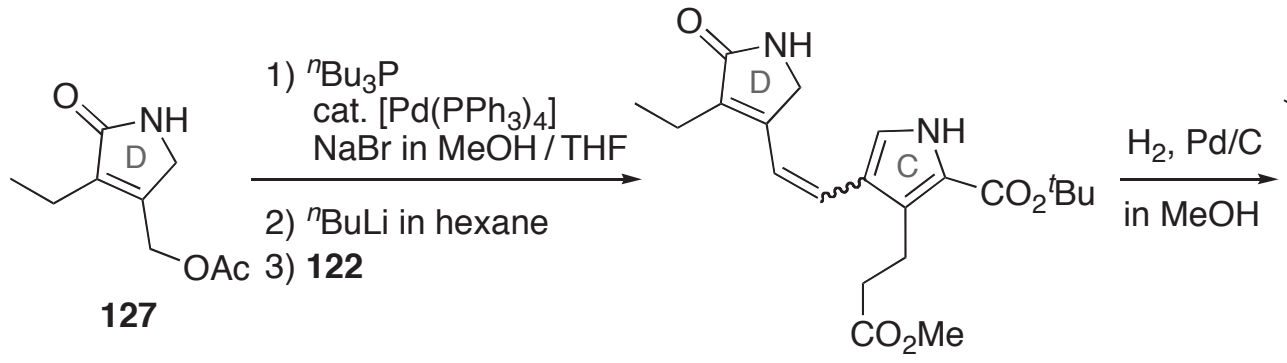

$128,50 \%(E / Z=1 / 2 ; 3$ steps $)$

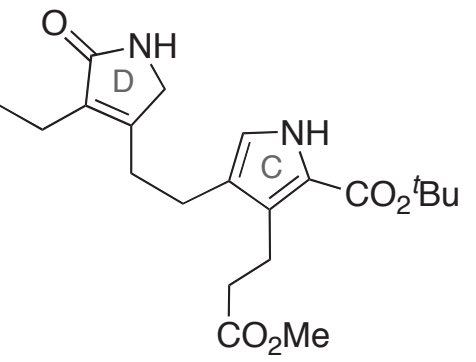

$129,90 \%$

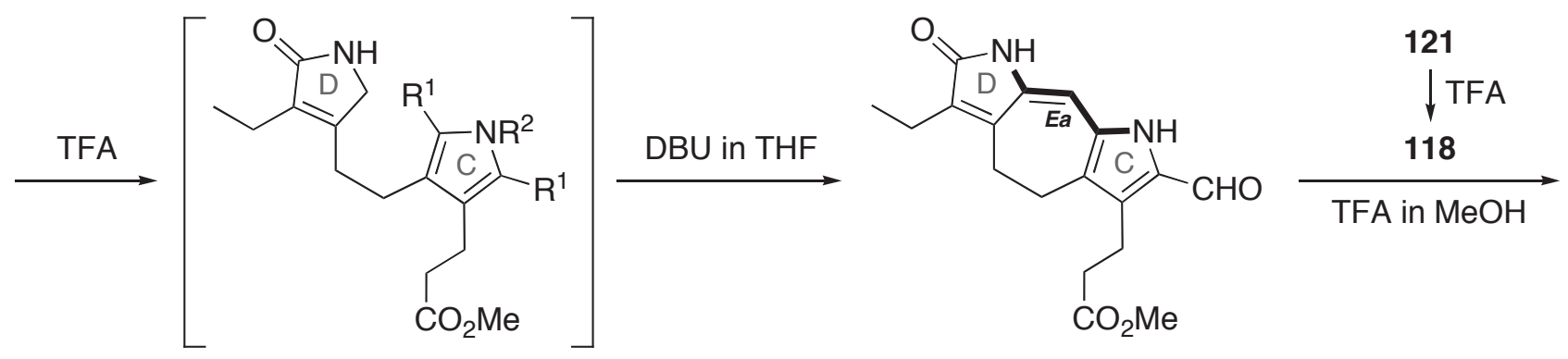

$117,50 \%$ (from 129)

TFA
$(\mathrm{MeO})_{3} \mathrm{CH}$ $\begin{aligned} & 130\left(\mathrm{R}^{1}=\mathrm{R}^{2}=\mathrm{H}\right) \\ & \rightarrow 131\left(\mathrm{R}^{1}=\mathrm{CHO}, \mathrm{R}^{2}=\mathrm{H} \text { or } \mathrm{CHO}\right)\end{aligned}$

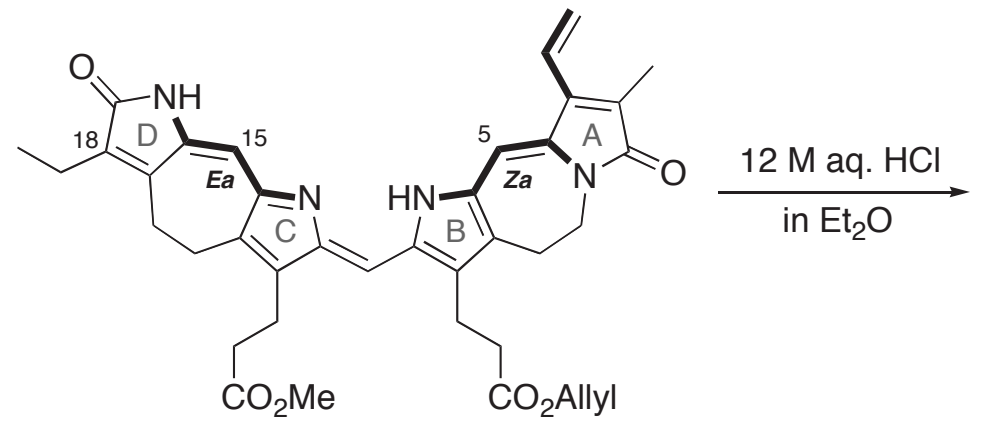

$132,80 \%$

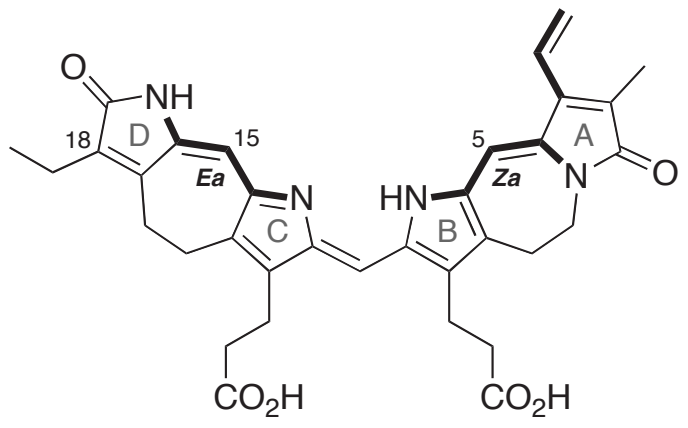

116 [5Za15Ea(7)-BV], 80\%

Scheme 25. Synthesis of the doubly locked $5 Z a 15 E a(7)-B V(116)$ corresponding to Pfr form.

The locked Z-anti AB-ring 118 and E-anti CD-ring 117 were coupled with TFA in MeOH to construct the doubly locked 5Za15Ea(7)-BV allyl methyl ester 132, which was further hydrolyzed under acidic conditions to give the doubly locked $5 Z a 15 E a(7)-B V(116)$ in free acid form (Scheme 25).

As described above, we succeeded to prepare the doubly locked $5 Z a 15 E a(7)-B V(116)$ corresponding to the chromophore in Pfr form of Agp1 by a new convergent synthetic method. Development of a convenient method for the synthesis of the locked E-anti CD-ring component such as $\mathbf{1 1 7}$ is essential for the synthesis of the chromophore corresponding to the Pfr form. We are now studying on assembly of the doubly locked bilin chromophores synthesized above with phytochrome apoproteins in vitro and in vivo. 


\section{CONCLUSION}

We could establish an efficient and flexible general method for the preparation of the linear tetrapyrrole (bilin) chromophores to investigate the structure and function of phytochrome chromophores by developing several new reactions, i.e., (1) rearrangement of the tosyl group of 2-tosylpyrroles to the 5-position under mild acidic conditions, (2) efficient transformation of 2-bromo-5-tosylpyrroles to the corresponding 5-tosylpyrrolinones by a redox reaction, (3) the Wittig-type coupling reaction between 5-tosylpyrrolinone and 2-formylpyrrole for the preparation of the AB- and CD-ring components, (4) reductive transformation of the AB-ring component of $\mathrm{BV}$ to the $\mathrm{AB}$-ring component of $\mathrm{P} \Phi \mathrm{B}$ and $\mathrm{PCB}$, and (5) protection and palladium-catalyzed deprotection of propanoic acid side chains at the C8 and C12 positions via allyl esters.

This general method made it possible to synthesize not only РФВ and PCВ as natural chromophores used in plants and cyanobacteria, but also BV used in other bacteria. Furthermore, various unnatural types of bilin chromophores bearing modified side chain(s) and sterically locked BV and PCB derivatives could be prepared in free acid forms by applying the present synthetic method.

Assembly experiments of the synthesized bilin chromophores with recombinant Arabidopsis phytochrome PhyB apoprotein (PHYB) in vitro provided insights into the structure and function of phytochromes, i.e., the different role of each substituents on four pyrrole rings of the bilin chromophore in plant phytochrome: (1) the A-ring acts mainly as the anchor for ligation to an apophytochrome, (2) hydrophobic environment and open space accommodate the A- and D-rings of the bilin chromophore at the binding site, (3) stereochemistry at the C2 position of the chromophore of plant phytochrome is not crucial, (4) the side chains of the B- and C-rings are crucial to position the chromophore properly in the chromophore pocket and for photoreversible spectral changes, (5) a propanoic acid side chain at the C8 position of the bilin chromophore is more crucial for photoreversible conversion of phytochrome than that at the $\mathrm{C} 12$ position, (6) the side-chain structure of the D-ring is required for the photoreversible spectral change of adducts, and the environment around the C18 position of the chromophore within the chromophore-biding pocket is more flexible than that around the $\mathrm{C} 17$ position.

Based on these results, we could outline the order of events during in vitro assembly of PHYB with its chromophore as shown in Figure 7.

In vitro assembly with Agrobacterium phytochrome Agp1 and/or Agp2 revealed the following: (1) BV chromophore in Agp1 covalently binds to the apoprotein via the A-ring vinyl side chain, (2) the stereochemistry of the Agp1 and Agp2 chromophores is most likely to be $5 Z s / 10 Z s / 15 Z a$ in the Pr and $5 Z a / 10 Z s / 15 E a$ or $5 E a / 10 Z s / 15 E a$ in the Pfr form, respectively, (3) photoinsensitive single crystals of $\operatorname{Pr}$ with a $15 Z a$-locked chromophore were obtained for X-ray crystallographic analysis of the N-terminal photosensory module of phytochrome Agp1. 
On the other hand, by feeding synthetic bilins exogenously to Arabidopsis hyl and hy2 mutant seedlings in vivo, a double bond in the vinyl side chain at the C18 position of the D-ring of РФВ was found to be crucial for the photosensory function of PhyA, whereas PhyB function was restored with both РФВ and PCB with a saturated D-ring substituent.

Furthermore, in vivo assembly experiments with the locked PCB derivatives provided very important new insights into the structure and function of phytochromes, i.e., phytochrome responses are induced in darkness by $15 E a \mathrm{PCB}$, not only in the mutant but also in the wild type: (1) feeding of $15 E a \mathrm{PCB}$, but not $15 \mathrm{ZaPCB}$, to protonemal filaments of the moss Ceratodon purpureus resulted in increased chlorophyll accumulation, modulation of gravitropism, and induction of side branches in darkness, (2) the effect of locked chromophores on phytochrome responses, such as induction of seed germination, inhibition of hypocotyl elongation, induction of cotyledon opening, randomization of gravitropism, and gene regulation, were also observed in wild-type Arabidopsis thaliana and the phytochrome-chromophore-deficient long hypocotyl mutant hyl.

These studies show that the $15 E a$ stereochemistry of the chromophore results in the formation of active Pfr-like phytochrome in the cell.

We have recently succeeded to synthesize the doubly locked BV and PCB chromophores. Such locked PCB chromophores would allow us to investigate phytochrome responses in vivo in detail. A further goal could be to use the locked PCB chromophores in agriculture and horticulture to induce phytochrome responses in crop plants.

From the results described above, it is obvious that an approach based on the synthetic organic chemistry toward the elucidation of the structure and function of phytochromes and also toward the related studies $^{113-115}$ is very effective and necessary. Especially, sterically locked chromophores will further open the new avenues for investigation of phytochrome chromophores both in vitro and in vivo in future.

\section{ACKNOWLEDGEMENTS}

Author is very grateful to Professors H. Kinoshita, Y. Ukaji, M. Furuya, T. Lamparter, and N. Krauß, Drs. H. Hanzawa and Y. Murata, and other colleagues and students whose names are in the references, for the synthetic, biological, and crystallographic experiments and discussions.

The present work was financially supported in part by Grant-in-Aid for Scientific Research (Nos. 06640685, 07640715, 11440187) and Grant-in-Aid for Scientific Research on Priority Areas (13029041, 14044033) from The Ministry of Education, Culture, Sports, Science and Technology (MEXT), Japan, and Grand-in-Aid for Scientific Research (Nos. 15350021, 19350082) from Japan Society for the Promotion of Science (JSPS). 


\section{REFERENCES}

1. W. Rüdiger and F. Thümmler, 'Photomorphogenesis in Plants,' 2nd ed., ed. by R. E. Kendrick and G. H. M. Kronenberg, Kluwer Academic Publishers, Dordrecht, The Netherlands, 1994.

2. M. M. Neff, C. Frankhauser, and J. Chory, Genes Dev., 2000, 14, 257.

3. C. Fankhauser, J. Biol. Chem., 2001, 276, 11453.

4. M. Wada, K. Shimazaki, and M. Iino, 'Light Sensing in Plants,' Springer-Verlag, Tokyo, 2005.

5. $\quad$ N. C. Rockwell, Y.-S. Su, and J. C. Lagarias, Annu. Rev. Plant Biol., 2006, 57, 837.

6. H. A. Borthwick, S. B. Hendricks, M. W. Parker, E. H. Toole, and V. K. Toole, Proc. Natl. Acad. Sci. U.S.A., 1952, 38, 662.

7. W. L. Butler, K. H. Norris, H. W. Siegelman, and S. B. Hendricks, Proc. Natl. Acad. Sci. U.S.A., 1959, 45, 1703.

8. K. C. Yeh, S. H. Wu, J. T. Murphy, and J. C. Lagarias, Science, 1997, 277, 1505.

9. T. Lamparter, F. Mittmann, W. Gärtner, T. Börner, E. Hartmann, and J. Hughes, Proc. Natl. Acad. Sci. U.S.A., 1997, 94, 11792.

10. S. J. Davis, A. V. Vener, and R. D. Vierstra, Science, 1999, 286, 2517.

11. S. H. Bhoo, S. J. Davis, J. Walker, B. Karniol, and R. D. Vierstra, Nature, 2001, 414, 776.

12. H. Falk, 'The Chemistry of Linear Oligopyrrole and Bile Pigment,' Springer Verlag, New York, 1989.

13. W. Rüdiger and F. Thümmler, Angew. Chem., Int. Ed. Engl., 1991, 30, 1216.

14. M. Furuya and P.-S. Song, 'Assembly and Properties of Holophytochrome in Photomorphogenesis in Plants,' 2nd ed., ed. by R. E. Kendrick and G. H. M. Kronenberg, Kluwer Academic Publishers, Dordrecht/Boston/London, 1994, Cap. 4.3, pp. 105-140.

15. M. Stanek and K. Grubmayr, Chem. Eur. J., 1998, 4, 1653; 1998, 4, 1660.

16. T. Lamparter, FEBS Lett., 2004, 573, 1.

17. N. C. Rockwell and J. C. Lagarias, Plant Cell, 2006, 18, 4.

18. J. C. Lagarias and H. Rapoport, J. Am. Chem. Soc., 1980, 102, 4821.

19. N. Frankenberg, K. Mukougawa, T. Kohchi, and J. C. Lagarias, Plant Cell, 2001, 13, 965.

20. T. Hübschmann, T. Börner, E. Hartmann, and T. Lamparter, Eur. J. Biochem., 2001, 268, 2055.

21. A. Blumenstein, K. Vienken, R. Tasler, J. Purschwitz, D. Veith, N. Frankenberg-Dinkel, and R. Fischer, Curr. Biol., 2005, 15, 1833.

22. I. Oberpichler, I. Molina, O. Neubauer, and T. Lamparter, FEBS Lett., 2006, 580, 437.

23. W. Rüdiger, F. Thümmler, E. Cmiel, and S. Schneider, Proc. Natl. Acad. Sci. U.S.A., 1983, 80, 6244.

24. A. T. Ulijasz, G. Cornilescu, C. C. Cornilescu, J.-R. Zhang, M. Rivera, J. L. Markley, and R. D. 
Vierstra, Nature, 2010, 463, 250.

25. Y. Mizutani, S. Tokutomi, and T. Kitagawa, Biochemistry, 1994, 33, 153.

26. C. Kneip, P. Hildebrandt, W. Schlamann, S. E. Braslavsky, F. Mark, and K. Schaffner, Biochemistry, 1999, 38, 15185.

27. F. Andel, III, J. T. Murphy, J. A. Haas, M. T. McDowell, I. van der Hoef, J. Lugtenburg, J. C. Lagarias, and R. A. Mathies, Biochemistry, 2000, 39, 2667.

28. M. A. Mroginski, D. H. Murgida, D. von Stetten, C. Kneip, F. Mark, and P. Hildebrandt, J. Am. Chem. Soc., 2004, 126, 16734.

29. J. R. Wagner, J. Zhang, J. S. Brunzelle, R. D. Vierstra, and K. T. Forest, J. Biol. Chem., 2007, 282, 12298.

30. L. Li and J. C. Lagarias, J. Biol. Chem., 1992, 267, 19204.

31. P. Schmidt, U. H. Westphal, K. Worm, S. E. Braslavsky, W. Gärtner, and K. Schaffner, J. Photochem. Photobiol. B, 1996, 34, 73, and references cited therein.

32. J. T. Murphy and J. C. Lagarias, Photochem. Photobiol., 1997, 65, 750.

33. L. Deforce, M. Furuya, and P.-S. Song, Biochemistry, 1993, 32, 14165.

34. S. H. Bhoo, T. Hirano, H.-Y. Jeong, J.-G. Lee, M. Furuya, and P.-S. Song, J. Am. Chem. Soc., 1997, 119, 11717.

35. A. Remberg, P. Schmidt, S. E. Braslavsky, W. Gärtner, and K. Schaffner, Eur. J. Biochem., 1999, 266, 201.

36. A. Gossauer and W. Hirsch, Justus Liebigs Ann. Chem., 1974, 1496.

37. A. Gossauer and R.-P. Hinze, J. Org. Chem., 1978, 43, 283.

38. J.-P. Weller and A. Gossauer, Chem. Ber., 1980, 113, 1603.

39. H. Kinoshita, Y. Hayashi, Y. Murata, and K. Inomata, Chem. Lett., 1993, 1437.

40. H. Kinoshita, H. Ngwe, K. Kohori, and K. Inomata, Chem. Lett., 1993, 1441.

41. K. Kohori, M. Hashimoto, H. Kinoshita, and K. Inomata, Bull. Chem. Soc. Jpn., 1994, 67, 3088.

42. T. Kakiuchi, H. Kato, K. P. Jayasundera, T. Higashi, K. Watabe, D. Sawamoto, H. Kinoshita, and K. Inomata, Chem. Lett., 1998, 1001.

43. K. P. Jayasundera, H. Kinoshita, and K. Inomata, Chem. Lett., 1998, 1227.

44. T. Kakiuchi, H. Kinoshita, and K. Inomata, Synlett, 1999, 901.

45. A. Ohta, D. Sawamoto, K. P. Jayasundera, H. Kinoshita, and K. Inomata, Chem. Lett., 2000, 492.

46. D. Sawamoto, H. Nakamura, H. Kinoshita, S. Fujinami, and K. Inomata, Chem. Lett., 2000, 1398, see also the references cited therein.

47. S. Takeda, K. P. Jayasundera, T. Kakiuchi, H. Kinoshita, and K. Inomata, Chem. Lett., 2001, 590.

48. K. P. Jayasundera, H. Kinoshita, and K. Inomata, Bull. Chem. Soc. Jpn., 2000, 73, 497. 
49. M. A. S. Hammam, H. Nakamura, Y. Hirata, H. Khawn, Y. Murata, H. Kinoshita, and K. Inomata, Bull. Chem. Soc. Jpn., 2006, 79, 1561.

50. K. Inomata, Bull. Chem. Soc. Jpn., 2008, 81, 25, and references cited therein.

51. M. Nasal, Liebigs Ann. Chem., 1983, 1510.

52. M. Nasal, J. Am. Chem. Soc., 1984, 106, 7540.

53. T. Masukawa, H. Kato, T. Kakiuchi, K. P. Jayasundera, H. Kinoshita, and K. Inomata, Chem. Lett., $1998,27,455$.

54. B. E. Hoogenboon, O. H. Oldenziel, and A. M. van Leusen, Org. Synth., 1988, Coll. Vol. VI, 987.

55. D. H. R. Barton, J. Kervogoret, and S. Z. Zard, Tetrahedron, 1990, 46, 7587.

56. K. Kohori, H. Kinoshita, and K. Inomata, Chem. Lett., 1995, 799.

57. A. Hiyoshi, K. Kohori, H. Kato, H. Kinoshita, and K. Inomata, 1997, unpublished data.

58. A. Gossauer and M. Blacha-Puller, Liebigs Ann. Chem., 1981, 1492.

59. A. Gossauer, F. Nydegger, E. Benedikt, and H.-P. Köst, Helv. Chim. Acta, 1989, 72, 518.

60. M. A. S. Hammam, Y. Murata, H. Kinoshita, and K. Inomata, Chem. Lett., 2004, 33, 1258.

61. H. Kunz and C. Unverzagt, Angew. Chem., Int. Ed. Engl., 1984, 23, 436.

62. P. H. Quail, Nature Rev. Mol. Cell Biol., 2002, 3, 85.

63. T. Shinomura, A. Nagatani, H. Hanzawa, M. Kubota, M. Watanabe, and M. Furuya, Proc. Natl. Acad. Sci. U.S.A., 1996, 93, 8129.

64. T. Shinomura, K. Uchida, and M. Furuya, Plant Physiol., 2000, 122, 147.

65. H. Hanzawa, K. Inomata, H. Kinoshita, T. Kakiuchi, K. P. Jayasundera, D. Sawamoto, A. Ohta, K. Uchida, K. Wada, and M. Furuya, Proc. Natl. Acad. Sci. U.S.A., 2001, 98, 3612; a related paper was reported: U. Robben, I. Lindner, W. Gärtner, and K. Schaffner, Angew. Chem. Int. Ed., 2001, 40, 1048.

66. T. D. Elich and J. C. Lagarias, J. Biol. Chem., 1989, 264, 12902.

67. J. A. Wahleithner, L. M. Li, and J. C. Lagarias, Proc. Natl. Acad. Sci. U.S.A., 1991, 88, 10387.

68. L. Deforce, K. Tomizawa, N. Ito, D. Farrens, P.-S. Song, and M. Furuya, Proc. Natl. Acad. Sci. U.S.A., 1991, 88, 10392.

69. R. A. Sharrock and P. H. Quail, Genes Dev., 1989, 3, 1745.

70. T. Clack, S. Mathews, and R. A. Sharrock, Plant Mol. Biol., 1994, 25, 413.

71. S. J. Davis, J. Kurepa, and R. D. Vierstra, Proc. Natl. Acad. Sci. U.S.A., 1999, 96, 6541.

72. T. Muramoto, T. Kohchi, A. Yokota, I. Hwang, and H. M. Goodman, Plant Cell, 1999, 11, 335.

73. T. Kohchi, K. Mukougawa, N. Frankenberg, M. Masuda, A. Yokota, and J. C. Lagarias, Plant Cell, $2001,13,425$.

74. B. M. Parks and P. H. Quail, Plant Cell, 1991, 3, 1177. 
75. H. Hanzawa, T. Shinomura, K. Inomata, T. Kakiuchi, H. Kinoshita, K. Wada, and M. Furuya, Proc. Natl. Acad. Sci. U.S.A., 2002, 99, 4725.

76. T. Lamparter, N. Michael, F. Mittmann, and B. Esteban, Proc. Natl. Acad. Sci. U.S.A., 2002, 99, 11628.

77. T. Lamparter, N. Michael, O. Caspani, T. Miyata, K. Shirai, and K. Inomata, J. Biol. Chem., 2003, 278, 33786 .

78. J. R. Wagner, J. S. Brunzelle, K. T. Forest, and R. D. Vierstra, Nature, 2005, 438, 325.

79. A. R. Holzwarth, E. Venuti, S. E. Braslavsky, and K. Schaffner, Biochim. Biophys. Acta, 1992, 1140, 59.

80. S. Rentsch, G. Hermann, M. Bischoff, D. Strehlow, and M. Rentsch, Photochem. Photobilol., 1997, 66, 585.

81. K. Heyne, J. Herbst, D. Stehlik, B. Esteban, T. Lamparter, J. Hughes, and R. Diller, Biophys. J., 2002, 82, 1004.

82. C. F. Zhang, D. L. Farrens, S. C. Bjorling, P. S. Song, and D. S. Kliger, J. Am. Chem. Soc., 1992, $114,4569$.

83. J. J. van Thor, B. Borucki, W. Crielaard, H. Otto, T. Lamparter, J. Hughes, K. J. Hellingwerf, and M. P. Heyn, Biochemistry, 2001, 40, 11460.

84. B. Borucki, D. von Stetten, S. Seibeck, T. Lamparter, N. Michel, M. A. Mroginski, H. Otto, D. H. Murgida, M. P. Heyn, and P. Hildebrandt, J. Biol. Chem., 2005, 280, 34358.

85. R. Tsumura, M. Kanemaru, and N. Ishi, Japan Kokai Tokkyo Koho, 7505315, 1975 (Chem. Abstr., $1975, \mathbf{8 3}, 27573 q)$.

86. T. Urasaki and W. Funakoshi, Japan Kokai Tokkyo Koho, 76131817, 1976 (Chem. Abstr., 1977, 86, 120786h).

87. H. Kinoshita, M. A. S. Hammam, and K. Inomata, Chem. Lett., 2005, 34, 800.

88. L.-Y. Chen, H. Kinoshita, and K. Inomata, Chem. Lett., 2009, 38, 602.

89. K. Nishiyama, A. Kamiya, M. S. A. Hammam, H. Kinoshita, S. Fujinami, Y. Ukaji, and K. Inomata, Bull. Chem. Soc. Jpn., 2010, 83, 1309.

90. K. Inomata, M. A. S. Hammam, H. Kinoshita, Y. Murata, H. Khawn, S. Noack, N. Michael, and T. Lamparter, J. Biol. Chem., 2005, 280, 24491.

91. J. C. Lagarias and F. M. Mercurio, J. Biol. Chem., 1985, 260, 2415.

92. E. Chen, V. N. Lapko, P. S. Song, and D. S. Kliger, Biochemistry, 1997, 36, 4903.

93. B. Esteban. M. Carrascal, J. Abian, and T. Lamparter, Biochemistry, 2005, 44, 450.

94. T. Hübschmann, H. J. M. M. Jorissen, T. Börner, W. Gärtner, and N. Tandeau de Marsac, Eur. J. Biochem., 2001, 268, 3383. 
95. K. Inomata, S. Noack, M. A. S. Hammam, H. Khawn, H. Kinoshita, Y. Murata, N. Michael, P. Scheerer, N. Krauss, and T. Lamparter, J. Biol. Chem., 2006, 281, 28162.

96. J. R. Wagner, J. Zhang, J. S. Brunzelle, R. D. Vierstra, and K. T. Forest, J. Biol. Chem., 2007, 282, 12298.

97. S. Seibeck, B. Borucki, H. Otto, K. Inomata, H. Khawn, H. Kinoshita, N. Michael, T. Lamparter, and M. P. Heyn, FEBS Lett., 2007, 581, 5425.

98. X. Yang, E. A. Stojkovic, J. Kuk, and K. Moffat, Proc. Natl. Acad. Sci. U.S.A., 2007, 104, 12571.

99. C. Dugave and L. Demange, Chem. Rev., 2003, 103, 2475.

100. P. Scheerer, N. Michael, J. H. Park, S. Noack, C. Förster, M. A. S. Hammam, K. Inomata, H.-W. Choe, T. Lamparter, and N. Krauß, J. Struct. Biol., 2006, 153, 97.

101. P. Scheerer, N. Michael, J. H. Park, S. Nagano, H.-W. Choe, K. Inomata, B. Borucki, N. Krauß, and T. Lamparter, ChemPhysChem, 2010, 11, 1090.

102. L.-O. Essen, J. Mailliet, and J. Hughes, Proc. Natl. Acad. Sci. U.S.A., 2008, 105, 14709.

103. X. Yang, J. Kuk, and K. Moffat, Proc. Natl. Acad. Sci. U.S.A., 2008, 105, 14715.

104. X. Yang, J. Kuk, and K. Moffat, Proc. Natl. Acad. Sci. U.S.A., 2009, 106, 15639.

105. X. Yang, Z. Ren, J. Kuk, and K. Moffat, Nature, 2011, 479, 428.

106. R. Yang, K. Nishiyama, A. Kamiya, Y. Ukaji, K. Inomata, and T. Lamparter, Plant Cell, 2012, 24, 1936.

107. H. Khawn, L.-Y. Chen, H. Kinoshita, and K. Inomata, Chem. Lett., 2008, 37, 198.

108. B. Zienicke, L.-Y. Chen, H. Khawn, M. A. S. Hammam, H. Kinoshita, J. Reichert, A. S. Ulrich, K. Inomata, and T. Lamparter, J. Biol. Chem., 2011, 286, 1103.

109. K. Inomata, H. Khawn, L.-Y. Chen, H. Kinoshita, B. Zienicke, I. Molina, and T. Lamparter, Biochemistry, 2009, 48, 2817.

110. L.-Y. Chen, R. Iwamoto, Y. Ukaji, and K. Inomata, Chem. Lett., 2011, 40, 632.

111. R. Iwamoto, Y. Ukaji, and K. Inomata, Chem. Lett., 2010, 39, 176.

112. Y. Tsukahara, H. Kinoshita, K. Inomata, and H. Kotake, Bull. Chem. Soc. Jpn., 1984, 57, 3013.

113. E. M. Franklin, S. Browne, A.-M. Horan, K. Inomata, M. A. S. Hammam, H. Kinoshita, T. Lamparter, G. Golfis, and T. J. Mantle, FEBS Journal, 2009, 276, 4405.

114. Y. Hagiwara, M. Sugishima, H. Khawn, H. Kinoshita, K. Inomata, L. Shang, J. C. Lagarias, Y. Takahashi, and K. Fukuyama, J. Biol. Chem., 2010, 284, 1000.

115. T. Ishizuka, A. Kamiya, H. Suzuki, R. Narikawa, T. Noguchi, T. Kohchi, K. Inomata, and M. Ikeuchi, Biochemistry, 2011, 50, 953. 


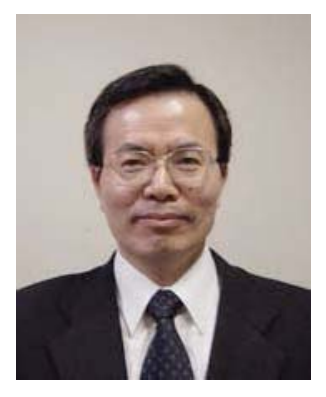

Katsuhiko Inomata was born in 1945 and received his B. Sci. degree in Chemistry in 1968 and D. Sci. degree in Organic Chemistry in 1973 from Tokyo Institute of Technology (TIT) under the guidance of Professor T. Mukaiyama. After joining Prof. Mukaiyama's group as a research assistant at TIT, he moved to Kanazawa University as Lecturer in 1974 and was promoted to the rank of Associate Professor in 1977. After spending two years (1981-1983) at ETH (Professor A. Eschenmoser) as a Postdoctoral Fellow, he was promoted to a Full Professor of Kanazawa University in 1988. He has been the recipient of the Chemical Society of Japan (CSJ) Award for Young Chemists (1980), the BCSJ Award (2004, 2010), the Ishikawa TV Award (2005), and the CSJ Award for Creative Work (2007). He retired from Kanazawa University in 2011 and has been an emeritus Professor of Kanazawa University since then. His current research interests include total synthesis of bilin chromophores toward elucidation of the structure and function of phytochrome chromophores, development of new enantioselective reactions, reactions catalyzed by transition metals, and elucidation of the origin of "syn-effect." 